ERNEST DRLANDD LAWRENCE

BERKELEY NATIONAL LABDRATDRY

Leakage Diagnostics, Sealant

Longevity, Sizing and Technology

Transfer in Residential Thermal

Distribution Systems I. Walker, M. Sherman, M. Modera, and J. Siegel $P B C D$
Environmental Energy Technologies Division

January 1998

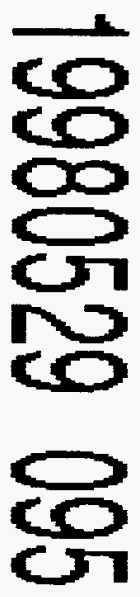

DISTRIBUTION OF THS DOCUMENT IS UNLMITED 


\section{DISCLAIMER}

This document was prepared as an account of work sponsored by the United States Government. While this document is believed to contain correct information, neither the United States Government nor any agency thereof, nor The Regents of the University of California, nor any of their employees, makes any warranty, express or implied, or assumes any legal responsibility for the accuracy, completeness, or usefulness of any information, apparatus, product, or process disclosed, or represents that its use would not infringe privately owned rights. Reference herein to any specific commercial product, process, or service by its trade name, trademark, manufacturer, or otherwise, does not necessarily constitute or imply its endorsement, recommendation, or favoring by the United States Government or any agency thereof, or The Regents of the University of California. The views and opinions of authors expressed herein do not necessarily state or reflect those of the United States Government or any agency thereof, or The Regents of the University of California.

This report has been reproduced directly from the best available copy.

Available to DOE and DOE Contractors

from the Office of Scientific and Technical Information

P.O. Box 62, Oak Ridge, TN 37831

Prices available from (615) 576-8401

Available to the public from the National Technical Information Service

U.S. Department of Commerce

5285 Port Royal Road, Springfield, VA 22161

Ernest Orlando Lawrence Berkeley National Laboratory is an equal opportunity employer. 


\title{
Leakage Diagnostics, Sealant Longevity, Sizing and Technology Transfer in Residential Thermal Distribution Systems
}

\author{
I. Walker, M. Sherman, M. Modera and J. Siegel \\ Environmental Energy Technologies Division \\ Energy Performance of Buildings Group \\ Lawrence Berkeley National Laboratory \\ Berkeley, CA 94720
}

January 1998

This study was sponsored by the California Institute for Energy Efficiency (CIEE), a research unit of the University of California, (Award No. BG-90-73) through the U.S. Department of Energy under Contract No. DE-AC03-76SF00098. Publication of research results does not imply CIEE endorsement of or agreement with these findings, nor that of any CIEE sponsor. 


\section{Table of Contents}

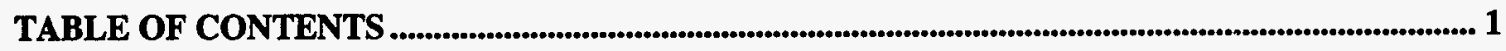

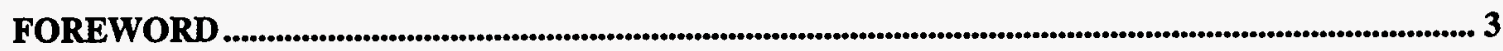

1. FIELD TESTING OF DUCT LEAKAGE DIAGNOSTICS ................................................................... 3

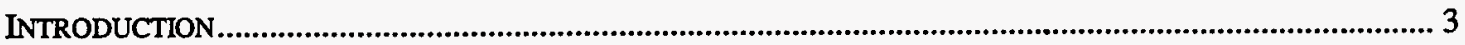

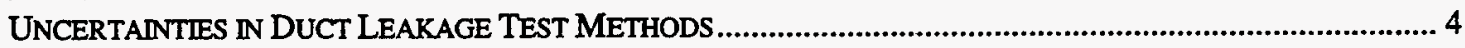

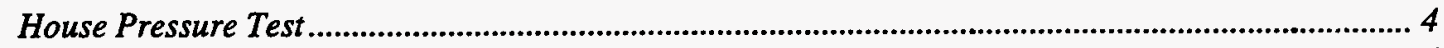

Nulling Pressure Test ................................................................................................................................ 6

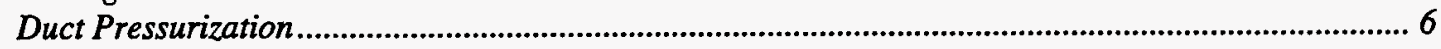

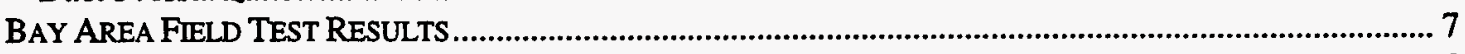

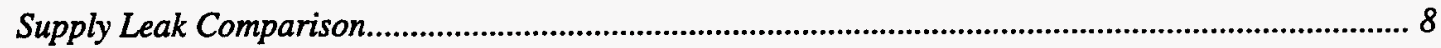

Return Leak Comparison................................................................................................................... 8

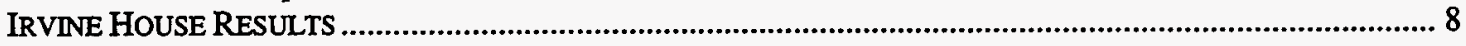

Comparison of total duct leakage measured using HPT and duct pressurization.................................. 8

Multiple test comparisons in houses $M$ and $N$....................................................................................... 9

Repeatability of $I Q+$ protocol tests (Duct Pressurization total leakage at $25 \mathrm{~Pa}$ )................................ 9

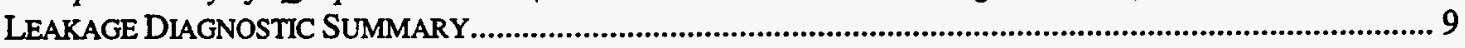

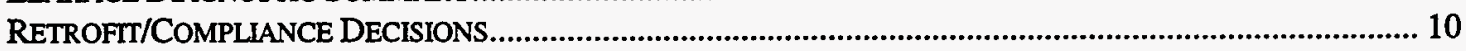

2. DUCT SEALANTS AND LONGEVITY TESTING............................................................................. 10

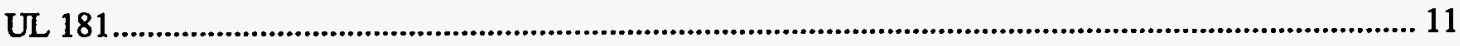

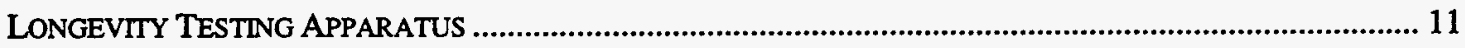

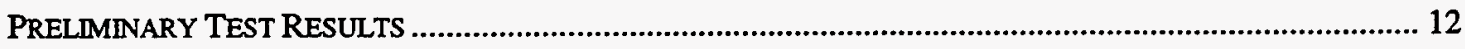

3. DUCT SYSTEM INTERACTIONS WITH SYSTEM SIZING AND CAPACITY ........................... 16

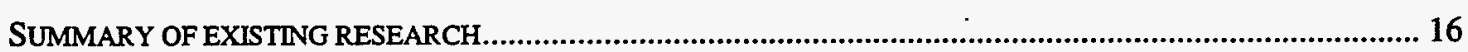

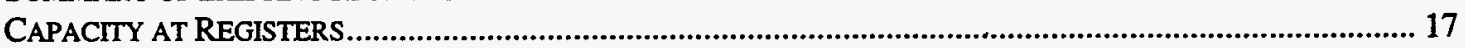

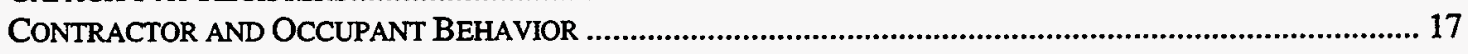

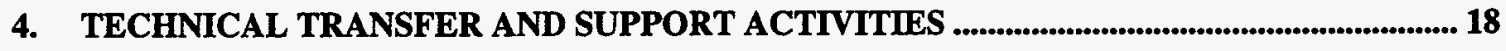

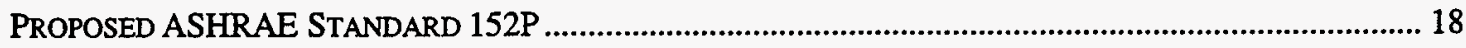

CALIFORNIA ENERGY COMMISSION - TITLE 24/HERS ……...................................................................... 18

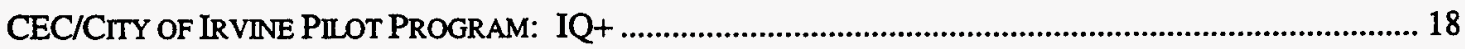

COLLABORATION WITH AIR CONDITIONING CONTRACTORS OF AMERICA (ACCA) .................................. 19

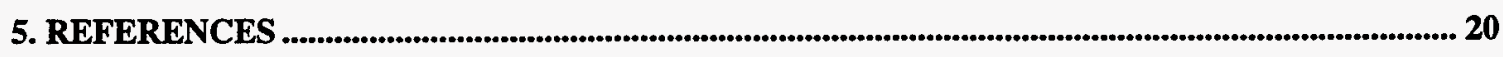

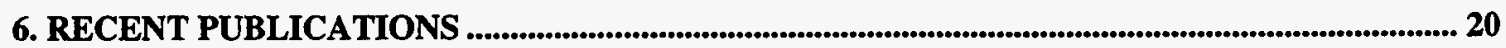

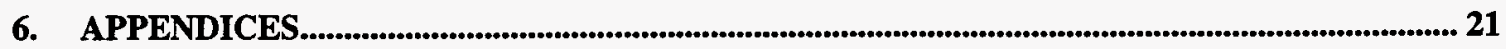

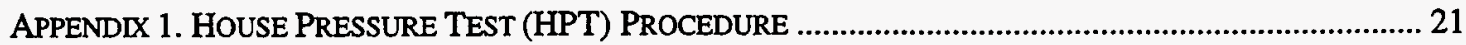

APPENDIX 2. NULLING PRESSURE TEST (NPT) PROCEDURE .................................................................. 25

APPENDIX 3. DUCT PRESSURZATION TEST PROCEDURE ............................................................................. 27

APPENDIX 4. IRVINE QUALITY PLUS (IQ+) PRESSURIZATION PROCEDURE .................................................. 29

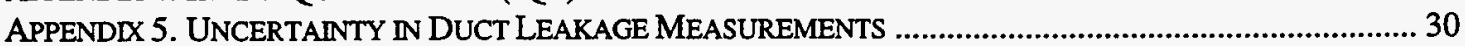

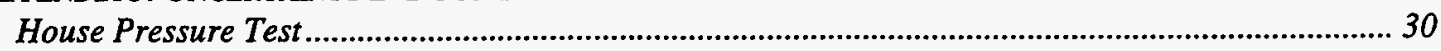

Physical Measurements ...................................................................................................................... 30 
Weather induced changes in ceiling pressure differences .................................................................................30

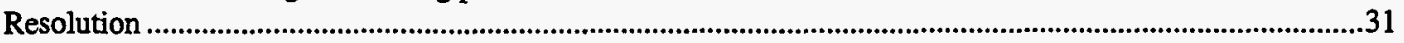

Repeatability ..............................................................................................................................................31

Removing bias due to assuming envelope leakage does not include the ducts....................................................34

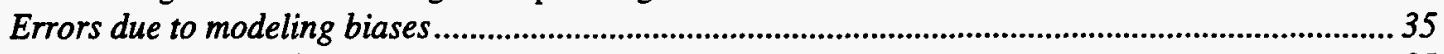

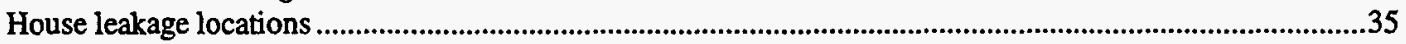

Effect of Pressure differences between the house and outside on the measurement of duct pressures. 37

Attic leakage...........................................................................................................................................38

Assuming stack effect only...................................................................................................................................38

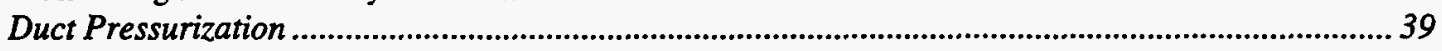

Physical measurements....................................................................................................................................

Converting physical measurements to operating conditions.............................................................................40

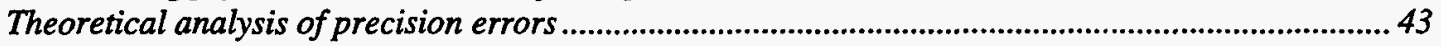

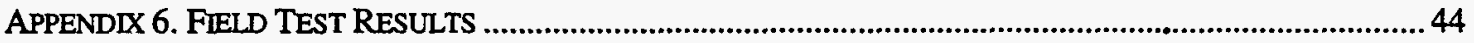

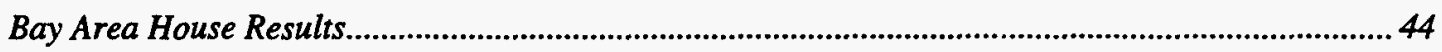

Supply Leak Comparison ............................................................................................................................................44

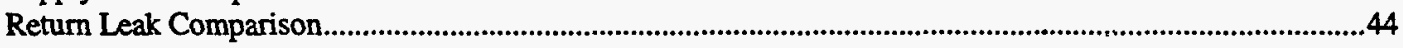

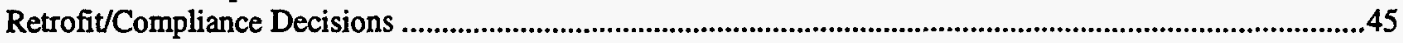

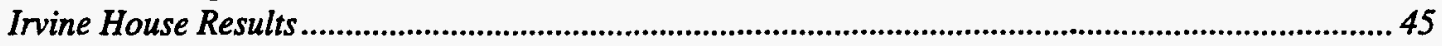

Comparison of total duct leakage measured using HPT and duct pressurization ..................................................46

Multiple test comparisons in houses $\mathrm{M}$ and $\mathrm{N}$..................................................................................................46

Repeatability of IQ+ protocol tests (Duct Pressurization total leakage at 25 Pa) ..............................................46

Retrofit/Compliance Decisions .....................................................................................................................................46

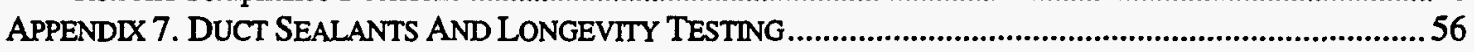

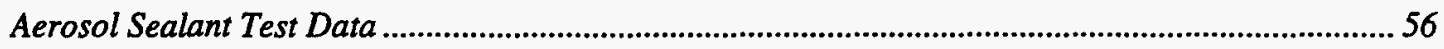

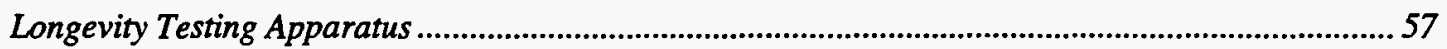

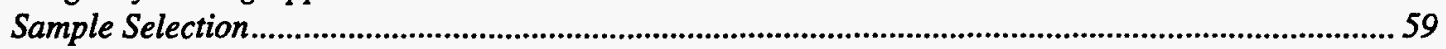

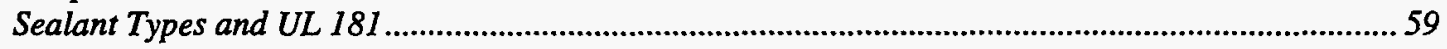

APPENDIX 8. DUCT SYSTEM INTERACTIONS WITH SYSTEM SIZING AND CAPACITY ...................................61

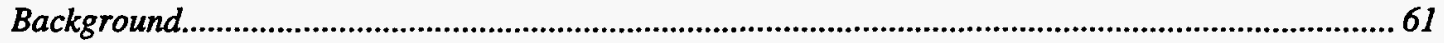

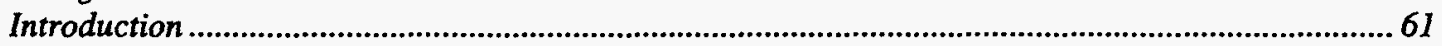

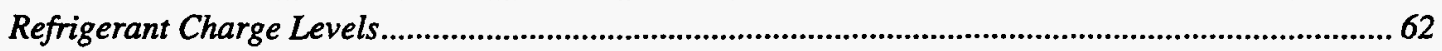

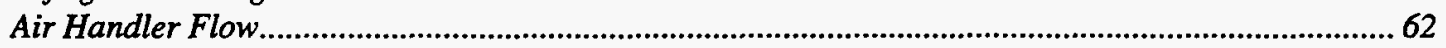

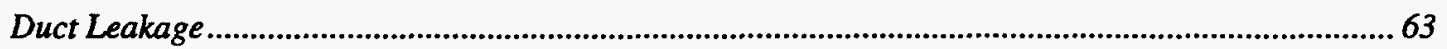

Impacts of Duct Leakage on Capacity at the Registers .............................................................................. 63

Cost Effectiveness of Retrofit Measures and Peak Energy Savings....................................................... 64

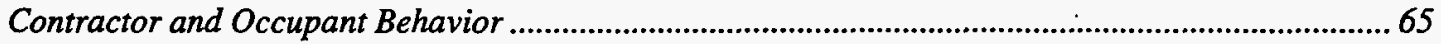

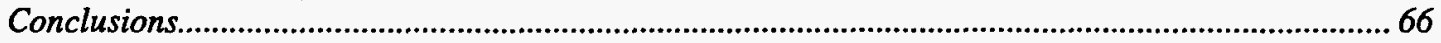

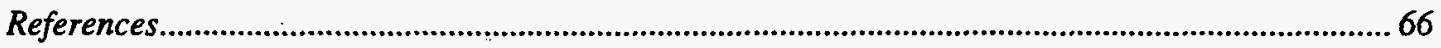




\section{Foreword}

This report documents the Phase V technical results of the Residential Thermal Distribution Systems research done by Lawrence Berkeley National Laboratory (LBNL) for the California Institute for Energy Efficiency (CIEE) through September 30, 1997.

This report consists of a summary of each part of the project and a set of appendixes containing more detailed information regarding each section. In addition, the first four appendixes give the field test procedures for the diagnostic tests under study.

\section{Field Testing of Duct Leakage Diagnostics}

\section{Introduction}

This field study concentrated on measurement of duct leakage to outside the conditioned space because this is most useful in energy calculations, e.g., proposed ASHRAE Standard 152P (ASHRAE 1997). For room by room load/comfort requirements, the total duct leakage (including leaks to conditioned space) is more appropriate, particularly for additional comfort considerations. The objective of this field study is to help to identify major sources of uncertainty and to quantify the trade-offs between different test methods. The identification of the areas requiring significant improvement will aid in future development of duct leakage test methods. For example, during the course of this study a new method for correcting house pressure tests to account for the presence of duct leakage in measured envelope leakage was developed.

Each of the measurement techniques investigated has resulted from a different set of priorities and hence compromises. Thus each one of them is measuring a different physical quantity, although they all report the same parameter - duct leakage to outside at operating conditions. Given that real houses do not meet all of the simplifying assumptions that must be made to achieve similarity, the same numbers from each test method are not expected. Potentially these differences can be quite large and one of the benefits of field measurement is that the differences in the measurements helps put a realistic bound on how different some of these leakage diagnostics may be.

To evaluate current duct leakage diagnostic methods, field tests were performed in 17 houses. The field tests were divided into two parts. The first part was performed in occupied S.F. Bay Area houses. The second part was performed in new unoccupied houses (some with unfinished interiors) in Irvine, CA. In the Bay Area, nine houses were tested using four diagnostic techniques. The three diagnostics that could reasonably be used by other practitioners have detailed procedures in the referenced appendixes.

1. House Pressure Test (HPT) - Appendix 1.

2. Nulling Pressure Test (NPT) - Appendix 2.

3. Duct and house pressurization with separate supply and return leakage - Appendix 3.

4. Duct only pressurization with combined return and supply leakage (IQ+) - Appendix 4.

5. Tracer gas.

The tracer gas tests inject tracer gasses into the house and the duct system at various locations. Samples are than taken from the house and duct system (and outside) and the changes and differences in tracer gas concentration are used to calculate duct leakage flows. The detailed analysis and sophisticated equipment required for the tracer gas technique make it unsuitable for use as a simple field diagnostic. Additional measurements included envelope leakage, fan flow, house floor area and multiple tests to check for repeatability. The Bay Area houses had their ducts sealed and were retested after sealing. The sealing 
process used the Aeroseal ${ }^{\mathrm{TM}}$ system or manual application of mastic and/or metal foil tape, both of which are UL 181A listed.

In Irvine, two houses had the same test protocol as in the Bay Area houses. An additional six houses had only duct pressurization and house pressure tests performed. The Irvine houses had an additional duct leakage test, where the entire duct system is pressurized without separating supplies from returns. Tests were also performed by California Energy Commission (CEC) staff on the Irvine houses. Comparing CEC and LBNL tests will provide an estimate of the repeatability between different test crews for the same house. The CEC tests were performed twice by the CEC staff to provide a measure of repeatability of the tests for an individual crew.

The HPT, duct pressurization and house and duct pressurization methods are tests currently used in proposed ASHRAE Standard 152P, and the measurement procedures used in the standard were used (and reproduced in the appendixes of this report). The simplified duct pressurization test, used in the Irvine houses, is roughly equivalent to the test in 152P for new houses for checking to see if duct leakage meets a building plan specification.

Additional field test data from previous studies performed by LBNL (SMUD study (Jump, Walker and Modera (1996)), BNL (Andrews (1996)) and CEC (Modera and Wilcox (1995)) has also been analyzed to assist in the evaluation of the test methods.

\section{Uncertainties in Duct Leakage Test Methods}

Uncertainties are made up of precision and bias errors. Biases are systematic errors that are repeated in every measurement. For example, if duct pressurization is done without the house pressurized to the same level, then the leaks to inside are also included. These tests will therefore always have higher leakage than the leakage to outside that we are trying to measure. Every test performed this way will result in leakage that is too great and will be biased too high. The precision is the uncertainty due to random changes from measurement to measurement. An example of this kind of error is the measurement of building envelope pressures that vary due to wind speed fluctuations. The envelope pressures fluctuate about the desired value and measurements at different times will have different values. The magnitude of the precision error in this case depends on the magnitude of the pressure fluctuations.

The following uncertainty estimates are discussed in greater detail in Appendix 5. The major sources and magnitudes of precision and bias are summarized in Table 1 for the duct pressurization and house pressure test. The nulling pressure test and tracer gas tests are not likely to be used in compliance or Home Energy Rating tests and are therefore not discussed in Table 1 for brevity.

To put the following uncertainty estimates into perspective, the magnitude of the leakage that is to be measured by field testers can be estimated from the leakage specifications that exist in the proposed California Title 24 energy code (6\% of fan flow). For the new houses in Irvine this specification is $140 \mathrm{cfm}$ on average for the houses tested here. For the smaller Bay Area houses this drops to an average of $55 \mathrm{cfm}$. The IQ+ program specifies a maximum allowable leakage of $50 \mathrm{cfm}$ (@25 Pa) per $1000 \mathrm{ft}^{2}$ of floor area. This results in a specification for the Irvine houses that averages $160 \mathrm{cfm}$, that is within $20 \mathrm{cfm}$ of the Title 24 specification.

\section{House Pressure Test}

For the House Pressure Test, the dominant precision and bias errors are due to the measurement of very low pressures and violations of the assumptions used in the calculation procedure.

The most significant bias is due to assumptions about leak location and building envelope pressures used in the calculations. The calculations assume an even split between ceiling and floor level leaks. Non-even leakage splits are biased downwards and have a lower average value than for the evenly split leakage. Example calculations were performed assuming that the leakage was split with $25 \%$ in the ceiling and $75 \%$ in the floor and also with $75 \%$ in the ceiling and $25 \%$ in the floor. The leakage flows for these leakage 
splits were compared to the leakage flows for evenly split leakage in 119 test houses. The 119 test houses combine the tests for this study with other tests performed by LBNL (see above for references). The average leakage flows for both cases were lower than the even leakage split by about $10 \mathrm{cfm}$. This bias was not the same for all houses and using this comparison of the average of all the houses allows positive and negative biases for individual houses to cancel. The average absolute difference (between the leakage calculated using evenly distributed leakage and the $3 / 4-1 / 4$ split) was about $20 \mathrm{cfm}$ for most leakage high and about $90 \mathrm{cfm}$ for most leakage low. These larger differences are not the same for each house and depend on the specific leak location and pressure distribution for the building under test during the test period.

\section{Table 1. Summary of Precision and Bias for Duct Pressurization and HPT}

\begin{tabular}{|c|c|c|c|c|c|}
\hline \multicolumn{3}{|c|}{ HPT } & \multicolumn{3}{|c|}{ Duct Pressurization } \\
\hline Error source & $\begin{array}{l}\text { Error } \\
\text { estimation } \\
\text { method } \\
\end{array}$ & $\begin{array}{l}\text { Error } \\
\text { magnitude }\end{array}$ & Error source & $\begin{array}{l}\text { Error } \\
\text { Estimation } \\
\text { method } \\
\end{array}$ & $\begin{array}{l}\text { Error } \\
\text { magnitude }\end{array}$ \\
\hline $\begin{array}{l}\text { Building } \\
\text { envelope leak } \\
\text { location }\end{array}$ & $\begin{array}{l}\text { From example } \\
\text { calculation of } \\
\text { reformulated } \\
\text { equations }\end{array}$ & $\begin{array}{l}10 \mathrm{cfm} \text { Bias } \\
\text { too high } \\
20-90 \mathrm{cfm} \\
\text { precision }\end{array}$ & $\begin{array}{l}\text { Cabinet } \\
\text { leakage } \\
\text { included in } \\
\text { supplies }\end{array}$ & Field tests & $\begin{array}{l}50 \text { cfm bias ( } 20 \\
\text { cfm if filter at } \\
\text { grille) high for } \\
\text { supply and low } \\
\text { for return }\end{array}$ \\
\hline $\begin{array}{l}\text { Ceiling } \\
\text { pressure } \\
\text { variation (from } \\
\text { weather } \\
\text { effects) }\end{array}$ & $\begin{array}{l}\text { Standard error } \\
\text { in mean of } \\
\text { measured data }\end{array}$ & $\begin{array}{l}30-35 \mathrm{cfm} \\
\text { precision }\end{array}$ & $\begin{array}{l}\text { Pressure Pan } \\
\text { register } \\
\text { pressures }\end{array}$ & $\begin{array}{l}\text { calculated for } \\
\text { typical system } \\
\text { based on field } \\
\text { pressure } \\
\text { measurements }\end{array}$ & $\begin{array}{l}25 \mathrm{cfm} \text { bias too } \\
\text { high }\end{array}$ \\
\hline $\begin{array}{l}\text { Instrument } \\
\text { Resolution } \\
\text { limit }\end{array}$ & $\begin{array}{l}\text { Manufacturer's } \\
\text { specification } \\
\text { and calculated } \\
\text { for typical } \\
\text { house }\end{array}$ & $\begin{array}{l}55 \mathrm{cfm} \\
\text { precision }\end{array}$ & $\begin{array}{l}\text { Conversion to } \\
\text { operating } \\
\text { condition } \\
\text { pressures }\end{array}$ & $\begin{array}{l}\text { calculated for } \\
\text { typical system } \\
\text { based on field } \\
\text { pressure } \\
\text { measurements }\end{array}$ & $\begin{array}{l}20 \mathrm{cfm} \\
\text { precision }\end{array}$ \\
\hline $\begin{array}{l}\text { Return pressure } \\
\text { measurement } \\
\text { (for systems } \\
\text { with filter at } \\
\text { cabinet only) }\end{array}$ & $\begin{array}{l}\text { Field } \\
\text { measurements }\end{array}$ & $\begin{array}{l}100 \mathrm{cfm} \\
\text { precision }\end{array}$ & $\begin{array}{l}\text { Instrumentation } \\
\text { limits }\end{array}$ & $\begin{array}{l}\text { manufacturers } \\
\text { specification } \\
\text { (standard } \\
\text { deviation) }\end{array}$ & $5 \mathrm{cfm}$ precision \\
\hline Repeatability & $\begin{array}{l}\text { Average RMS } \\
\text { difference } \\
\text { between field } \\
\text { tests }\end{array}$ & $\begin{array}{l}75 \mathrm{cfm} \\
\text { precision }\end{array}$ & Repeatability & $\begin{array}{l}\text { Average RMS } \\
\text { difference of } \\
\text { measured data }\end{array}$ & $\begin{array}{l}15 \mathrm{cfm} \\
\text { precision }\end{array}$ \\
\hline
\end{tabular}

All of the available test results indicate that the precision of the ceiling pressure measurements are limited by the resolution of the pressure measuring device and the variation in envelope pressures during a test (normally caused by wind pressure fluctuations). The variation in pressures during the tests was estimated using the standard error in the mean of measured ceiling pressures, and indicated a precision error of about $30 \mathrm{cfm}$ for supplies and $35 \mathrm{cfm}$ for returns. This sensitivity arises from the calculation technique that uses the difference between two ceiling pressure differences under different conditions.

The resolution of the HPT is limited by the quantity of flow through the building envelope corresponding to a $0.05 \mathrm{~Pa}$ pressure difference (half the resolution of the pressure measurements). The HPT tests in new houses in Irvine had a leakage flow resolution due to the pressure resolution of about $55 \mathrm{cfm}$. Note that this resolution uncertainty scales directly with envelope leakage and will be lower for tight houses and higher for leaky houses. To reduce the effect of the sensitivity to envelope pressure measurements it is recommended that the HPT test should only be considered valid if the change in ceiling pressure from fan 
off to either of fan on OR fan on with the return blocked is greater than $0.5 \mathrm{~Pa}$. This specification of a minimum pressure change acts to increase the probability of the envelope pressure changes being due to system operation (rather than weather changes). In addition, it eliminates tests where the building envelope leakage is too large to reveal the duct system characteristics because large duct induced flows would be needed to significantly change the envelope pressures. An additional constraint for improving HPT precision is to also disregard the test if the standard deviation of each 10 measurements is greater than the difference in the means of each group of ten measurements. This constraint is intended to eliminate tests during which fluctuating envelope pressures due to changing wind speed and direction mask the changes in envelope pressure that the HPT utilizes.

The repeatability was evaluated using the RMS difference between measurements performed by the same work crew each time (indicating the uncertainty arising from changing weather conditions and changes in pressure measurement location) and other tests performed by different work crews testing the same houses (to examine the variability between testers). The results indicate that precision error due to repeatability is typically about $75 \mathrm{cfm}$ for both supply and return leaks. Crucially, it was found that false zero readings are common with this test procedure. These false zeros are mainly due errors in duct pressure measurements. The standard test procedure requires that the return duct pressure is measured near the midpoint of the duct system. In practice this is difficult to achieve and the test results show an extreme sensitivity to this return pressure measurement, with errors of typically $100 \mathrm{cfm}$ (essentially the error is the same size as the measurement). Note that this uncertainty only applies to systems with the filter near the air handler and is much smaller for systems with the filter at the return grille, therefore it is recommended that the HPT only be used in systems with simple returns and the filters at the return grille.

\section{Nulling Pressure Test}

The NPT has the same uncertainties as the HPT except:

- Less envelope related uncertainties (including assumptions about leakage location and stack effect) because the flow is measured directly. However, the problems with leaky envelopes resulting in small envelope pressure differences still exists.

- Additional uncertainty due to operator requirements to balance flows. The uncertainty in this part of the test is dominated by the same resolution uncertainty as the HPT, because the flow balance is determined by measuring pressure differences across the envelope.

The decision to use the NPT depends on the tradeoff between eliminating errors associated with the assumptions about leakage location and building envelope pressure distribution (required for the HPT) and the added imprecision due to the requirement of balancing small pressures by the equipment operator. The field tests performed for this study indicated that these effects are about equal and the NPT was not significantly better at measuring duct leakage flows.

\section{Duct Pressurization}

For duct pressurization, the bias and precision errors in the physical measurements are small, and it is the conversion to leakage at operating conditions that dominates.

The main biases in this test method are due to the splitting of supply and return leaks and the use of pressure pans to measure register pressures. Supplies and returns are often blocked at the entrance to the fan cabinet or at the filter location (if it is at the plenum). This means that the fan cabinet and other equipment leaks on the supply side of the blockage (and some of the return plenum) are measured with the supply leaks, when under normal operating conditions they are part of the return system. This can create a systematic bias in the test where too much leakage is attributed to supplies and too little to returns. The filter slot/equipment cabinet leakage has been estimated to be about $50 \mathrm{cfm}$, and will exist for all systems with return plenums and equipment mounted outside conditioned space. This estimate is based on plenum pressure measurements and observations of the physical dimensions of filter slots and knockouts on equipment cabinets. Systems with filters at return grilles may have much less equipment associated leakage (probably 
on the order of 10-20 cfm rather than $50 \mathrm{cfm}$, because there are only knockouts at the cabinet and no filter slot). However, this will be offset by increased return system leakage because all of the return system is at the lower pressure downstream of the filter.

The current measurement procedure that employs pressure pans to estimate register pressures will tend to overestimate the pressures experienced by the leaks. This is because the pressure pans tend to measure the pressure close to the plenum pressure unless there are multiple connections between the register and the plenum, or there are large leakage sites close to the register. This leads to the pressure pans overestimating the register pressures at operating conditions and in turn this leads to overestimating the duct leakage. For systems without multiple connections or large register leakage, the overestimate of operating condition leakage flow could be as high as $50 \%$ (or about $50 \mathrm{cfm}$ ). Note that this is a limiting case and the majority of duct systems will have a lower bias. An estimate of bias for a typical system can be made by using one half of this maximum value, i.e., $25 \mathrm{cfm}$. The use of pressure pans allows the duct pressure measurements to be made more repeatable and this improved repeatability must be balanced against these possible biases. For the purposes of home energy rating or screening houses for code compliance it is preferable to err towards a more repeatable test, therefore the pressure pans should be retained in this test procedure. It would be possible to subtract the $25 \mathrm{cfm}$ bias from all tests, however this $25 \mathrm{cfm}$ is a number for a typical house and will vary over a large range, depending on the characteristics of each individual duct system.

Converting to leakage flow at operating conditions is the major source of precision error with this test method because of the large range of pressures in the duct system at operating conditions. Based on measured register and plenum pressures the error in converting to system operating pressures can be up to $40 \%$ of the measured flows (typically $40 \mathrm{cfm}$ ). As with the pressure pan biases, this is a high value and a typical value would be about half of this estimate.

The precision error in the physical measurements is dominated by the calibration uncertainty of the flowmeter (typically $\pm 3 \%$ of flow) and fluctuating envelope pressures due to wind The wind pressures produce worst case uncertainties in envelope pressure of about $2.5 \mathrm{~Pa}$, resulting in precision errors of about 2-3 cfm. Additional imprecision is due to the measurement of duct pressures during the test if the pressures are not measured near the leakage sites. A typical error in flow though the leak under measurement conditions is about $5 \mathrm{cfm}$ (see Appendix 5 for example calculation). This small precision error in the physical measurements contributes to the good repeatability of this test.

One of the key issues when using any field test is the repeatability uncertainty so that decisions regarding code compliance or screening for retrofitting can be made. The duct pressurization test was found to have good repeatability both between different testers (CEC and LBNL) and for repeated tests by the same test crew. The repeatability errors were on the order of $15 \mathrm{cfm}$ for the large leakage in the Irvine houses (this is 2-3\% of the measurement). If the proposed ASHRAE 152P test method is followed (using pressure pans) the duct operating pressure variability will be small (based on our field experience) and will not introduce significant repeatability errors. In effect, this trades a source of bias (overestimating operating pressures using the pressure pan) for improved precision (pressure pans make register pressure measurements consistent from user to user).

\section{Bay Area Field Test Results}

Details of the Bay area house measurements are given in Appendix 6. All of the houses had gas furnaces, and one house had air conditioning. Three houses had new duct systems (less than one year old) and the other houses had ducts that were at least 15 years old. The ducts were typically uninsulated sheet metal or R4 flex duct. Some of the older sheet metal ducts had a thin exterior layer of asbestos insulation. The duct systems were typical of California systems, with single returns, except for two houses that had two return grilles. 
The average fan flow for these systems was about $880 \mathrm{cfm}$. Combined with an average floor area of about $1400 \mathrm{ft}^{2}$, this resulted in about $0.70 \mathrm{cfm} / \mathrm{ft}^{2}$. After the ducts were sealed the average fan flow dropped slightly to $870 \mathrm{cfm}$.

\section{Supply Leak Comparison}

The measured supply leakage shows a wide variation between methods, with typical differences on the order of $100 \mathrm{cfm}$. The general trend is that duct pressurization predicts the greatest leakage, probably due to including cabinet leakage in the supplies and overestimation of system operating pressures due to using pressure pans. Another reason for the larger duct pressurization leakage is the false zero readings for the other tests, particularly the NPT. These false zeros are due to the sensitivity of the HPT and NPT to small envelope pressure changes and the uncertainty in measuring the appropriate return duct pressure. These differences between the tests are important if we are going to use these measurement techniques as screening tools for duct leakage because we need the test to tell us if the ducts are leaky or not and the results indicate that in some cases that passing or failing a leakage specification would depend on which diagnostic test was used.

Another way of evaluating these tests is to see if they measure a lower leakage post sealing. The pre/post comparison was made for the Bay Area houses plus 10 other houses that have been sealed during aerosol sealant development work by LBNL and other researchers. The results showed that in about half of the tests the HPT (and the NPT in the Bay Area houses) was not sensitive enough to detect the leakage reduction due to sealing. Pressurization tests on these duct systems showed that the area of the duct leaks decreased by $60 \%$ on average for these houses, so a reduction in leakage would be expected.

\section{Return Leak Comparison}

The results for return leakage are more uniform than the supply duct leakage tests, with typical differences between test procedures on the order of $50 \mathrm{cfm}$. For returns, we were able to use the tracer gas measurements as a baseline. The average absolute differences between the tracer tests and the other diagnostics were $40 \mathrm{cfm}$ for duct pressurization, $50 \mathrm{cfm}$ for NPT and $51 \mathrm{cfm}$ for the HPT. Given the uncertainties in these diagnostic tests, this result is inconclusive, however it should be noted that all the diagnostic tests tended to underestimate the leakage when compared to the tracer gas results.

\section{Irvine House Results}

Additional details on the Irvine house results are given in Appendix 6. All of the new Irvine houses were very similar in construction, floor plan, detail, architecture and duct system installation. Each house had two systems, one for upstairs and one for downstairs, with the air handler, furnace and cooling coils for both systems located in the attic. All the houses had both gas furnaces and split system air conditioning. The houses had minimal return systems with either one or two returns per system. The ducts were all constructed from R4 flex duct. All the houses used an interior wall cavity for one or more of the returns that was a major source of return leakage. All the systems in Irvine had the filters at the returns, and should avoid the return pressure problems with the HPT results found in the Bay Area tests. Note that from the point of view of system leakage, having the filter at the register to heavily depressurize the return and then using the leaky wall cavities for the returns will produce the maximum leakage, i.e., the worst possible scenario.

In all the Irvine tests, the duct pressurization was for the sum of supply and return leakage because it was not possible to split the supply from the return. The houses had this duct pressurization test performed twice by CEC staff and once by LBNL staff. The HPT was performed by both CEC and LBNL staff in each house also. These multiple tests were used as repeatability checks on the two types of test.

\section{Comparison of total duct leakage measured using HPT and duct pressurization}

The tests in houses $\mathrm{J}$ through $\mathrm{O}$ included both HPT and duct pressurization tests. The duct pressurization test used for comparison here is the $25 \mathrm{~Pa}$ combined supply and return leakage test. Because these duct pressurization tests were not corrected for leakage to inside or to operating condition pressures the differences between the two tests averaged over all the systems were acceptable, with the HPT giving 14 
cfm greater leakage. The differences for individual houses, however were significantly larger, averaging $174 \mathrm{cfm}$. Houses $\mathrm{N}$ and $\mathrm{O}$ had the largest differences, with the HPT predicting very large duct leakage (greater than $700 \mathrm{~cm}$ ) and the pressurization tests predicting less than half of this amount.

\section{Multiple test comparisons in houses $\mathrm{M}$ and $\mathrm{N}$}

Houses $\mathrm{M}$ and $\mathrm{N}$ were tested in detail, using the same test procedures as in the Bay Area houses. Typical differences between the tests are about $200 \mathrm{cfm}$, except for house N, where the HPT predicts more than 800 $\mathrm{cfm}$ of leakage which is double the pressurization and quadruple the NPT results.

\section{Repeatability of IQ+ protocol tests (Duct Pressurization total leakage at 25 $\mathrm{Pa})$}

The duct pressurization tests were preformed twice by CEC staff and once by LBNL staff in nine houses. The RMS uncertainty between the tests was used as an estimate of repeatability. The mean RMS uncertainty was $16 \mathrm{cfm}$ ( $3 \%$ of the measured leakage flow). Looking at the uncertainty for the two tests in each house performed by CEC, this gives an indication of the repeatability of the test if the same testers test the same house at different times. This resulted in an RMS uncertainty of only $11 \mathrm{cfm}$ or $2 \%$ of the measured values. These results show that repeatability uncertainty is low for pressurization tests. This is because the fluctuations in measured pressures are relatively small and the measurement technique has well defined physical parameters, so that each test team measures the same physical quantities.

\section{Leakage Diagnostic Summary}

In Part 1 of this study, nine houses (10 systems) in the Bay Area had their duct system leakage measured using duct pressurization, tracer gases and envelope pressure difference tests: HPT and NPT. In Part 2 of this study, eight new (unoccupied) houses were tested using a simplified duct pressurization test and the HPT. Two houses in Part 2 were also tested using the same procedures as the Part 1 houses.

The following average duct leakage values were determined by combining the HPT, NPT and Duct Pressurization tests for the Bay Area houses and the HPT and Duct Pressurization test for the Irvine houses. The Bay Area houses averaged about $13 \%$ of fan flow leakage for supplies and $13 \%$ of fan flow for returns. This was reduced to $7 \%$ and $8 \%$ respectively, by sealing the leaks. The new houses tested in Irvine had similar total (sum of supply and return) leakage to the Part 1 houses pre sealing with an average of $12 \%$ supply leakage and $11 \%$ return leakage.

There was a large range of duct leakage from house to house, even in the new houses that all had the same house and HVAC system design, and in some cases the same HVAC contractor. This large variation indicates that the specific installation rather than system design is the determining factor for duct leakage. In turn, this implies that any test for duct leakage used for compliance or screening purposes must be able to distinguish between individual systems. For example, proposed Title 24 and HERS ratings will have a default duct leakage of $22 \%$ of fan flow (combining both supplies and returns). The maximum available credit will allow the use of duct leakage of half of the default - $11 \%$. To claim this maximum, the tested duct system must have a leakage of less than $5 \%$ of fan flow. This difference between the tested value and that used in the energy calculations ( $6 \%$ of fan flow) is to account for uncertainty in the leakage measurement. This lower leakage credit is to ensure that homes are not given credit that they do not really qualify for. If this $6 \%$ difference is assumed to be two standard deviations of the error in measuring the system leakage, then the acceptable combined bias and precision errors for the duct leakage test are $3 \%$ of fan flow. This corresponds to about $30 \mathrm{cfm}$ in the older Bay Area houses in this study and $75 \mathrm{cfm}$ for the new houses in Irvine.

One of the key issues when using any field test is the repeatability uncertainty so that decisions regarding code compliance or screening for retrofitting can be made. The duct pressurization test was found to have good repeatability both between different testers and for repeated tests by the same test crew. The HPT has about $75 \mathrm{cfm}$ repeatability error due to a combination of poor resolution, large precision errors due to measurements of low pressures and sensitivity to duct pressure measurement location.

Because the HPT was found to be less robust than the duct pressurization method the following recommendations should be followed to limit the applicability of the HPT to suitable systems. Following 
these recommendations will reduce the effect of the resolution limits and also the sensitivity to duct pressure measurement. These recommendations will also help to eliminate false zero readings (e.g., for very leaky house envelopes recommendation 2 will be violated).

1. Only use the HPT on systems with the filter(s) at the return grille(s) and with two or less return grilles.

2. Only use the HPT if the ceiling pressure change between system off and system on OR system off and system on with the return blocked is greater than $0.5 \mathrm{~Pa}$. This limit removes houses with leaky envelopes.

3. Only use the HPT if the standard deviations of each group of ten ceiling pressure measurements is less than the differences between the means of each group of 10 measurements. This limits the use of the HPT to low wind speeds.

These test limitations were developed as part of this study, so these limits were not applied here and all the test houses were house pressure tested.

For the pressurization test the precision errors are acceptable and it would be possible to correct the pressure pan bias errors for most systems by subtracting about $25 \mathrm{cfm}$ from the measured leakage or $25 \%$ of the measured leakage flow - whichever is greater. Similarly, the cabinet leakage bias from supplies to returns could be reduced by simply transferring $50 \mathrm{cfm}$ or $50 \%$ of the measured return leakage - whichever is larger - to the supplies.

\section{Retrofit/Compliance Decisions}

The leakage test methods were used to produce a decision about passing or failing a leakage criteria at several levels. The lowest leakage criteria was based on existing (City of Irvine) and proposed (Title 24) criteria for California. The City of Irvine, CA., has a voluntary efficiency program for builders (called IQ+) that requires a maximum duct leakage level of $50 \mathrm{cfm}$ (at $25 \mathrm{~Pa}$ ) per $1000 \mathrm{ft}^{2}$ of floor area. The proposed credit for Title 24 duct leakage reduction is $6 \%$ of fan flow. At these low leakage criteria, few discrepancies were found between the test methods (none in the new Irvine houses). However, little discrimination is required at these low leakage rates because almost all the houses have poor duct systems whose leakage is much greater than these low leakage levels, even after leak sealing. When a leakage criteria is chosen that is close to the typical duct leakage the tests only agree for about half the houses. In addition, the HPT/NPT and duct pressurization techniques disagreed about which retrofitted systems would pass the $6 \%$ criteria. This is a critical result because retrofit/compliance decisions need to be independent of the test method used.

With current duct construction practice the decision about passing or failing the Title 24 or IQ+ minimum leakage criteria does not depend on the test method used in new houses (mostly because all the new house duct systems were much too leaky to meet these criteria). However, as system installations improve, the different results from different tests will become critical. To obtain a more definitive answer regarding disagreement between test methods houses with good duct systems need to be found and tested.

\section{Duct Sealants And Longevity Testing}

All current air distribution systems require some sort of sealant between duct sections, at branches and at register boots. Without these seals, duct systems would be extremely leaky and hence inefficient. While some duct sealant technologies are rated (e.g. by Underwriters Laboratory) on their manufactured properties, none of these ratings addresses the in-service lifetime. A key piece of the sealant selection puzzle would be answered if relative ratings for sealant longevity existed. To examine this question, LBNL has developed a longevity testing apparatus for accelerated aging of duct sealants.

LBNL has already tested an aerosol sealant for longevity. Three years ago EPA funded construction of a test rig to measure the longevity of the aerosol sealant technique under accelerated conditions. This testing 
involved heat-only testing of a few aerosol-sealed leaks with about a 20 minute cycle time. The results show no measurable change in the leakage of the samples sealed with the aerosol sealant over a 2 year period.

\section{UL 181}

The current UL Standard 181 deals with sealants for duct systems. The main standard deals mostly with factory assembly issues, but UL 181A and UL 181B, both of which are relatively new, deal with field assembled rigid and flexible duct systems respectively. There are many kinds of sealants used on ducts in California houses, but by far the most common system in new construction is field-assembled flexible ductwork. Thus UL 181B is the most relevant to CIEE's interests. The current UL 181 standards have very limited tests of the strength and longevity of duct sealants (see Appendix 7 for details) that we do not consider to be sufficient for rating duct sealants. For example, the adhesion tests only require tape to last for 24 hours. The low requirements for the UL 181 tests reinforces the necessity for developing other longevity test methods.

\section{Longevity Testing Apparatus}

Appendix 3 gives more details of the following summary. The longevity testing apparatus was developed to test a variety of different sealants in a repeatable and consistent manner. The design of the LBNL longevity apparatus is intended to overcome many of the limitations imposed by the simple rig built for EPA and ultimately to perhaps become a standardized way of testing the longevity of duct sealant systems using accelerated methods. The specific design objectives include the following:

- Combined thermal $\left(0\right.$ to $60^{\circ} \mathrm{C}$ [32 to $140^{\circ} \mathrm{F}$ ) and pressure cycling (up to $200 \mathrm{~Pa}$ ).

- Rapid cycle times: 6 minute target.

- Maximum duct surface temperature should be as hot as the hottest attic, but under $200^{\circ} \mathrm{F}$ due to temperature limits set by some duct tape ratings.

- Minimum duct surface temperature should be cold enough to form condensation and perhaps frost.

- A standardized leak and process should be used so that only the sealant is being tested.

- Multiple sealant materials evaluated simultaneously:

- Automated data taking and leak monitoring.

The test system has sealed loop hot and cold air systems that operate continuously. A selector valve, controlled by a linear actuator, directs air from either the hot system or the cold system to flow through the test section. Half of the test sections have hot air while the other half have cold air flowing through them. For more leakage measurements the testing is stopped and orifice flow meters are used in each individual test section.

Figure 1 shows the temperature cycling for one of the current test samples. The hot plenum is operating at $170^{\circ} \mathrm{F}\left(75^{\circ} \mathrm{C}\right)$ and the cold plenum operates at $10^{\circ} \mathrm{F}\left(-12^{\circ} \mathrm{C}\right)$. The test sample surface temperatures have an approximate maximum of $140^{\circ} \mathrm{F}\left(60^{\circ} \mathrm{C}\right)$ and a minimum of $32^{\circ} \mathrm{F}\left(0^{\circ} \mathrm{C}\right)$. These surface temperatures are not as extreme as the plenum temperatures, but still provide a reasonable stress for the sealants.

The initial tests have the sealant applied to a standard 4" sheet metal collar to plenum connection. This leak geometry was selected because it is common in almost all duct systems. Figure 2 shows four of the tested samples.

The samples to be tested in our apparatus are those tapes and sealants which are either commonly used or are being considered for use in various programs. One exception to this criterion is that no testing of any tape that has a maximum temperature rating of $120^{\circ} \mathrm{F}\left(49^{\circ} \mathrm{C}\right)$ or below. Not only would it to fail quickly in our accelerated testing because of its higher temperatures, but any duct tape with such a poor temperature rating should never be used.

A review of available duct tapes has shown that there are dozens of tapes (one major manufacturer lists 16 different cloth duct tapes (available in a range of colors) and 8 metalized tapes) available on the market, and the performance specifications are poorly defined in catalogs and by the manufacturers. Some of these tapes have their product codes printed on the tape, some on the hubs, and some do not have any product 
number on them. All the cloth tapes meet UL 723 (Test for Surface Burning characteristics of Building Materials) but only some of the metalized ones do. Some are listed as "Code Approved" (BOCA, HUD) and a tape that has nearly the same specs does not indicate that it is "Code Approved". Catalogues call the different qualities Economy, Utility, General Purpose, Contractors, Industrial, Professional, Premium and even Nuclear. They are all listed as being used on HVAC ducts. Several companies have just come out with a UL 181B-FX tape, generally these are not even listed in the product catalogs yet.

The manufacturers list and produce fewer grades of mastics than tapes. We have only found one mastic that is UL 181B approved although many are UL $181 \mathrm{~A}$. It is expected that this situation will change in the future.

Taking all of the information from both the sponsors of this research project and manufacturers of sealant products, the samples to be tested are prioritized Table 2. The first column is the ranking for immediate testing in the apparatus. The second column represents the priority for baking additional samples in the oven prior to testing.

\section{Preliminary Test Results}

Figure 3 shows the change of test sample leakage with time. The initial high leakage number (about $10 \mathrm{cfm}$ @ $25 \mathrm{~Pa}$ ) is the leakage of the test sections before the sealant was applied. The cloth backed tape showed visible signs of failure within about 3 days of the start of the test. The measured leakage for the cloth tapes showed that samples had about $10 \%$ to $20 \%$ of the leakage of the samples before sealing. The "Premium Grade" tape failed completely (it fell off the test section), but the other tapes had just started to delaminate at this time. This complete failure was due to separation of the cloth backing from the glue due to the thermal cycling. A second sample of the Premium Grade tape was tested to see if this a repeatable failure, and it lasted about 7 days before complete failure (note that this second sample is not shown in the figures). The metal backed tapes, the plastic backed tape, the aerosol and the mastic show no visible of measurable signs of degradation after two weeks of testing.

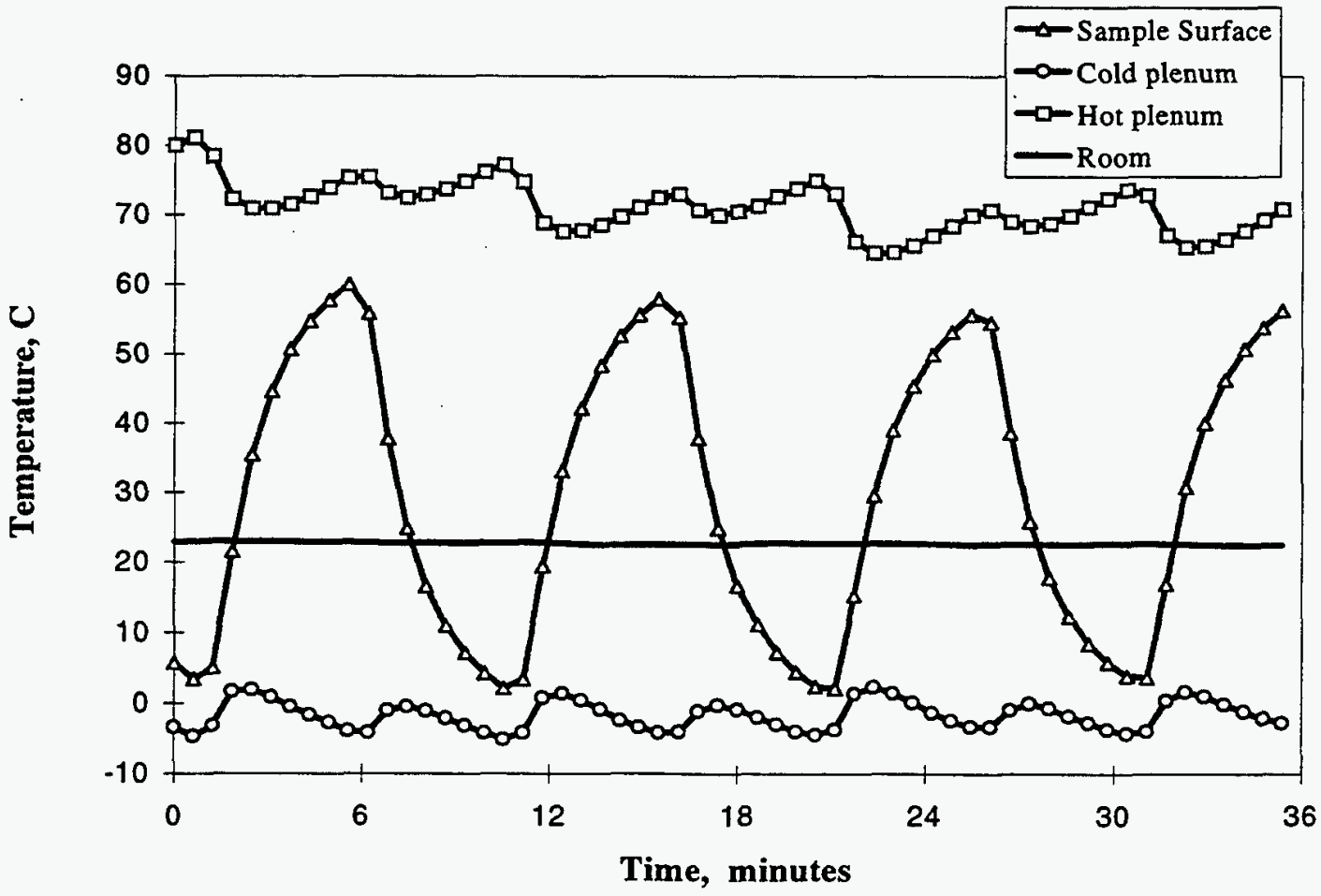


Figure 1. Temperature cycling in longevity test apparatus

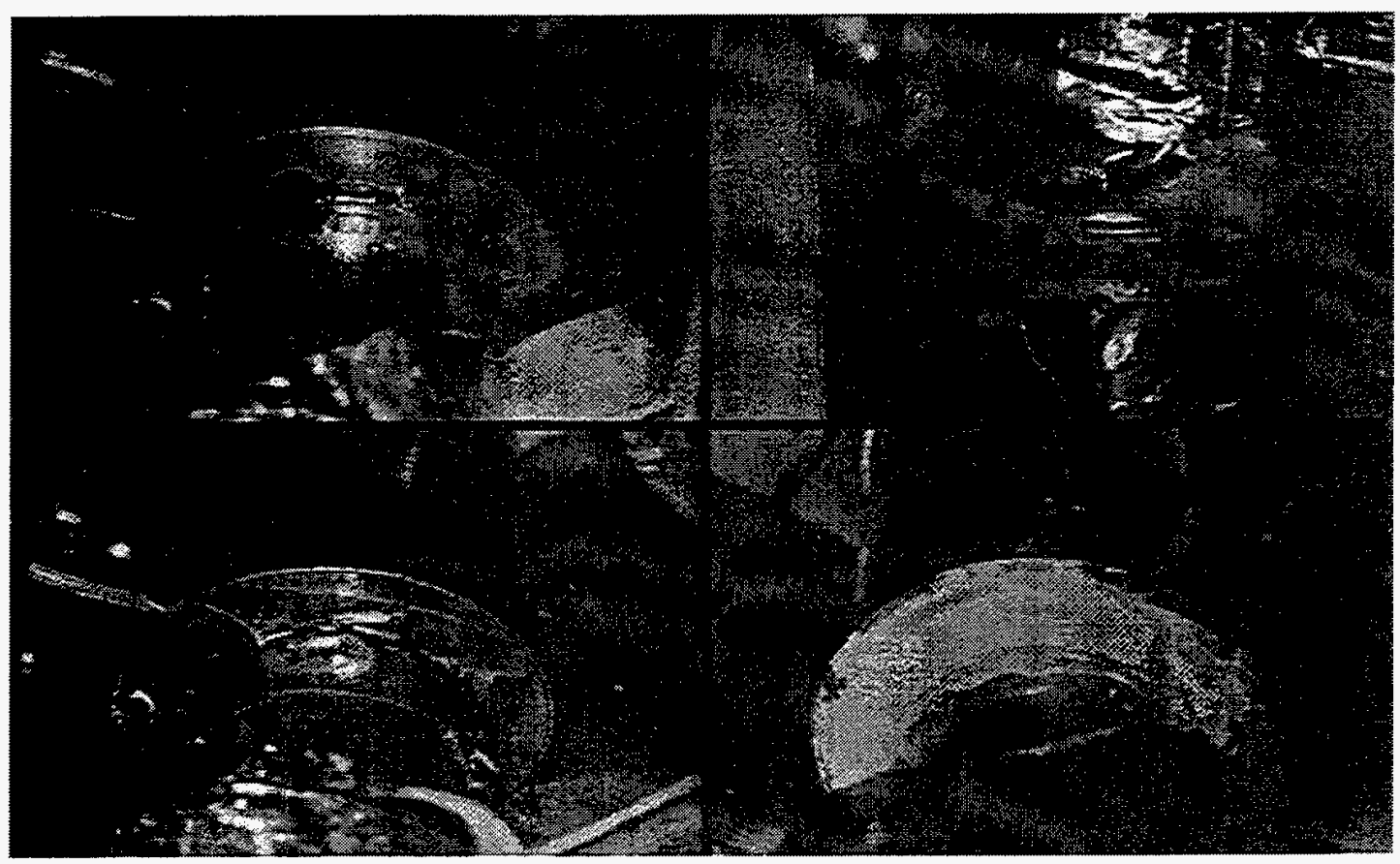

Figure 2. Four longevity samples. Clockwise from top left: clear tape, aerosol sealant, mastic and 181B-FX cloth tape. 


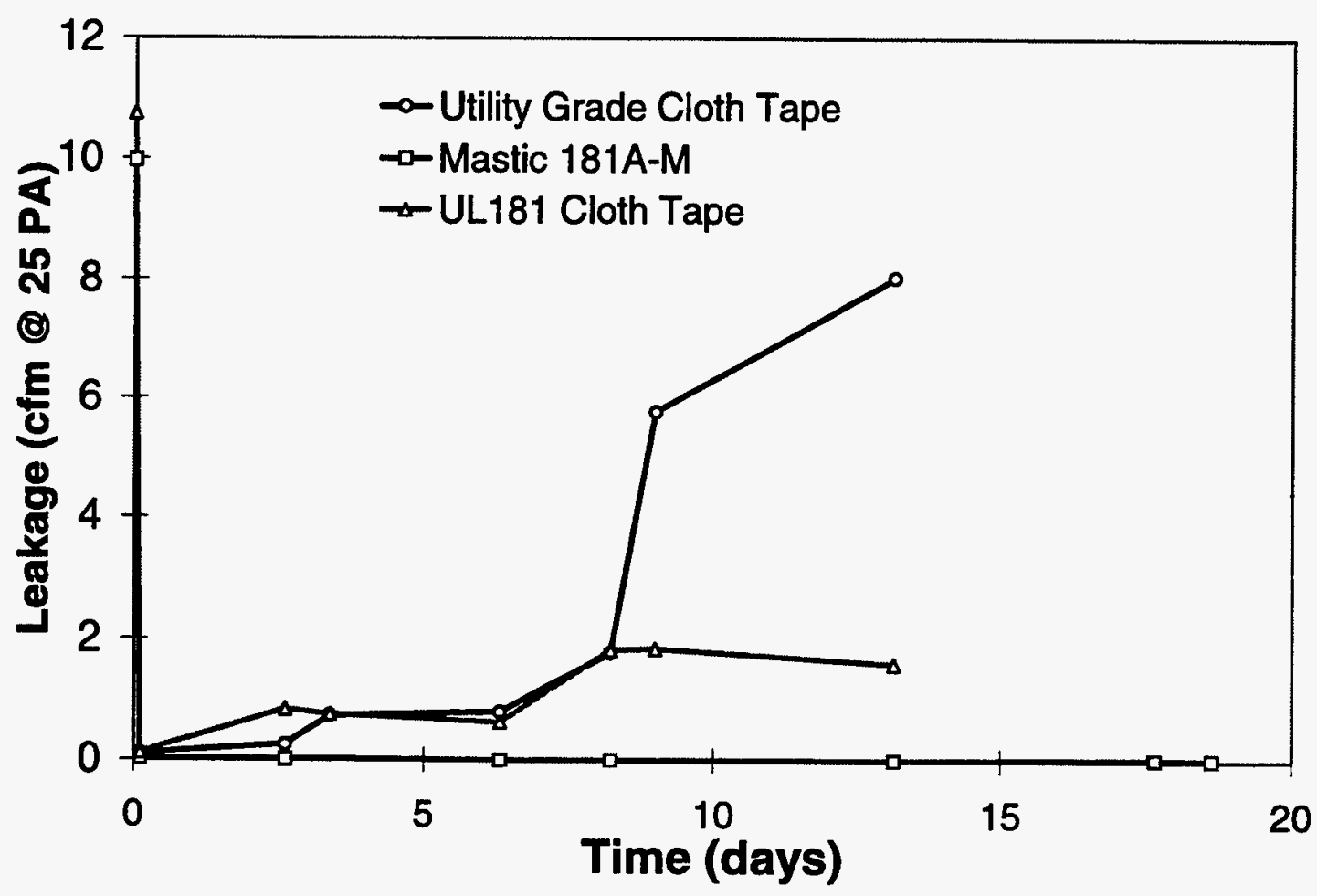

Figure 3. Changing test sample leakage from longevity test apparatus 


\section{Table 2. Ranking of samples for longevity testing}

\begin{tabular}{|c|c|c|c|}
\hline $\begin{array}{l}\text { Ranking for } \\
\text { cyclic testing }\end{array}$ & $\begin{array}{l}\text { Ranking for } \\
\text { baking }\end{array}$ & Sealing Method & Comments \\
\hline 1 & 11 & $\begin{array}{l}\text { "General Purpose" } \\
\text { cloth duct tape }\end{array}$ & $\begin{array}{l}\text { Rated to } 200 \mathrm{~F}, \mathrm{UL} 723^{*} \\
\text { A popular type will be used. }\end{array}$ \\
\hline 2 & 12 & $\begin{array}{l}\text { UL 181B-FX Cloth } \\
\text { Duct Tape }\end{array}$ & UL 181B-FX Rated (New Product) \\
\hline 3 & 4 & Plastic backed tape & $\begin{array}{l}\text { Popular in California. The suppliers will not } \\
\text { release information about these tapes to LBNL. }\end{array}$ \\
\hline 4 & 6 & Mastic & UL 181A Rated \\
\hline 5 & 8 & UL181A Foil Tape & UL181A is for duct boards and sheet metal ducts \\
\hline 6 & 10 & $\begin{array}{l}\text { Butyl backed metal } \\
\text { Foil Tape }\end{array}$ & $\begin{array}{l}\text { UL } 723 \text { Rated, } 15 \text { mil } \\
\text { (thicker coatings are not UL rated) }\end{array}$ \\
\hline 7 & 1 & Aerosol & UL Rating is pending \\
\hline 8 & 7 & $\begin{array}{l}\text { "Premium" cloth } \\
\text { tape }\end{array}$ & $\begin{array}{l}\text { UL } 723 \text { and BOCA and HUD "Code approved" } \\
\text { tape }\end{array}$ \\
\hline 9 & 13 & Mastic + mesh & Mastic combined with reinforcing mesh \\
\hline 10 & 2 & Mastic + fibers & $\begin{array}{l}\text { Some mastics have reinforcing fibers embedded in } \\
\text { the mastic }\end{array}$ \\
\hline 11 & 5 & $\begin{array}{l}30 \text { mil metal Foil } \\
\text { Tape }\end{array}$ & Not UL Rated \\
\hline 12 & 3 & $\begin{array}{l}\text { "Contractor Grade" } \\
\text { duct tape }\end{array}$ & Between Premium and general purpose \\
\hline 13 & 9 & Mastic UL181B & UL 181 B Rated Mastic (New Product) \\
\hline 14 & 14 & $\begin{array}{l}\text { "Economy" Duct } \\
\text { Tape }\end{array}$ & Rated for use below $200 \mathrm{~F}$ only. \\
\hline
\end{tabular}

* UL 723 is a "Test for Surface Burning Characteristics". This looks like a subset of the tests required for UL181A/B. 


\section{Duct System Interactions with System Sizing and Capacity}

For a duct system with no losses all of the equipment capacity will reach the conditioned space. However, with real systems, the duct system losses reduce the amount of energy delivered to the conditioned space. Therefore, to meet the same building load a poor duct system needs to have more energy input, and this means that higher capacity equipment is required to meet the load. Conversely, if a given equipment capacity is adequate with a poor duct system (as are currently installed) then a good duct system will require a smaller capacity piece of equipment. When a system is first installed, or renovations are being performed to a system, the use of a good duct system allows the purchase of lower capacity equipment, with resulting capital savings. The realization of these savings assumes that current practice compensates for poor ducts by oversizing the equipment so that the comfort level in the building is maintained.

The estimation of equipment capacity reduction that good ducts would allow requires thermal modeling of the duct system. Proposed ASHRAE standard 152P has developed a model for this purpose, and its calculation methods can be used to determine the fraction of equipment capacity that is delivered to the conditioned space. Conversely, if the space load is known, the distribution system efficiency calculated using ASHRAE 152P allows the estimation of required equipment capacity. Because ASHRAE 152P is based on many simplifying assumptions to make it easy to use for Home Energy Rating or Energy Codes (e.g., California Title 24), there is scope for more complex models to be used in parametric studies of duct system/equipment sizing performance. More complex models will be particularly useful in looking at non steady state tasks, e.g., pulldown times, that heating and cooling systems are often asked to perform.

In addition to direct losses from the duct system by leakage and conduction, the duct system can also change equipment performance by the design and construction of the duct layout. Ducts that are too small or are designed or installed with too many bends and turns will restrict the flow in the duct system. This flow restriction can change the operation of the equipment and adversely affect the equipment efficiency. In addition, the lower flow over the heating or cooling coils will tend to make the temperature of air in the supply ducts more extreme, which will lead to increased supply duct losses compared to a system with the correct system flows.

\section{Summary of existing research}

The detailed basis for the following summary is in Appendix 8.

The purpose of this section is to summarize existing work on the interacting factors between duct systems and air conditioner size and capacity. The three reports that are summarized here are Rodriguez et al. (1995), Blasnik et al. (1996), and Nerland et al. (1995). Between them, these reports combine measured field performance and controlled laboratory testing.

The field surveys have found that very few systems (probably less than $20 \%$ ) have the correct refrigerant change. Typical overcharging or undercharging results in about 30\% drop in equipment efficiency, with undercharging having the greatest effect. In addition, TXV control systems are less effected than orifice controlled systems.

Manufacturers typically recommend that a fan flow rate of $400 \mathrm{cfm}$ per ton of air conditioning. Lower air flows result in reduced efficiency and, if they are low enough, they can cause damage to the system. Manufacturers typically suggest that flow below $350 \mathrm{cfm} / \mathrm{ton}$ is the point at which the system needs corrective action to prevent damage to the condenser and evaporator. The Blasnik et al. study found the average system had $86 \%$ of the manufacturers recommended air flow. Laboratory tests indicate that this results in a capacity reduction of about $10 \%$. More restrictive duct systems will reduce equipment capacity further. 
Duct leakage was found to have a significant effect on air conditioning efficiency. The laboratory tests showed that air conditioner efficiency is halved and capacity reduced by about $30 \%$ with about $15 \%$ duct leakage that is typical of California duct systems (this includes the effect of hot attic air flowing into return leaks). Air conditioners are particularly sensitive to return duct leakage in hot attics because the introduction of hot attic air into the return increases the temperature of air entering the equipment. Because temperature changes are low in air conditioning equipment an increase of a few degrees in air temperature entering the equipment means that a large fraction of the equipment capacity is used to cool the attic air that entered through the retum leaks down to the indoor air temperature.

Reducing the installed capacity was found by both the Nerland and Blasnik reports to reduce peak energy use between about $2 \%$ and $5 \%$ compared to systems that were sealed and insulated, but not resized. A broader range of conditions than covered in these reports needs to be considered before definitive advice may be given regarding potential savings available from resizing equipment.

The results of the studies summarized above show that much work remains to be done before useful information regarding sizing issues can be given to HVAC installers and builders. For example, one question that remains is how might these various effects combine to effect capacity and peak energy demand? All of the reports cited in this study assume that these are multiplicative, which may not be true. Another question that remains is how peak energy demand and capacity will be affected by a system that was already oversized and then has a duct retrofit so it becomes even more oversized (because the effective building load gets smaller).

To answer many of these questions, there is a need to develop and use modeling tools that account for the interactions discussed in this report. Proposed ASHRAE Standard 152P allows for steady state interactions between duct losses and the equipment, but does not account for detailed interactions between the ducts and their surroundings. Previous modeling efforts at LBNL have produced complex and unwieldy calculation methods that attempted to model the duct system on an hour by hour basis, with assumptions made for equipment fraction ontime estimates. Future work for the current project will concentrate on developing equipment and duct models that are interactive and will allow transient analyses (for pulldown experiments) to be performed, as well as improving thermal loss calculations for the duct system.

\section{Capacity at Registers}

The effect of return duct leakage in cooling systems is felt most strongly in the reduction of effective capacity "at the register". This concept looks at the temperature of the air flowing out of the registers and calculates the combined equipment and duct capacity based on this measure. The temperature of air flowing out of the registers depends strongly on the temperature of air entering the cooling coil, which can change by a significant fraction of the available cooling capacity if there are return leaks in the system. Appendix 8 provides details of example calculations that show that $20 \%$ return leakage for a typical duct system will reduce the effective capacity at the registers to half of the equipment capacity.

\section{Contractor and Occupant Behavior}

It has been found through field surveys (e.g., Proctor (1996)) that almost all cooling systems are oversized. This is mainly driven by contractors who do not want to be called back to a job if a homeowner complains about lack of cooling. The easiest way to accomplish this is by installing extra capacity. This overcapacity means that systems tend to have short runtimes which has significant comfort impacts due to insufficient air mixing (leading to hot and cold parts of a home) and loss of latent capacity. Studies have also shown that this oversizing tends to increase peak energy demands due to increased system cyclic losses. The occupant behavior with the biggest impact on energy demand is the use of daytime setback. When the occupants return the system operates continuously until the house is cooled. Although the extra capacity makes this happen more rapidly, whilst the oversized system is operating it consumes more energy thus increasing the peak demand for utilities. 


\section{Technical Transfer and Support Activities}

\section{Proposed ASHRAE Standard 152P}

The ASHRAE effort to quantify duct efficiency in proposed standard 152P is at the heart of many of duct efficiency programs in the state of California and elsewhere. The three diagnostic techniques in the standard are the same or similar to those discussed in this report: 1) the House Pressure Test (HPT); 2) the duct and house pressurization technique and 3 ) the duct-only pressurization technique.

- The HPT is in many ways the quickest one to use, works at approximately normal operating pressures and can predict the supply/return split, but it is the least repeatable. Details on the use of the HPT have changed in the current standard as a result of the work reported here (e.g., correcting for duct leakage being included in envelope leakage).

- The duct and house pressurization technique requires the use of a Blower Door and DuctBlaster to determine the duct leakage to outdoors at a fixed pressure; it measures the supply/return split at a fixed pressure difference.

- The duct-only pressurization technique measures the total (supply plus return) duct leakage rather than leakage to outside, but it does not require the use of a Blower Door to pressurize the house. Proposed ASHRAE Standard 152 limits the use of this technique to new construction. (This is essentially the technique used in the IQ+ program.)

The standard requires a measurement using the above techniques to be made for an extant house; default values are only allowed when calculations are being made during the design process.

\section{California Energy Commission - Title 24/HERS}

LBNL has been working together with CEC staff to incorporate ASHRAE Standard 152P calculation procedures into Title 24 and HERS. For Title 24, most of this work has concentrated on determining appropriate input values for proposed ASHRAE 152P calculations that are representative of California houses. The defaults developed for Title 24 are in addition to those already in the ASHRAE standard. Duct leakage is the most significant default value developed specifically for CEC, and was based on field measurements performed by LBNL and others. The allowable range for duct sealing credit has been debated by LBNL, CEC and other interested parties over the last twelve months. LBNL has gone through several different scenarios together with CEC staff in order to satisfy comments made on the proposed changes to Title 24 with regards to developing appropriate default duct leakage levels and also providing estimates of the maximum credit assigned to duct improvements. In addition LBNL has assisted CEC in answering questions about distribution system efficiency put forward by reviewers of the proposed changes to Title 24 .

Considerable effort has been put into making the Title 24 calculation procedure robust enough to prevent users from having too much flexibility in input values that could result in incorrect estimates of system performance. For example, recent discussions with CEC have concentrated on linking equipment size to duct surface area.

LBNL has helped develop the composition of ASHRAE 152P so that it is in a format suitable for use in HERS ratings. This has included changes to measurement procedures and keeping the input requirements and calculation procedures as simple as possible. All of this HERS work has been performed in collaboration with CEC and CHEERS.

\section{CEC/City of Irvine Pilot Program: IQ+}

LBNL provided assistance to CEC for the pilot program in Irvine for improving duct systems. A simplified test was developed for the City of Irvine pilot program that would be economically feasible, 
provide sufficient repeatability for compliance testing and be a good indicator of system performance. For the rest of the Irvine pilot program LBNL provided test protocols and training for CEC staff and third party contractors. As part of the promotion and technology transfer aspect of the Irvine program, LBNL provided test demonstrations for third party testers, builders, and city and state officials. In addition, LBNL analyzed the measurements made by both LBNL and CEC in order to provide recommendations for further testing and to provide estimates of measurement uncertainty and repeatability.

LBNL also assisted the City of Irvine directly by providing editorial input for the documentation of their pilot program material. This Irvine Quality Plus (IQ+) program is now operational with multiple builders having signed on to this voluntary program. The CEC is pursuing similar efforts in other communities.

\section{Collaboration with Air Conditioning Contractors of America (ACCA)}

The ACCA manuals are currently being revised to have an improved method for including duct losses. An iterative process between ACCA and LBNL has led to considerable proposed changes for the next edition of ACCA Manual J, Load Calculation Procedure. Manual J will explicitly include distribution system loss calculations in the estimate of building loads. The calculations are based on those in proposed ASHRAE $152 \mathrm{P}$ with appropriate default values and simplification determined by consultation between ACCA and LBNL. LBNL has also examined the resulting loads and calculation methods to ensure that the simplified ACCA procedure produces reasonable results. Ongoing work with ACCA involves looking at improving the duct system loss calculations for individual ducts to improve load matching for individual rooms (rather than for the system as a whole).

The proposed changes to Manual J are outlined in an ACCA technical note: Bulletin 143 - Residential Duct Loads. The duct losses are incorporated into the load calculations by determining the losses from the ducts and adding these losses to the envelope losses to determine the total load for the building. The old Manual $\mathrm{J}$ had very low duct load multipliers that were in a simple look up table. The new duct load multipliers have been calculated using the proposed ASHRAE 152P procedures. The proposed format in Manual J is to have a page for each possible system type listing the sensible and latent cooling loads due to the ducts as a function of building floor area, outside air temperature and outside air moisture, discharge air temperature, with correction factor scalars for duct insulation. The system type depends on the register layout (e.g., in walls, centrally in the ceiling etc.) how the system is connected (e.g., octopus or trunk and branch), duct location (e.g., attic or crawlspace), and most important, duct system leakage. Rather than use SMACNA guidelines for leakage, the new Manual J calculations will have leakage set to either $15 \%$ of fan flow or 5\% of fan flow, where the $5 \%$ of fan flow systems must be leakage tested. This idea of performance testing requirements is a large conceptual change for the ACCA procedures and its significance should not be overlooked. 


\section{REFERENCES}

Andrews, J.W., (1997), "Error analysis for duct leakage tests in ASHRAE Standard 152P", Brookhaven National Laboratory Report 64679.

Andrews, J.W., Pierce, B.L., Hedrick, R., Lubliner, M., Reid, B., and Saum, D., (1997), "Repeatability of ASHRAE Standard 152P: results of a round robin test", Draft of paper for ASHRAE TC6.3 symposium.

Blasnik, M., Downey, T., Proctor, J. and Peterson, G, (1996), "Assessment of HVAC installations in New Homes in APS Service Territory", Proctor Engineering Group Report for Arizona Public Service Company.

Modera, M.P., and Wilcox, B., (1995), "Treatment of residential duct leakage in Title 24 energy efficiency standards", California Energy Commission Contract Report.

Nerland, E.,Treidler, B., and Modera, M. (1995), "Peak Impacts of Residential Air Conditioning", LBNL Report

Proctor, J. (1996), "Field Measurements of New residential Air Conditioners in Phoenix Arizona", Proctor Engineering Group report, San Rafael, CA.

Rodriguez, A.G., O'Neal, D.L., Bain, J.A., and Davis, M.A.(1995) "The Effect of Refrigerant Charge, Duct Leakage, and Evaporator Air Flow on the High Temperature Performance of Air Conditioners and Heat Pumps", Energy Systems Laboratory report for EPRI, Texas A\&M University.

\section{RECENT PUBLICATIONS}

Jump, D.A., Walker, I.S., and Modera, M.P., "Field Measurements of Efficiency and Duct Retrofit Effectiveness in Residential Forced-Air Distribution Systems." Proceedings of ACEEE Summer Study, Pacific Grove, CA, August 1996, Lawrence Berkeley Laboratory Report , LBL-38537.

Walker, I.S., Modera, M.P., Tuluca, A. and Graham, I. "Energy Effectiveness of Duct Sealing and Insulation in Multifamily Buildings." Proceedings of ACEEE Summer Study, Pacific Grove, CA, August 1996, Lawrence Berkeley Laboratory Report, LBL-38538.

Modera, M.P., Dickerhoff, D.J., Nilssen, O., Duquette, D. and Geyselaers, J. "Residential Field Testing of an Aerosol-Based Technology for Sealing Ductwork." Proceedings of ACEEE Summer Study, Pacific Grove, CA, August 1996, Lawrence Berkeley Report, LBL-38554.

Hageman R. and Modera, M.P., "Energy Savings and HVAC Capacity Implications of a Low-Emissivity Interior Surface for Roof Sheathing." Proceedings of ACEEE Summer Study, Pacific Grove, CA, August 1996.

Hammon, R.W. and Modera, M.P., "Improving the Energy Efficiency of Air Distribution Systems in New California Homes." Proceedings of ACEEE Summer Study, Pacific Grove, CA, August 1996.

Nilssen, O., "Laboratory Development and Field Testing of an Aerosol-Based Sealing Technology for InSitu Sealing of Duct Systems." Master's Thesis

Delp, W., Matson, N., Modera, M.P., "Exterior Exposed Ductwork: Delivery Effectiveness and Efficiency" LBL-39083

Modera, M.P., Dickerhoff, D.J., Wang, D., "Field Testing of Aerosol-Based Sealing Technology" LBL39521 
Modera, M.P., Carrie, F.R., "A Method and Device for Producing and Delivering an Aerosol for Remote Sealing and Coating", New application prepared and filed.

Modera, M.P., Byrne, J., Home Energy Article, "Can a New Duct Test Take the Pressure?" Home Energy Magazine, January/February 1997, pp. 29-33.

Walker, I.S., "Technical background for default values used for forced air systems in proposed ASHRAE standard 152P, ASHRAE TC 6.3 Symposium. (In Press)

Walker, I.S. and Modera, M.P., "Field Measurements of Interactions between Furnaces and Distribution Systems", ASHRAE TC 6.3 Symposium. (In Press)

Walker, I.S., "Distribution System Leakage Impacts on Apartment Building Ventilation Rates", ASHRAE TC 4.1 Symposium. (In Press)

\section{Appendices}

\section{Appendix 1. House Pressure Test (HPT) Procedure}

\section{Test Limitations}

1. Only use the HPT on systems with the filter at the return grille and systems with simple returns (i.e., not on systems with multiple branched returns).

2. Only use the HPT if the ceiling pressure change between system off and system on OR system off and system on with the return blocked is greater than $0.5 \mathrm{~Pa}$.

3. Only use the HPT if the standard deviations of each group of ten ceiling pressure measurements is less than the differences between the means of each group of 10 measurements.

\section{Building envelope leakage}

The building envelope leakage shall be characterized by a leakage coefficient, $C_{e n v}$, and a leakage exponent, $\mathrm{n}_{\text {env }}$. These characteristics shall be determined using a pressurization test of the building. This pressurization test may be either:

1. A standard pressurization test covering a range of pressures and flowrates (for example, ASTM E779 (1992)).

2. A single-point fan pressurization test. A fan pressurization system shall be used to pressurize the building to $25 \mathrm{~Pa}$ [0.1 inch water]. The fan flow at $25 \mathrm{~Pa}$ [0.1 inch water] is recorded ( $\mathrm{Q}_{\mathrm{env}, 25}$ or $\left.\mathrm{Q}_{\mathrm{env}, 0.1}\right)$. If this test is used, the pressure exponent shall be set to $\mathbf{n}_{\text {env }}=\mathbf{0 . 6 5}$ for the calculation of $C_{\text {env }}$ and the leakage flow calculations. The flow coefficient for the envelope, $\mathrm{C}_{\mathrm{env}}$, shall be calculated using:

For SI:

$\mathrm{C}_{\mathrm{env}}=\frac{\mathrm{Q}_{\mathrm{env}, 25}}{25^{0.65}}$

For IP:

$C_{\text {env }}=\frac{Q_{\text {env }, 0.1}}{0.1^{0.65}}$ 


\section{House Pressure Test Procedure}

If the filters are located at the return plenum/air handler unit, then the pressure measurement point shall be upstream of the filter and the location of the filter shall be recorded.

Time averaging of pressures for this test can be accomplished in different ways, depending on the pressure measuring device. Pressure measuring equipment that has built in averaging is preferable, in which case a five second average shall be used. For equipment without averaging capability, the user must record 25 individual pressure readings in place of the 10 five second averages and five readings in place of the single measurements as required in the following procedure.

The pressure differences across the ceiling ( $\Delta \mathbf{P}_{\mathrm{on}}, \Delta \mathbf{P}_{\mathrm{off}}$ and $\Delta \mathbf{P}_{\mathrm{RB}}$ ) are measured using the attic as the reference pressure.

The pressure differences for the supply and return ducts $\left(\Delta \mathbf{P}_{\text {ret, }} \Delta \mathbf{P}_{\text {sup }} \Delta \mathbf{P}_{\text {ret, }, R B}\right.$, and $\left.\Delta \mathbf{P}_{\text {supRB }}\right)$ are measured using the building as a reference pressure.

If a single pressure measuring device is used, this requires switching the reference port between the attic and the building. The use of two pressure measuring devices is preferred to reduce the number of times tubing has to removed/swapped.

If two pressure measuring devices are used, one should be used for pressures across the ceiling (with the tubing from the attic connected to the reference port) and the second should be used for pressure differences between the building and the ducts (with the reference port open to the building conditions and the input port connected to the appropriate tube for each measurement).

1. Close all the exterior windows and doors of the conditioned space. If the basement is conditioned space open the door(s) between the basement and the other conditioned space and ensure that basement windows are closed. If the basement is unconditioned, then close the door(s) between the conditioned space and the basement and open a window or door to outside from the basement.

2. Install one plastic tube between the building and attic, passing one end of the tube through the attic access hatch, and connecting the end to the reference port of a pressure measuring device.

3. Install a second plastic tube between the return duct and the building, passing one end through the return grille and connecting a static pressure probe, and connecting the other end to the input port of a pressure measuring device. If the filter(s) are located at the return grille, the end of the tube should be passed through the filter to measure the pressure on the equipment side of the filter. If the filter(s) are located at the plenum, then the filters shall be removed (and the filter access sealed) and the end of the tube within the return duct shall be located mid-way (within $1 \mathrm{~m}(3 \mathrm{ft}$ ) of the mid point) between the grille and the plenum.

4. Connect a third plastic tube to a pressure pan. A pressure pan is a device used to seal individual forced air system registers and grilles. Usually it consists of a perimeter seal that seals to the surface surrounding the register and a panel to prevent air flow out of the register or grille.

5. Turn on the air handler fan and wait at least thirty seconds for the fan to reach steady operation. Record the pressure difference between the building and the attic ten times $\left(\Delta \mathbf{P}_{\mathrm{on}}\right)$, and the pressure differential between the return duct and building once $\left(\Delta \mathbf{P}_{\text {ret }}\right)$. Note that some systems do not have a fan switch. In these cases, the fan shall be turned on by raising or lowering the thermostat setting for heating and cooling fan flows respectively.

6. Turn off the air handler fan and wait for the air handler fan to come to a complete stop (Note that some air handler fans continue to operate for some time after they have been "switched off"). Record the pressure difference between the building and the attic ten times $\left(\Delta \mathbf{P}_{\text {off }}\right)$.

7. Turn on the air handler fan and wait at least thirty seconds for the fan to reach steady operation. Record the pressure difference between the building and the attic ten times $\left(\Delta \mathbf{P}_{\mathrm{on}}\right)$. Cover one supply register with the pressure pan and wait ten seconds for the system to return to equilibrium. Record the pressure difference between the pressure pan and the building once $\left(\Delta \mathbf{P}_{\text {sup }}\right)$. Remove the pressure pan after this measurement is complete.

8. Turn off the air handler fan and wait for the air handler fan to come to a complete stop Record the pressure difference between the building and the attic ten times $\left(\Delta \mathbf{P}_{\text {off }}\right)$. 
9. Turn on the air handler fan and wait at least thirty seconds for the fan to reach steady operation. Slowly block the return grille until the pressure differential between the return duct and the building is approximately $-100 \mathrm{~Pa}\left(-0.4\right.$ inches $\left.\mathrm{H}_{2} \mathrm{O}\right)$, or the register is fully blocked. For systems with more than one return grille, each return grille shall be blocked approximately equal amounts in order to keep the pressures in each branch of the return as uniform as possible.

10. Record the pressure difference between the building and the attic ten times $\left(\Delta \mathbf{P}_{\mathbf{R B}}\right)$. Record the pressure difference between the return duct and building once $\left(\Delta \mathbf{P}_{\text {retRB }}\right)$. Cover one supply register temporarily with the pressure pan and wait ten seconds for the system to reach equilibrium. Record the pressure difference between the pressure pan duct and the building once $\left(\Delta \mathbf{P}_{\text {supRB }}\right)$.

11. Turn off the air handler fan, and wait for the air handler fan to come to a complete stop. Record the pressure difference between the building and the attic ten times $\left(\Delta \mathbf{P}_{\text {off }}\right)$.

$\Delta \mathbf{P}_{\text {on }}$ and $\Delta \mathbf{P}_{\text {off }}$ shall be averaged over their multiple measurements:

$\Delta P_{\text {of }}$ from steps 6,8 and 11 shall be averaged.

$\Delta \mathbf{P}_{\text {on }}$ from steps 5 and 7 shall be averaged.

The net flow leaving the building due to supply and return duct leakage shall be calculated using (In Equations A1.3 to A1.12 it is assumed that supply leaks have a positive sign and return leaks have a negative sign):

$$
\mathrm{Q}_{\text {sleak }+ \text { rleak }}=\frac{1}{2} \mathrm{C}_{\text {env }}\left(\operatorname{sign}\left(2 \Delta \mathrm{P}_{\text {off }}-\Delta \mathrm{P}_{\text {on }}\right)\left|\Delta \mathrm{P}_{\text {on }}-2 \Delta \mathrm{P}_{\text {off }}\right|^{\mathrm{n}_{\text {env }}}-\operatorname{sign}\left(\Delta \mathrm{P}_{\text {on }}\right)\left|\Delta \mathrm{P}_{\text {on }}\right|^{\mathrm{n}_{\text {env }}}\right)
$$

The unbalanced duct leakage flow under blocked-return conditions shall be calculated using:

$$
\mathrm{Q}_{\text {sleak +rleakRB }}=\frac{1}{2} C_{\text {env }}\left(\operatorname{sign}\left(2 \Delta P_{\text {off }}-\Delta P_{R B}\right)\left|\Delta P_{R B}-2 \Delta P_{\text {off }}\right|^{n_{\text {env }}}-\operatorname{sign}\left(\Delta P_{R B}\right)\left|\Delta P_{R B}\right|^{n_{\text {eav }}}\right)
$$

The following equations shall be used to calculate the supply and return duct leakage flows under normal operating conditions:

Supply pressure ratio:

$\mathrm{S}=\left(\frac{\Delta \mathrm{P}_{\text {sup } R \mathrm{~B}}}{\Delta \mathrm{P}_{\text {sup }}}\right)^{0.6}$

Return pressure ratio:

$\mathrm{Z}=\left(\frac{\Delta \mathrm{P}_{\text {retRB }}}{\Delta \mathrm{P}_{\text {ret }}}\right)^{0.6}$

Supply leakage flow:

$$
\mathrm{Q}_{\text {sleak }}=\frac{\mathrm{ZQ}_{\text {sleak }+ \text { rleak }}-\mathrm{Q}_{\text {sleak }+ \text { rleakRB }}}{\mathrm{Z}-\mathrm{S}}
$$

Return leakage flow

$$
Q_{\text {rleak }}=\frac{-S_{\text {Sleak }+ \text { rleak }}+Q_{\text {Sleak }+ \text { rleakRB }}}{Z-S}
$$




\section{Correction for neutral level shift: $\mathbf{F}_{\mathbf{n}}$}

The results obtained with the above equations shall be corrected for the shift in neutral level associated with turning on the distribution system fan. High level leaks are those in attics, low level leaks are those in crawlspaces and basements (when the basements are outside the conditioned space). The corrections for leak location shall be as follows.

\section{Ducts in both high and low locations : no correction $\left(F_{n d}=1.0\right)$}

2. Ducts at high level only:

$$
\mathrm{F}_{\mathrm{nl}}=\left(\frac{1+\left(2\left(\frac{\mathrm{Q}_{\text {sleak }}}{\mathrm{C}_{\mathrm{env}} \Delta \mathrm{P}_{\mathrm{sup}}^{\mathrm{n}_{\mathrm{env}}}}+\frac{\mathrm{Q}_{\text {rleak }}}{\mathrm{C}_{\mathrm{env}} \Delta \mathrm{P}_{\mathrm{ret}}^{\mathrm{n}_{\mathrm{env}}}}\right)+1\right)^{\frac{1}{\mathrm{n}_{\mathrm{env}}}}}{2}\right)^{\mathrm{n}_{\mathrm{env}}}
$$

\section{Duct at low level only:}

$$
\mathrm{F}_{\mathrm{nl}}=\left(\frac{1+\left(2\left(\frac{\mathrm{Q}_{\text {sleak }}}{\mathrm{C}_{\mathrm{env}} \Delta \mathrm{P}_{\mathrm{sup}}^{\mathrm{n}_{\text {env }}}}+\frac{\mathrm{Q}_{\mathrm{rleak}}}{\mathrm{C}_{\mathrm{env}} \Delta \mathrm{P}_{\mathrm{ret}}^{\mathrm{n}_{\mathrm{env}}}}\right)+1\right)^{\frac{-1}{\mathrm{n}_{\mathrm{env}}}}}{2}\right)^{\mathrm{n}_{\mathrm{env}}}
$$


Correction for duct leakage fraction of house leakage

The duct leakage coefficient shall be calculated using Equation A1.11

$C_{\text {ducts }}=Q_{r}\left|\frac{1}{\Delta P_{\text {ret }}}\right|^{0.6}+Q_{s}\left|\frac{1}{\Delta P_{\text {sup }}}\right|^{0.6}$

The supply and return leakage shall be multiplied by the duct leakage correction factor: $F_{\text {dff }}$.

$$
F_{\mathrm{dlf}}=\frac{C_{\text {env }}}{C_{\text {env }}+C_{\text {ducts }}}
$$

Application of correction factors to duct leakage

The correction factors shall be applied to the flow rates using:

$$
Q_{\mathrm{s}}=\mathrm{F}_{\mathrm{nl}} \mathrm{F}_{\mathrm{dlf}} \mathrm{Q}_{\text {sleak }}
$$

$$
Q_{\mathrm{r}}=-\mathrm{F}_{\mathrm{nl}} \mathrm{F}_{\mathrm{dlf}} \mathrm{Q}_{\mathrm{rleak}}
$$

Note the change in sign for return leaks in Equation A1.14.

If this calculation method results in leakage flows having the incorrect sign (correct supply leaks have a positive sign and correct return leaks a negative sign), the results shall be corrected as follows:

If the return flow is positive, the supply flow is recalculated to be the sum of supply and return flows and the return flow is set to zero.

If the supply flow is negative, the return flow is recalculated to be the sum of return and supply flows and the supply flow is set to zero.

\section{Appendix 2. Nulling Pressure Test (NPT) Procedure}

1. Install duct blaster in window or door way with a cover installed to prevent flow through the fan.

2. Install pressure measuring tube into attic (to measure $\Delta \mathrm{P}_{\text {on }}$ and $\Delta \mathrm{P}_{\text {off }}$, use the house for the reference).

3. Measure $\Delta \mathbf{P}_{\text {off }}$ ten times (at five second averages).

All the following register pressures should be five second averages measured using a static pressure probe or pressure pan.

4. Install tubing to measure return pressure into a return grille for systems with the filter at the plenum. For systems with the filter at the return grille the return pressure should be measured on the duct side of the filter (i.e. the tubing is inserted through or past the filter).

5. Turn on system fan and wait 30 seconds for system to come to equilibrium.

6. Measure the pressure difference between the attic and the conditioned space, $\Delta \mathbf{P}_{\text {on }}$, ten times (using conditioned space as reference).

7. Measure the pressure difference between the return and the conditioned space, $\Delta \mathbf{P}_{\text {ret }}$ (using conditioned space as reference).

8. Install a pressure pan over one of the supply registers (do not choose a register with small flows) with a tube to measure the supply pressure.

9. Measure the pressure difference between the supply and the conditioned space, $\Delta \mathbf{P}_{\text {sup }}$ (using 
conditioned space as reference).

10. Slowly block the return grille until the pressure differential between the return duct and the building is approximately $-100 \mathrm{~Pa}\left(-0.4\right.$ inches $\left.\mathrm{H}_{2} \mathrm{O}\right)$, or the register is fully blocked. For systems with more than one return grille, each return grille shall be blocked approximately equal amounts in order to keep the pressures in each branch of the return as uniform as possible.

11. Measure the pressure difference between the supply and the conditioned space, $\Delta \mathbf{P}_{\text {sup, }, R B}$ (using conditioned space as reference).

12. Remove the pressure pan from the supply register.

13. Measure the pressure difference between the return and the conditioned space, $\Delta \mathbf{P}_{\text {ret,RB }}$ (using conditioned space as reference).

14. Measure the pressure difference between the attic and the conditioned space, $\Delta \mathbf{P}_{\mathrm{on}, \mathrm{RBB}}$, ten times (using conditioned space as reference).

15. Unblock the duct blaster.

16. Turn on duct blaster and adjust the flow make pressure difference across the ceiling the same as with the system off ( $\Delta$ Poff).

17. Measure the flow through the duct blaster required to balance the flows - $\mathbf{Q}_{\mathrm{d}, \mathrm{RB}} \cdot \mathbf{Q}_{\mathrm{d}, \mathrm{RB}}$ is negative for flow out of the house through the duct blaster (indicating excess return leakage) and positive for flow into the house (indicating excess supply leakage).

18. Unblock the return(s).

19. Adjust the duct blaster flow make pressure difference across the ceiling the same as with the system off ( $\Delta$ Poff).

20. Measure the flow through the duct blaster required to balance the flows $-\mathbf{Q}_{d} \cdot \mathbf{Q}_{d}$ is negative for flow out of the house through the duct blaster (indicating excess return leakage) and positive for flow into the house (indicating excess supply leakage).

21. Turn off system fan.

22. Turn off the duct blaster and remove from the door or window.

23. Calculate the supply pressure ratio,

$$
S=\left(\frac{\Delta P_{\text {sup }, R B}-\Delta P_{\text {on }, R B}}{\Delta P_{\text {sup }}-\Delta P_{\text {on }}}\right)^{0.6}
$$

24. Calculate the return pressure ratio,

$$
R=\left(\frac{\Delta P_{\text {ret }, R B}-\Delta P_{\text {on }, R B}}{\Delta P_{\text {ret }}-\Delta P_{\text {on }}}\right)^{0.6}
$$

25. Calculate supply leakage,

$$
\mathrm{Q}_{\mathrm{s}}=\frac{\mathrm{RQ}_{\mathrm{d}}-\mathrm{Q}_{\mathrm{d}, \mathrm{RB}}}{\mathrm{R}-\mathrm{S}}
$$

25. Calculate return leakage,

$$
\mathrm{Q}_{\mathrm{r}}=\frac{-\mathrm{SQ}_{\mathrm{d}}+\mathrm{Q}_{\mathrm{d}, \mathrm{RB}}}{\mathrm{R}-\mathrm{S}}
$$




\section{Appendix 3. Duct Pressurization Test Procedure}

The following procedure is for pressurization of both supply and return ducts. It is permissible to use either pressurization or depressurization on either supply or return ducts. The duct leakage shall be determined by pressurizing the ducts and the building to the same pressure relative to outside. One fan shall be used to pressurize the building and a second fan to pressurize the ducts. The following procedure shall be used for the fan pressurization tests:

1. Block the supply from the return at either the supply or return plenum. Filters are often located in an ideal location for this blockage.

The supply and return leaks shall be measured separately, as follows.

\section{For supply leakage:}

2. Seal all the registers, except for one supply register (or the system fan access) and one return register. The unsealed supply register or access door should be selected to have the least flow resistance to the supply plenum as possible. If a supply register is used, it will normally be either the supply register closest to the supply plenum or in some cases the largest supply register

3. Attach the fan/flowmeter device to the duct system at the unsealed supply register or access door so as to pressurize the duct system.

4. Install a duct pressure probe at a supply register other than that to which the fan/flowmeter is connected.

5. Install a blower door in an exterior doorway of the building.

6. Adjust the blower door fan until the pressure between the building and outside is $25 \mathrm{~Pa}$ [0.1 inch water] such that the building will be at a higher pressure than outside.

7. Adjust the fan/flowmeter to give zero pressure difference between the supply duct and the building.

8. Adjust the fan/flowmeter to maintain zero pressure ( $\pm 0.5 \mathrm{~Pa}[ \pm 0.002$ inches water]) between supply ducts and the building and the blower door fan to maintain $25 \mathrm{~Pa}( \pm 0.1 \mathrm{~Pa})[0.1$ inch water $( \pm 0.004$ inches water)] between the building and outside. This step may require several iterations.

9. Record the flow through the flowmeter $\left(\mathrm{Q}_{25,5}\left[\mathrm{Q}_{0.1, \mathrm{~s}}\right]\right)$ - this is the supply leakage flow at $25 \mathrm{~Pa}[0.1 \mathrm{inch}$ water].

For return leakage:

10. Seal all the registers, except for one return register and one supply register. The unsealed return register should be selected to have the least flow resistance to the return plenum as possible (usually this will be the return register closest to the return plenum).

11. Attach the fan/flowmeter device to the duct system at the unsealed return register so as to depressurize the duct system.

12. Adjust the blower door fan until the pressure between the building and outside is $25 \mathrm{~Pa}[0.1$ inch water], with the building at a lower pressure than outside.

13. Adjust the fan/flowmeter until the pressure between return ducts and the building is zero.

14. Adjust the fan/flowmeter to maintain zero pressure ( $\pm 0.5 \mathrm{~Pa}[ \pm 0.002$ inches water]) between return ducts and the building and the blower door fan to maintain $25 \mathrm{~Pa}( \pm 0.1 \mathrm{~Pa})[0.1$ inch water $( \pm 0.004$ inches water)] between the building and outside. This step may require several iterations.

15. Record the flow through the flowmeter $\left(\mathrm{Q}_{25, \mathrm{r}}\left[\mathrm{Q}_{0.1, \mathrm{r}}\right]\right)$ - this is the return leakage flow at $25 \mathrm{~Pa}[0.1$ inch water].

\section{System Operating Pressures}

The system operating pressures shall be measured using the following "pressure pan" technique. For the system operating pressure tests all registers shall be unsealed and there shall be no blocking between the supply and return.

1. Turn on the system fan (but not the heating or cooling).

2. Cover each register in turn with a pressure pan and record the indicated pressure $\left(\mathrm{P}_{\mathrm{s}, \mathrm{i}}\right.$ for each supply register and $P_{r, i}$ for each return register).

3. If there are less than five return registers, the pressure pan measurement will be inappropriate. In this 
case, $P_{r, i}$ shall be estimated by dividing the return plenum pressure, $P_{r p}$, by 2 .

4. The pressure pan measurements shall be averaged using:

$$
P_{s}=\frac{\sum_{i=1}^{N_{\text {supply }}} P_{s, i}}{N_{\text {sup ply }}}
$$

$P_{r}=\frac{\sum_{i=1}^{N_{\text {reaurm }}} P_{r, i}}{N_{\text {return }}}$

\section{Converting Measured Flows to Flows at System Operating Pressures}

The $25 \mathrm{~Pa}\left[0.1\right.$ inch water] duct leakage flows $\left(\mathrm{Q}_{25, \mathrm{~s}}\right.$ and $\mathrm{Q}_{25, \mathrm{~s}}\left[\mathrm{Q}_{0.1, \mathrm{~s}}\right.$ and $\left.\left.\mathrm{Q}_{0.1, \mathrm{r}}\right]\right)$ shall be converted to leakage flows at operating conditions using the following equations.

For SI:

$$
\begin{aligned}
& Q_{s}=Q_{25, s}\left(\frac{P_{s}}{25}\right)^{0.6} \\
& Q_{r}=Q_{25, r}\left(\frac{P_{r}}{25}\right)^{0.6}
\end{aligned}
$$

For IP:

$$
\begin{aligned}
& \mathrm{Q}_{\mathrm{S}}=\mathrm{Q}_{0.1, \mathrm{~s}}\left(\frac{\mathrm{P}_{\mathrm{S}}}{0.1}\right)^{0.6} \\
& \mathrm{Q}_{\mathrm{r}}=\mathrm{Q}_{0.1, \mathrm{r}}\left(\frac{\mathrm{P}_{\mathrm{r}}}{0.1}\right)^{0.6}
\end{aligned}
$$




\section{Appendix 4. Irvine Quality Plus (IQ+) Pressurization Procedure}

1. Seal all the registers, except for the system fan access or one return register.

2. Attach the fan/flowmeter device to the duct system at the unsealed return register or access door so as to pressurize the duct system.

3. Install a duct pressure probe at a supply.

4. Adjust the fan/flowmeter to give $25 \mathrm{~Pa}(0.1$ inch water) pressure difference between the duct and outside (or the building if a window or door is open).

5. Record the flow through the flowmeter $\left(\mathrm{Q}_{25}\left[\mathrm{Q}_{0.1}\right]\right)$ - this is the total duct leakage flow at $25 \mathrm{~Pa}[0.1$ inch water].

A house meets the criteria for the IQ+ program if the $25 \mathrm{~Pa}$ leakage flow is numerically less than the floor area in square feet divided by 20 . This corresponds to an allowable leakage of $50 \mathrm{cfm} / 1000 \mathrm{ft}^{2}(0.9$ $\mathrm{m}^{3} / \mathrm{hour} / \mathrm{m}^{2}$ ). 


\section{Appendix 5. Uncertainty in Duct Leakage Measurements}

\section{House Pressure Test}

The uncertainty in the House Pressure Test (HPT) can be divided into two parts. The first part is the uncertainty in the physical measurements. The second part is uncertainty due to violations of the assumptions used in the modeling of the duct leakage. The uncertainties are made up of precision and bias errors. The bias is the systematic errors that are repeated in every measurement. The precision is the uncertainty due to random changes from measurement to measurement.

The HPT measurement and calculation procedures are given in Appendix 1 (from proposed ASHRAE Standard 152P).

\section{Physical Measurements}

\section{Weather induced changes in ceiling pressure differences}

This test requires measurements of pressure across the ceiling to the attic and between the ducts and the conditioned space. The pressures across the ceiling are made several times and each individual measurement is a five second time average. The 100 houses tested by Modera and Wilcox (1995) had standard errors in the mean for these multiple measurements that were almost always below the resolution of the hand held digital manometers $(0.1 \mathrm{~Pa})$. The nine new houses tested in Irvine as part of the current study also had standard errors in the mean below the resolution of the instruments for all the houses. An additional 33 tests conducted in older homes in the bay area (also part of the CIEE study) agreed with the above results, where the standard error in the mean of the readings was less than the instrument resolution. All of these results indicate that these ceiling pressure measurements are limited by the resolution of the pressure measuring device. Note that these tests meet test limit criterion 3 (see Appendix 1) for small changes in pressure between each group of measurements. Tests with greater wind pressure fluctuations (and therefore greater envelope pressure fluctuations) will violate this criterion and have large standard errors in the lean that exceed the resolution of the test instruments.

A more detailed analysis of 92 tests looked at the uncertainty in supply and return leakage based on using all the measured values of ceiling leakage and then using only one of the groups of 10 measurements (the fan off ceiling pressures are measured 30 times in total, in three groups of ten). The supply and return leakage was calculated using the mean of the measurements, the mean plus the standard error and also the mean minus the standard error. The differences between the leakage calculated using the mean and the mean plus and minus the standard error were averaged over the 92 tests. The average difference using 10 measurements only was $29 \mathrm{cfm}$ for supplies and $34 \mathrm{cfm}$ for returns. Using all 30 measurements resulted in differences of $27 \mathrm{cfm}$ for supplies and $36 \mathrm{cfm}$ for returns. The errors expressed as a fraction of the mean leakage are about $40 \%$ for supplies and $50 \%$ for returns. These large fractional errors show the extreme sensitivity of calculated leakage flows on these small $(0.1 \mathrm{~Pa})$ uncertainties. The sensitivity arises from the calculation technique taking the difference between two ceiling pressure differences under different conditions. This difference is often close to the measurement resolution of the instruments.

The above result shows that the additional measurement (i.e., using 30 measurements instead of 10) did not improve the precision. This is because the differences between the means of each group of 10 measurements were greater then the standard deviation of the 10 readings within each group. This indicates that each group of ten measurements is a different population. These changes between each group of 10 measurements are due to changes in the wind and temperature induced pressures on the building envelope. Thus these measurements are tracking weather changes during the test. This is an important indicator of the possible changes in weather induced pressures between the measurements made with the system fan on and 
off. These changes introduce a precision error into the difference between the on and off measurements (it is the difference that is used in the calculation procedure). This precision error is larger than the standard deviation of the 10 readings in each group because the difference in the means of each group is greater than the standard deviation.

\section{Resolution}

The ceiling pressure measurements are used to calculate the difference in supply and return duct leakage for two cases. The first case is under normal operating conditions and the second case is with the return duct blocked. Under normal operating conditions, any change in the pressure difference across the ceiling is directly related to the imbalance in duct leakage between supply and return. Thus the uncertainty in the ceiling pressure measurements can be used to estimate the uncertainty in the split between supply and return leaks. For the 100 houses tested by Modera and Wilcox, the envelope leakage coefficient was 270 ( $\mathrm{cm} / \mathrm{Pa} \mathrm{n}^{\mathrm{n}}$ ). A pressure uncertainty of $0.05 \mathrm{~Pa}$ (half the last digit of a typical hand help pressure gauge) across this envelope leakage results in an imbalance flow uncertainty of about $35 \mathrm{cfm}$. Thus the resolution of the HPT is limited to about $35 \mathrm{cfm}$ for these houses. This resolution uncertainty scales directly with envelope leakage, so that the new houses in Irvine, with envelope leakage of $400\left(\mathrm{cfm} / \mathrm{Pa}^{\mathrm{n}}\right)$ [corresponding to an ELA@4Pa of $5.2 \mathrm{~cm}^{2} / \mathrm{m}^{2}$ floor area] have a resolution of about $55 \mathrm{cfm}$. Rather than express these as absolute values it may be useful to scale the uncertainty with the size of the house. Using the Irvine test houses (that were roughly $3000 \mathrm{ft}^{2}$, and the envelope leakage of $400 \mathrm{cfm} / \mathrm{Pa}^{\mathrm{n}}$, and assuming $\mathrm{n}=2 / 3$ ) we get an uncertainty of $18 \mathrm{cfm} / 1000 \mathrm{ft}^{2}$ of floor area due to measurement resolution.

This resolution uncertainty also exists for the return blocked measurements. The calculation of supply and return leakage uses the difference between the blocked and unblocked case (they are multiplied by scalars that account for the change in pressure in the duct system with the return blocked) so the uncertainty in the blocked and unblocked flows must be combined to find the uncertainty in supply and/or return leakage. Assuming that the measurements are independent means that they can be combined in quadrature, thus the pressure measurement resolution results in a precision error in supply and return leakage of about $50 \mathrm{cfm}$ for the houses measured by Modera and Wilcox or $78 \mathrm{cfm}$ for the field tests in the Irvine houses.

\section{Repeatability}

Repeatability tests have been performed in 17 houses. Table A5.1 summarizes the results of all the repeatability tests, where the RMS difference is the root mean square of the differences of individual tests from the mean of all the tests at each house. For samples with multiple houses, the RMS differences for all the individual houses have been averaged together to determine the mean RMS difference. The CIEE and Pleasant Hill house tests were performed by the same work crew each time and indicate the uncertainty arising from changing weather conditions and changes in pressure measurement location. Round robin repeatability tests have also been performed by Brookhaven National Laboratory (BNL, Andrews et al. (1997)). The Irvine and BNL tests had different work crews testing the same houses and include the variability between testers. The results in Table A5.1 indicate that repeatability uncertainty averages about $75 \mathrm{cfm}$ (but can be considerably larger in some circumstances) and will reduce the precision of the measurements. This average precision uncertainty can also be expressed as the average of the standard deviations, which is about $100 \mathrm{cfm}$ (the difference is the square root of the ratio of the number of tests to the number of tests minus one). These repeatability problems are fundamentally due to the uncertainty in measuring small pressure differentials, and then computing differences between small pressures with large uncertainties. Crucially, it was found that false zero readings are common with this test procedure. These false zeros are mainly due to errors in duct pressure measurements (discussed in the next section). Therefore the HPT cannot be used in situations where the variability from house to house is important, (e.g., as a screening tool for retrofitting, by Home Energy Raters, or for duct leakage compliance testing) unless the house being tested meets some restrictive criteria that will limit the possibility of large uncertainties.

The large differences between tests in houses with either multiple returns (BNL) or with filters at the 
plenum (Pleasant Hill) are a result of differences in return pressure measurement. The next section gives explicit examples of this sensitivity. For the purposes of limiting repeatability uncertainty it is recommended that only houses with filters at the return grilles and having simple returns (one or two registers) are suitable for testing using the HPT. The smaller RMS differences for the Irvine test houses (that had the filters at the return grilles) confirm a reduction in repeatability error.

The apparent increase in leakage in the Pleasant Hill test house after sealing is due to measuring return pressures in different locations pre and post retrofit. This is shown in greater detail in the following section.

Table A5.1 Repeatability of the HPT

\begin{tabular}{|c|c|c|c|c|c|c|}
\hline \multirow[b]{2}{*}{ Data Set } & \multirow[b]{2}{*}{$\begin{array}{c}\text { Number of } \\
\text { systems }\end{array}$} & \multirow[b]{2}{*}{$\begin{array}{c}\text { Number of tests per } \\
\text { system }\end{array}$} & \multicolumn{2}{|c|}{ Mean leakage flows, $\mathrm{cfm}$} & \multicolumn{2}{|c|}{ RMS difference, $\mathrm{cfm}$} \\
\hline & & & Supply & Return & Supply & Return \\
\hline CIEE House B & 1 & 12 & 13 & 102 & 32 & 73 \\
\hline CIEE House E & 1 & 2 & 23 & 53 & 10 & 11 \\
\hline CIEE House F & 1 & 2 & 25 & 165 & 25 & 94 \\
\hline $\begin{array}{l}\text { CIEE House G - pre } \\
\text { sealing }\end{array}$ & 1 & 3 & 113 & 240 & 97 & 89 \\
\hline $\begin{array}{l}\text { CIEE House G - } \\
\text { post sealing }\end{array}$ & 1 & 3 & 0 & 111 & 0 & 8 \\
\hline $\begin{array}{l}\text { Pleasant Hill - pre } \\
\text { sealing }\end{array}$ & 1 & 3 & 77 & 247 & 86 & 76 \\
\hline $\begin{array}{l}\text { Pleasant Hill - post } \\
\text { sealing }\end{array}$ & 1 & 2 & 248 & 248 & 45 & 45 \\
\hline Irvine new houses & 9 & 2 & 188 & 149 & 30 & 22 \\
\hline BNL round robin & 1 & 5 & 703 & 763 & 402 & 318 \\
\hline
\end{tabular}

\section{Duct Pressure Differences}

The pressures are measured in the supply and return ducts under normal operating conditions and with the return blocked (RB). The ratio of the blocked to unblocked pressures is used in the calculation of the supply and return leaks in the:

supply pressure ratio:

$$
S=\left(\frac{\Delta P_{\text {sup RB }}}{\Delta P_{\text {sup }}}\right)^{0.6}
$$

and return pressure ratio:

$$
\mathrm{R}=\left(\frac{\Delta \mathrm{P}_{\mathrm{retRB}}}{\Delta \mathrm{P}_{\mathrm{ret}}}\right)^{0.6}
$$

In Equations A5.1 and A5.2 the exponent is assumed to be 0.6. The expected range of this exponent is about \pm 0.05 for most duct system leaks. The uncertainty due to the pressure exponent can be estimated by taking typical ratios of pressures and calculating values of $R$ and $S$ for the different exponents. From 117 tested systems the average values were $R=2.85$ and $S=0.84$. Working backwards, and knowing the exponents used were 0.6 , the pressure ratio for returns would be 5.729 and for supplies would be 0.748 .

These pressure ratios can then be used with different exponents. For supplies $\mathrm{S}^{+}$is calculated using an exponent of 0.65 rather than 0.6 and $S^{+}=0.83$. $S^{-}$is calculated using an exponent of 0.55 , and $S^{-}=0.85$. This 
result shows that $\mathrm{S}$ is relatively insensitive to the assumed exponent, only changing by about $1 \%$.

$\mathrm{R}^{+}$and $\mathrm{R}^{-}$refer to the values of $\mathrm{R}$ using the larger and smaller exponents respectively, resulting in $\mathrm{R}^{+}=3.11$ and $R^{\prime}=2.61$. These are substantially different from $R=2.85$ using the assumed exponent of 0.6 . The $R M S$ difference between $\mathrm{R}^{+}$and $\mathrm{R}^{-}$and $\mathrm{R}$ is 0.25 or about $10 \%$.

The standard deviation over the 117 tests of $S$ was 0.16 , and for $R$ was 2.16 . The return pressures tend to change much more than supply pressures when the return is blocked, and the larger deviation for $R$ indicated the large uncertainty in $R$ in many leakage tests. This uncertainty arises from the large variations in return duct pressure at different locations in the return. In systems with a single return with the filter at the return grille, there is an even pressure throughout the return and the return pressure ratios will be less sensitive to their measurement location. However, in multi return systems, or systems with filters at the plenum/equipment, the return pressure ratio can be highly dependent on the measurement location. For example, there may only be a $10 \mathrm{~Pa}$ pressure difference across the return grille but a $100 \mathrm{~Pa}$ pressure difference across the walls of the return plenum, downstream of the plenum mounted filter. With the return blocked, the entire return is now depressurized by $100 \mathrm{~Pa}$, and all the return duct leaks have $100 \mathrm{~Pa}$ across them. For leaks at the register end, the pressure difference has changed by a factor of 10 , but leaks at the plenum may not have changed at all. The measured pressure changes at the grille will then be correct for any leaks at the grille, but much too big for leaks at the plenum/fan cabinet (or anywhere else in the return system). Therefore, the measurement of return pressures introduces a bias in to the measurement, and the bias can be either positive or negative depending on where the duct system leaks are located with respect to the duct pressure measurement location. This sensitivity to return pressure measurement location has been observed in the following field tests.

For example, at the Pleasant Hill test house, the HPT was performed three times with the return pressure measurement at the grille, approximately half way along the return duct, and at the return plenum. The results were as follows:

$\begin{array}{lcc}\text { Pleasant Hill test house } & \text { Supply leakage }(\mathrm{cfm}) & \text { Return leakage }(\mathrm{cfm}) \\ \mathrm{P}_{\text {ret }} \text { at grille } & 0 & 180 \\ \mathrm{P}_{\text {ret }} \text { half way } & 33 & 207 \\ \mathrm{P}_{\text {ret }} \text { at plenum } & 197 & 353\end{array}$

These results indicate that the measured leakage is completely dependent on the return pressure measurement for this system (with filter at the return plenum/air handler).

A similar test was performed in house $G$ of the CIEE study. In this case the return pressures were measured at the return grille and at the return plenum. In addition, the calculation was performed using the average of the grille and plenum pressures:

$\begin{array}{lcc}\text { CIEE house } G & \text { Supply leakage }(\mathrm{cfm}) & \text { Return leakage }(\mathrm{cfm}) \\ \mathrm{P}_{\text {ret }} \text { at grille } & 0 & 132 \\ P_{\text {ret }} \text { averaged } & 102 & 236 \\ P_{\text {ret }} \text { at plenum } & 238 & 351\end{array}$

John Andrews (Brookhaven National Laboratory) gave a presentation at ACEEE 1996, where he showed the following results for a house he had tested where he measured the return duct pressures at five locations along the duct. Three values are given below, using the two extreme results (plenum and register) and a single interim result, from half way into the duct system.

$\begin{array}{lcc}\text { Brookhaven test house } & \text { Supply leakage }(\mathrm{cfm}) & \text { Return leakage }(\mathrm{cfm}) \\ \mathrm{P}_{\text {ret }} \text { at grille } & 36 & 191 \\ \mathrm{P}_{\text {ret }} \text { averaged } & 128 & 285 \\ \mathrm{P}_{\text {ret }} \text { at plenum } & 214 & 371\end{array}$


All of the above tests indicate that for houses without the filters at the return grille, the imprecision associated with return pressure measurement is roughly the same as the calculated flows. In other LBNL tests about one third of the houses had severe problems with return pressure measurements, resulting in falsely zero leakage flows for either supplies or returns. This evidence, together with the results of the repeatability tests shown above indicate that the HPT should only be used in houses with simple returns with filters at the grilles.

\section{Removing bias due to assuming envelope leakage does not include the ducts}

The HPT uses the envelope leakage, $\mathrm{C}_{\mathrm{env}}$, in calculating the leakage imbalance flows. In most field tests, including HERS, the registers are uncovered when the envelope leakage is measured so that the duct leakage is included in $\mathrm{C}_{\text {env }}$. This will tend to make the value of $\mathrm{C}_{\mathrm{env}}$ larger and result in a bias in the calculated duct leakage. This effect will be greatest in buildings that have good envelopes, but leaky duct systems. In general, the leakier the duct system the greater the bias in the leakage. Correcting for this will tend to reduce the extremes of duct leakage calculated using the HPT. A simple iterative method has been used to calculate the leakage coefficient for the ducts, based on the HPT calculated flows and the measured duct pressures. The duct leakage coefficient was then subtracted from the house envelope leakage and a new house leakage coefficient calculated. This reduced house leakage coefficient was then used to calculate a reduced duct leakage. This reduced duct leakage implies a smaller change in envelope leakage than in the first iteration, and so on.

Additional analysis of the inclusion of duct leakage in the envelope leakage allows an exact analytical correction to be made. This analysis assumes that the calculation of duct leakage is linearly dependant on the envelope leakage. This is not strictly true because the neutral level shift factor depends on both the envelope and duct leakage. However the neutral level shift is a secondary effect and does not change so long as the ratio of duct to envelope leakage remains the same. This ratio does not change in the HPT calculation method and so the above assumption is not violated.

In the HPT calculation procedure, the total envelope leakage $\left(\mathrm{C}_{\text {env }}\right)$ is used to calculate the duct leakage flows $\left(Q_{s}\right.$ and $\left.Q_{r}\right)$. The leakage flows are converted to a total duct leakage coefficient $\left(C_{\text {ducts }}\right)$ using the following equation:

$$
\mathrm{C}_{\text {ducts }}=\mathrm{Q}_{\mathrm{r}}\left|\frac{1}{\Delta \mathrm{P}_{\text {ret }}}\right|^{0.6}+\mathrm{Q}_{\mathrm{s}}\left|\frac{1}{\Delta \mathrm{P}_{\text {sup }}}\right|^{0.6}
$$

The functional form of the HPT calculations are such that the duct leakage is directly proportional to the envelope leakage. Because all the measured pressures and other coefficients are always the same for a given test, the ratio of duct to envelope leakage coefficients is also a constant. Therefore, the ratio of the duct to envelope leakage coefficients is constant. Letting this ratio be given by $\mathrm{Z}$ :

$$
\mathrm{Z}=\frac{\mathrm{C}_{\text {ducts }}}{\mathrm{C}_{\text {env }}}=\frac{\mathrm{C}_{\text {ducts, new }}}{\mathrm{C}_{\text {env, noducts }}}
$$

where $C_{\text {env,noducts }}$ is the envelope leakage without the duct leakage and $C_{\text {ducts,new }}$ is the duct leakage calculated using $\mathrm{C}_{\text {env,noducs. }}$. Assuming the same pressure exponent for the envelope and the ducts:

$$
\mathrm{C}_{\text {env,noducts }}+\mathrm{C}_{\text {duct, new }}=\mathrm{C}_{\mathrm{env}}
$$

Using Equation A1.4, $C_{\text {duces,new }}$ can be given in terms of $C_{\text {env,noducts, }}$ such that Equation $A 5.5$ can be rewritten 
as:

$$
\mathrm{C}_{\text {env, noducts }}+\mathrm{ZC}_{\text {env, noducts }}=\mathrm{C}_{\mathrm{env}}
$$

Rearranging Equation A5.6:

$$
\mathrm{C}_{\mathrm{env}, \text { noducts }}=\left(\frac{1}{1+\mathrm{Z}}\right) \mathrm{C}_{\mathrm{env}}
$$

From Equation $\mathrm{A} 5.4, \mathrm{Z}$ can be given in terms of $\mathrm{C}_{\text {ducts }}$ and $\mathrm{C}_{\mathrm{env}}$, and substituted into Equation A5.7.

$$
C_{\text {env, noducts }}=\left(\frac{1}{1+\frac{C_{\text {ducts }}}{C_{\text {env }}}}\right) C_{\text {env }}
$$

Rearranging Equation A5.8:

$$
\frac{C_{\text {env,noducts }}}{C_{\text {env }}}=\frac{C_{\text {env }}}{C_{\text {env }}+C_{\text {ducts }}}
$$

Because the leakage flows are directly proportional to the envelope leakage, the original leakage flows used to calculate $\mathrm{C}_{\text {ducts }}$ are multiplied by the ratio in Equation A5.9 to get the leakage flows corrected for duct leaks being included in the envelope leakage. This means that the HPT calculation procedure only has to be gone through once, with the resulting leakage flows multiplied by the ratio in Equation A5.9.

This analytical approach has been compared to the iterative solution for 62 houses (for which detailed envelope leakage measurements were made) and the differences were smaller than those due to rounding off leakage numbers to the nearest whole $\mathrm{cfm}$ so that the above correction factors are good at removing this source of bias. Figure A5.1 shows a comparison of the analytical and iterative duct leakage multiplication factors for these 62 houses.

\section{Errors due to modeling biases}

\section{House leakage locations}

In the HPT it is assumed that half of the building envelope leakage is in the ceiling and half of the building envelope leakage is at floor level (either to/from a crawlspace or around the perimeter of the building). To examine the sensitivity to this assumption, the equations for the HPT were rederived twice. In the first case it was based on 3/4 of the leaks being at the ceiling and $1 / 4$ at the floor and the second case has $1 / 4$ of the leaks at the ceiling and 3/4 in the floor. All of these simplifications ignore leakage that is distributed over the walls of the structure (e.g., around doors and windows), but are used here for illustrative purposes in order to estimate the magnitude of uncertainty associated with these leakage location assumptions. For the first case, the equation for the imbalance leakage under normal operating conditions becomes (compare the following Equations to Equations A5.3 and A5.4): 


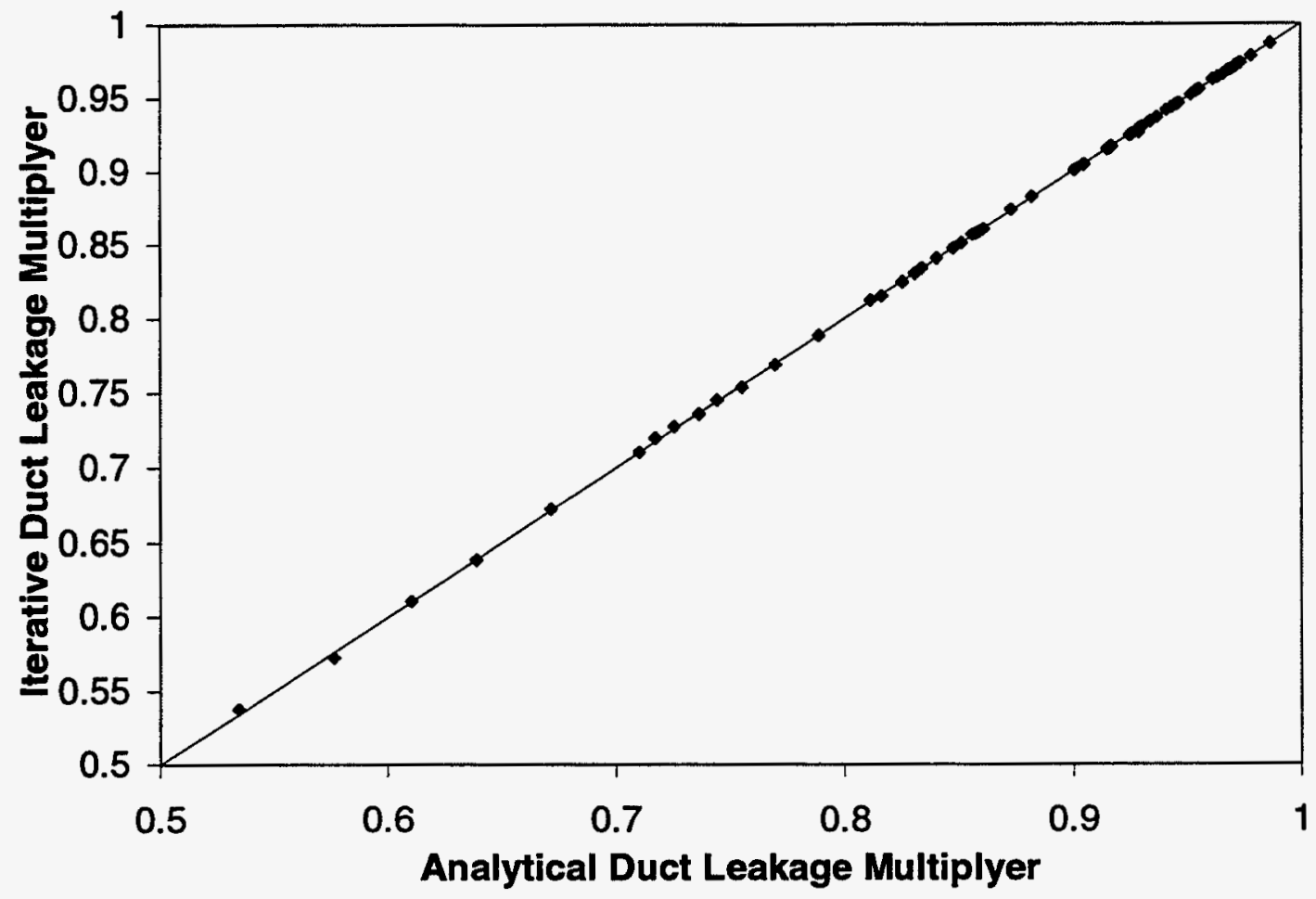

Figure A5.1 Comparison of iterative to analytical estimates for accounting for the inclusion of duct leakage in measured envelope leakage

$$
Q_{d}=C_{e n v}\left(0.75\left(\Delta P_{\text {on }}\right)^{n}-0.25\left(7 \Delta P_{\text {off }}-\Delta P_{\text {on }}\right)^{n}\right)
$$

With the return blocked, the imbalance with the return blocked is given by:

$$
Q_{d, R B}=C_{e n v}\left(0.75\left(\Delta P_{\text {on }, R B}\right)^{n}-0.25\left(7 \Delta P_{\text {off }}-\Delta P_{\text {on }, R B}\right)^{n}\right)
$$

The rest of the derivation is the same as for the original derivation that assumes half of the leaks are in the ceiling and half in the floor. Equations for A5.10 and A5.11 have also been derived for case 2 to give Equations A5.12 and A5.13:

$$
\begin{aligned}
& \mathrm{Q}_{d}=C_{\text {env }}\left(0.75\left(\Delta \mathrm{P}_{\text {on }}\right)^{\mathrm{n}}-0.25\left(1.2 \Delta \mathrm{P}_{\text {off }}-\Delta \mathrm{P}_{\text {on }}\right)^{\mathrm{n}}\right) \\
& \mathrm{Q}_{\mathrm{d}, \mathrm{RB}}=\mathrm{C}_{\text {env }}\left(0.75\left(\Delta \mathrm{P}_{\text {on }, \mathrm{RB}}\right)^{\mathrm{n}}-0.25\left(1.2 \Delta \mathrm{P}_{\text {off }}-\Delta \mathrm{P}_{\text {on }, \mathrm{RB}}\right)^{\mathrm{n}}\right)
\end{aligned}
$$

These new definitions of $Q_{d}$ and $Q_{d, R B}$ were used to recalculate $Q_{s}$ and $Q_{r}$ for the 117 houses that combine the current study together with previous LBNL studies. The differences (in cfm) between $50 / 50$ split leakage the other leakage distributions are given in Table A5.2. These results show that the non-even leakage splits are biased downwards and have a lower average value than for the evenly split leakage. This bias is smaller for supplies than for returns: ranging from $1 \mathrm{to} 9 \mathrm{cfm}$ for supplies rather than 15 to $17 \mathrm{cfm}$ 
for returns. The biases, however, are small compared to the house to house errors that reduce the precision of the test. For the case with most leakage high, the average absolute difference between the 50/50 split and most leakage high is about $20 \mathrm{cfm}$. For the case with most leakage low, the supply and return leakage are about $90 \mathrm{cfm}$ different from the even leakage (about $90 \%$ of the average leakage flow). These differences for individual houses are substantial, indicating that the HPT test method is sensitive to leakage distributions that differ from those assumed in the derivation of the calculations.

In summary, the leakage distribution assumption introduces bias errors of about $10 \mathrm{cfm}$ and precision errors ranging from 20 to $90 \mathrm{cfm}$ depending on the house leak location.

\section{Table A5.2 Differences in HPT duct leakage flows arising from changing leakage distributions}

\begin{tabular}{|c|c|c|c|c|c|}
\hline \multirow{2}{*}{\multicolumn{2}{|c|}{$\frac{\text { Mean difference, } \mathrm{cfm}}{\text { Most leakage high }}$}} & \multicolumn{2}{|c|}{ Absolute Difference, $\mathrm{cfm}$} & \multicolumn{2}{|c|}{ Mean leakage flows, $\mathrm{cfm}$} \\
\hline & & \multirow[b]{2}{*}{ Supplies: } & \multirow[b]{2}{*}{ Returns: } & \multirow[b]{2}{*}{$\begin{array}{l}\text { Supplies, } \\
\text { Q50/50 }\end{array}$} & \multirow[b]{2}{*}{$\begin{array}{l}\text { Returns, } \\
\text { Q } 50 / 50\end{array}$} \\
\hline $\begin{array}{c}\text { Supplies: } \\
Q_{s} 75 / 25- \\
Q_{5} 50 / 50\end{array}$ & $\begin{array}{l}\text { Returns: } \\
\text { Qs75/25 - }_{\text {s }} 50 / 50\end{array}$ & & & & \\
\hline-9 & -15 & 21 & 23 & 100 & 132 \\
\hline \multicolumn{2}{|c|}{ Most leakage low } & \multirow[b]{2}{*}{ Supplies: } & \multirow[b]{2}{*}{ Returns: } & \multirow[b]{2}{*}{$\begin{array}{l}\text { Supplies, } \\
\text { Q50/50 }\end{array}$} & \multirow[b]{2}{*}{$\begin{array}{l}\text { Returns, } \\
\text { Q } 50 / 50\end{array}$} \\
\hline $\begin{array}{l}\text { Supplies: } \\
\text { Q } 25 / 75 \text { - } \\
Q_{5} 50 / 50\end{array}$ & $\begin{array}{c}\text { Returns: } \\
Q_{s} 25 / 75- \\
Q_{5} 50 / 50\end{array}$ & & & & \\
\hline-1 & -17 & 88 & 89 & 100 & 132 \\
\hline
\end{tabular}

\section{Effect of Pressure differences between the house and outside on the measurement of duct pressures}

When the duct pressures are measured, they are relative to the house, when they should use the outdoors as a reference because we are trying to measure the leakage to outside and it is therefore the pressure difference between the ducts and outside that drives the duct leakage flows. To include this effect, Equations A5.1 and A5.2 can be rewritten as:

Supply pressure ratio:

$$
S=\left(\frac{\Delta P_{\text {sup }, R B}-\Delta P_{\text {on, RB }}}{\Delta P_{\text {sup }}-\Delta P_{\text {on }}}\right)^{0.6}
$$

Return pressure ratio:

$$
\mathrm{R}=\left(\frac{\Delta \mathrm{P}_{\text {ret }, \mathrm{RB}}-\Delta \mathrm{P}_{\text {on }, \mathrm{RB}}}{\Delta \mathrm{P}_{\text {ret }}-\Delta \mathrm{P}_{\text {on }}}\right)^{0.6}
$$

The error arising from neglecting the envelope pressures can be estimated by recalculating the supply and return leaks with and without these terms. For 117 tests, six were found to produce negative ratios when ceiling pressure differences were greater than between the ducts and the room. The remaining tests showed a negative bias due to using the simplified forms of $S$ and $R$ without the envelope pressures of $3 \mathrm{cfm}$ for supply leaks and a bias of $2 \mathrm{cfm}$ for return leaks. The RMS difference was $10 \mathrm{cfm}$ for both supplies and 
returns. These small biases are negligible compared to the other bias and precision errors with this test method. However, they could simply be removed if we use equations A5.14 and A5.15 in place of A5.1 and A5.2 in the future.

\section{Attic leakage}

The calculation method assumes that the attic does not affect the duct leakage. If there is substantial duct leakage in the attic, the pressures in the attic will change depending on the attic leakage. Fortunately, most attics are designed and built to be leaky. A typical rule of thumb is a 1:300 ratio of vent area to plan area for the attic. For a $100 \mathrm{~m}^{2}$ floor plan, this is equivalent to $1 / 3 \mathrm{~m}^{2}$ of venting area. Given this area we can estimate the pressure changes induced in an attic by leakage flows, assuming a pressure exponent of 0.6 , an orifice coefficient of 0.6 , and an air density of $1.2 \mathrm{Kg} / \mathrm{m}^{3}$ :

$$
\Delta \mathrm{P}_{\text {attic }}=\left(\frac{\mathrm{Q}_{\mathrm{d}}}{\frac{1}{3} 0.6 \sqrt{\frac{2}{1.2}}}\right)^{2}=\left(\frac{\mathrm{Q}_{\mathrm{d}}}{0.258}\right)^{2}
$$

For duct imbalance flow of $100 \mathrm{cfm}\left(170 \mathrm{~m}^{3} /\right.$ hour or $\left.0.047 \mathrm{~m}^{3} / \mathrm{s}\right)$, the pressure change across the attic leaks is only $0.033 \mathrm{~Pa}$. This result implies that attic leakage does not introduce a significant bias into the measured ceiling pressures because these pressures have a resolution limit three times greater than this. The attic leakage effect was also found to be negligible by Modera and Wilcox (1995).

\section{Assuming stack effect only}

Assuming that only stack effect is acting is poor almost all of the time, except on windless days. However this is not the real assumption behind the HPT calculations. Really, it is assumed that there is an equal magnitude pressure across some other (other than the ceiling) leak in the building that acts to balance the flow in and out. The flow model assumes that there are two equal sized leaks (the leaks would have to be different sizes to conserve mass when the indoor temperature is not equal to the outside temperature), one of which has the pressure across it measured and the pressure across the other leak is inferred from the flow balance. The assumed pressure with the system off is therefore linked to the leak location assumption. The two hole model works best for the example case of one hole at the top and one at the bottom, with stack effect only. In a real house with holes all over the envelope and the wind blowing to create different pressures on each leak, the simple pressure changes used in the calculation of imbalance flows $\left(Q_{d}\right.$ and $\mathrm{Q}_{\mathrm{d}, \mathrm{RB}}$ ) will introduce errors. The magnitude of these errors is difficult to quantify, given the large range of possibilities for leak location and size. For example, the wind pressures across a ceiling are usually small and do not fluctuate as much as the wind pressures on the walls of the house. Therefore, it would be possible to measure zero pressure across the ceiling when there are pressures of several Pascals on the other building leaks, thus violating the assumptions behind the derivation of the equations. Note that if the two hole assumption is correct, then it does not matter if we have stack or wind induced natural pressures with the system off. However multiple leakage sites over the surface of the building experiencing many different pressures will generate significant biases precision errors similar to those in the house leakage location calculations above.

The temporal and spatial fluctuation of surface pressures due to the wind is a separate effect that appears mainly in the repeatability uncertainty and in the variation in the multiple ceiling pressure measurements. Field experiences have shown that higher windspeeds correlate with higher variability in measured pressures. 


\section{Duct Pressurization}

The uncertainty in duct pressurization measurements can be divided into two parts; the first part discusses the errors in the physical measurements (flow and pressures), the second part discusses the errors due to the modeling assumptions required to convert these measurements into the desired quantity: leakage flow to outside at operating conditions. In general, the uncertainties in the physical measurements are small, and it is the conversion to leakage at operating conditions that dominates the uncertainty.

Proposed ASHRAE Standard 152P contains two duct pressurization test methods. The simpler pressurization test assumes that the fraction of leakage to outside scales with the fraction of duct surface area outside the conditioned space and the $25 \mathrm{~Pa}$ leakage flow is split equally between supply and return. In addition, the operating condition pressures are assumed to be fixed fractions of the system fan operating pressure. The expected precision and bias errors using the simple method are greater due to these assumptions. However, it is intended for use in low leakage systems where a low leakage quantity has been specified. This test is only intended to be used to determine if the system was put together without leaks rather than measuring large leakage flows exactly.

The analysis in the following sections concentrates on the test in which the duct and house are both pressurized, the supply and return are split and the leakage flow is converted to operating conditions using measured duct operating pressures. The exact field test procedure is specified in Appendix 3.

\section{Physical measurements}

\section{Flow Measurement}

The flow uncertainty depends on the flowmeter used in the measurements. Typically the flowmeter has a specified combined precision and bias error of $3 \%$ of flow, and a typical measured leakage flow of $100 \mathrm{cfm}$ would have an combined precision and bias error of $3 \mathrm{cfm}$.

\section{Duct pressure during flow measurement}

The required pressure during measurement is $25 \mathrm{~Pa}$. The error in this pressure is limited by the skill of the operator in controlling the fan and by instrument resolution. In most cases, the instrument resolution is the dominant factor. In addition, it is not critical to have a reading of exactly $25 \mathrm{~Pa}$ so long as the operator notes the pressure used. The flow uncertainty due to the instrument resolution of $0.1 \mathrm{~Pa}$ at $25 \mathrm{~Pa}$ can be estimated by assuming a pressure exponent of 0.6 for duct leaks to be about $0.2 \%$ of flow, or less than 1 cfm.

\section{Envelope pressures during flow measurement}

For this test the envelope pressure is required to be maintained at the same pressure as the duct pressures. In this case, the ability of the operator to match and maintain pressures depends on the weather. Under calm conditions it is a relatively easy task, however, on a windy day the envelope pressures can fluctuate substantially resulting in large changes in envelope pressures. Typically the pressures can be matched within a fraction of a Pascal. A good approximation would be to estimate that the pressures can be matched to within $0.25 \mathrm{~Pa}$. Given a measured leakage flow to outside of $100 \mathrm{cfm}$ at $25 \mathrm{~Pa}$ and assuming that about $3 / 4$ of the total duct leakage is to outside (as found by pressurization of ducts in the SMUD study of Jump et al. (1996)), then we would have about $33 \mathrm{cfm}$ leakage to inside at $25 \mathrm{~Pa}$. At $0.25 \mathrm{~Pa}$ (and assuming a pressure exponent of 0.6 ) the leakage flow to inside would be about $2 \mathrm{cfm}$. The worst case for balancing the duct and envelope pressures is on a windy day where the pressures might only be matched to within 2.5 $\mathrm{Pa}$. For this worst case, the flow to inside would be about $8 \mathrm{cfm}$. These flows to (or from) inside would be measured in the total leakage, thus they represent precision errors for the leakage flow to outside. 


\section{Duct pressures at operating conditions}

The duct pressures are measured at registers (and at plenums). The precision error is dominated by the resolution of the measurement instrument (typically $0.1 \mathrm{~Pa}$ ). For plenum measurements on the order of 50 $\mathrm{Pa}$, the flow uncertainty is on the order of $0.1 \%$, which is negligible. For register measurements, the measured pressures are much less - typically $5 \mathrm{~Pa}$, with a resulting flow uncertainty of about $1 \%$. As with all these pressure measurements, this flow uncertainty is a reduction in the precision of the measurement.

\section{Converting physical measurements to operating conditions}

\section{Splitting supply and return leakage and estimating equipment cabinet/filter slot leakage}

Supplies and returns are often blocked at the entrance to the fan cabinet or at the filter location (if it is at the plenum). This means that the fan cabinet and other equipment leaks on the supply side of the blockage (and some of the return plenum) are measured with the supply leaks, when under normal operating conditions they are part of the return system. This can create a systematic bias in the test where too much leakage is attributed to supplies and too little to returns.

The following calculations estimate the magnitude of the filter slot/equipment cabinet leakage (and therefore the possible supply/return split bias). For the filter slot, assuming a typical return plenum pressure difference of $65 \mathrm{~Pa}$ (as found in a study of 25 houses in California (see Jump, Walker and Modera (1996)), a slot length of $1 \mathrm{~m}$ ( 3.3 feet) and a gap between the filter and the filter slot of $3 \mathrm{~mm}(1 / 8$ inch), we get a leakage of about $40 \mathrm{cfm}$. For the fan/equipment cabinet, each knockout has a diameter of about $25 \mathrm{~mm}$ (one inch) and using the same $65 \mathrm{~Pa}$ pressure difference results in a flow of about $7 \mathrm{cfm}$ per hole. This leakage is rarely (never?) sealed and is present in all systems. For systems outside conditioned space this represents the minimum leakage to outside that can be attained using sealing methods that do not seal the equipment cabinet or the filter slot.

The filter slot/equipment cabinet leakage of about $50 \mathrm{cfm}$ will exist for all systems with return plenums and equipment mounted outside conditioned space. In cases where these were included in supply leakage due to blockage location, then the supply leakage will be overestimated by about $50 \mathrm{cfm}$ and the return leakage underestimated by the same amount. Systems with filters at return grilles (as is popular in California) may have much less equipment associated leakage because there are no leaks around the filters from unconditioned spaces (on the order of $10-20 \mathrm{cfm}$ rather than $50 \mathrm{cfm}$ ). However, this will be offset by increased return system leakage because all of the return system is at the lower pressure downstream of the filter.

\section{Uniform pressure distribution throughout duct system during testing}

It is assumed that the $25 \mathrm{~Pa}$ pressure difference is the same across all leaks to outside during testing. The pressure change in the ducts between where the fan pressurization device is attached and the end of the duct system depends on how leaky the ducts are. With no leaks, there will be no pressure changes (and no measured flow) but as the leaks increase, the pressure drop though the system will increase. The pressure distribution depends on the duct system geometry and the leak location. For a trunk and branch system, with evenly distributed leakage, the single measured pressure at the far end of the duct system will be the lowest pressure in the system. For more localized leakage, for example at a single register, the pressure across that specific leak would not be well indicated by the pressure measured in another branch. Octopus type systems, where each register has its own duct leading from the plenum, are also susceptible to this problem, where a localized leak only has an effect on the pressure measured at the register at the end of the particular branch that the leak is in. Without explicit knowledge of leak location it is not possible to determine if the single pressure measurement over or under estimates the pressures across the leaks. However, it is possible to estimate the magnitude of this uncertainty by estimating a typical pressure drop 
through the system based on field tests where pressures were measured at each register.

In the field tests performed for this study, a typical pressure drop during pressurization testing through the supply or return was found to be about $2 \mathrm{~Pa}$. The maximum error in flow occurs when $25 \mathrm{~Pa}$ is measured at the end of the system, but all the leaks are near the fan and have $27 \mathrm{~Pa}$ across them. The error in flow though the leak is therefore about $(27 / 25)^{0.6}$, or about $5 \%$ of the measured flow at $25 \mathrm{~Pa}$. For a system with $100 \mathrm{cfm}$ leakage, this represents a flow error of $5 \mathrm{cfm}$. Because this flow error is always positive (the procedure measures the flow at $27 \mathrm{~Pa}$ pressure difference across the leaks, not the $25 \mathrm{~Pa}$ at the end of the duct system) it represents a bias error. Note that this is the maximum possible bias because a system with large pressure drops between the plenum and the measurement location must have leaks between the plenum and the pressure measurement location. These leaks will then have pressures between 27 and $25 \mathrm{~Pa}$ across them with resulting smaller uncertainties in flow.

\section{Converting to system operating pressures}

Pressurizing the whole system to a single uniform pressure of $25 \mathrm{~Pa}$ gives the flow through the leaks at this pressure. Converting to leakage flow at operating conditions is the major source of precision error with this test method because of the range of pressures in a duct system at operating conditions and lack of knowledge of explicit leak locations. The SMUD data set (Jump et al. (1996)) had the pressures measured at each register and at the plenums. The average ratio of register pressures to plenum pressures was 0.19 for both supplies and returns, i.e., the plenum pressures were about five times the register pressures. If we assume that either all the leaks are at the plenums or all the leaks are at the registers this becomes almost a factor of three range of flow. The following example calculations assume a measured leakage flow of 100 $\mathrm{cfm}$ at $25 \mathrm{~Pa}$ for both supplies and returns. The operating condition leakage flow was calculated for three cases:

1. using the recommended weighted average of register and plenum pressures

2. using the average register pressures (for minimum leakage) and

3. using the plenum pressures (for maximum leakage).

The supplies and returns are investigated separately, but the results indicate that the magnitude of the errors are about the same for both supplies and returns.

The recommended weighting scheme for duct pressures averages all the register pressures together with the plenum pressures multiplied by the number of registers. This is approximately equivalent to assuming that half the leaks are at the plenum and half are at the registers (if flow was linear with pressure). This weighted average pressure for the SMUD data was $26 \mathrm{~Pa}$ for supplies and $38 \mathrm{~Pa}$ for returns. Using the weighted average pressure to calculate the operating condition leakage flows results in supply leakage flows of $102 \mathrm{cfm}$ and return leakage flows of $129 \mathrm{cfm}$.

Taking the average supply register pressure of $7 \mathrm{~Pa}$, the resulting operating condition leakage flow assuming all leaks are at the registers is $46 \mathrm{cfm}\left[(7 / 25)^{0.6} \times 100 \mathrm{cfm}\right]$. Alternatively, assuming all the leaks are at the plenum at $44 \mathrm{~Pa}$ results in leakage flows of $140 \mathrm{cfm}\left[(44 / 25)^{0.6} \times 100 \mathrm{cfm}\right]$. So the maximum precision error is about $40 \mathrm{cfm}$ based on a measured $100 \mathrm{cfm}$, or plus or minus $40 \%$ of the measured flow.

For the returns, the average return register pressure was $10.5 \mathrm{~Pa}$, and the leakage flow is $60 \mathrm{cfm}$ $\left[(10.5 / 25)^{0.6} \times 100 \mathrm{cfm}\right]$. The average return plenum pressure was $64 \mathrm{~Pa}$, and assuming all the leaks were at the plenum results in a leakage flow of $176 \mathrm{cfm}\left[(64 / 25)^{0.6} \mathrm{X} 100 \mathrm{cfm}\right]$. The difference between these extreme flows, and those calculated using the average is an underprediction of $37 \mathrm{~cm}$ if all the leaks are at the plenum and an overprediction of $69 \mathrm{cfm}$ if all the leaks were at the registers. The average difference is $53 \mathrm{cfm}$ (or about $45 \%$ of the predicted return leakage flow) using the weighted average of the plenum and registers.

The flow uncertainty (in $\mathrm{cfm}$ ) scales with measured leakage flow because the fractional error due to the variation of pressure through the system remains the same. Note that this is a maximum precision error, and with leaks in different locations in the duct system, this fractional error will go down. A reasonable 
estimate would be to use about half of the above extreme values, or $20 \mathrm{cfm}$ for supplies and $25 \mathrm{cfm}$ for returns as precision errors in converting to system operating pressures.

The current measurement procedure that employs pressure pans to estimate register pressures will tend to overestimate in some circumstances. This is because the pressure pans tend to measure the pressure close to the plenum pressure unless there are multiple connections between the register and the plenum, or there are large leakage sites close to the register. This leads to the pressure pans overestimating the register pressures at operating conditions and in turn this leads to overestimating the duct leakage.

Using the above example system, if we assume that the pressure pan reading is close to the $44 \mathrm{~Pa}$ plenum pressure, e.g., $40 \mathrm{~Pa}$, then the average pressure used in the calculations would be $42 \mathrm{~Pa}$. The average using the measured register pressure differences of $7 \mathrm{~Pa}$ would be $25.5 \mathrm{~Pa}$. If we also assume the worst case with all of the leaks at the register, then the overestimate of flow using the pressure pan measurements is $(42 / 25.5)^{0.6}=1.45$. Therefore, for systems without multiple connections or large register leakage, the overestimate of operating condition leakage flow could be as high as $45 \mathrm{cfm}$ for our standard $100 \mathrm{cfm}$ leakage system. Note that this is a limiting case where we used high pressures and assumed all the leaks were at the registers. The majority of duct systems will have a lower bias and a typical bias error can be estimated by dividing this maximum error in half to about $20 \mathrm{cfm}$.

\section{Splitting supply and return leaks}

In some situations (and for the proposed ASHRAE 152P total duct pressurization test), it is not possible to put a physical barrier between the supply and return. The most prevalent example of this occurs with furnaces in which the furnace flue is located inside the return plenum/fan cabinet. The flue runs up the front of cabinet so that it blocks most of the fan access opening. The flue is sealed into place (because flue gasses leaking into the return would be an important safety concern) and it would require a great deal of effort to remove and replace the flue in order to have access to the inside of the return plenum/fan cabinet to install the supply/return blockage. In addition, the pressurization fan is usually connected to this opening and the presence of the flue in this opening will place an extreme restriction on the pressurization fan flow into the cabinet. There are also safety and equipment warranty issues associated with flue removal and reinstallation that are best avoided. Alternative physical barrier locations, e.g., between the equipment cabinet and supply plenum, can sometimes be used. However, they often require cutting of existing sheet metal or disassembly of the HVAC system and would therefore be difficult to justify for most field measurement situations.

Without the physical barrier in place it is not possible to pressurize the supply and return separately. In this case the whole system must be pressurized and the split between supply and return is assumed. A summary of 46 tests in Sacramento houses showed that two thirds (66\%) of the total leakage flow (cfm @ $25 \mathrm{~Pa}$ ) was in the supplies (the remaining $34 \%$ was return leakage), with a standard deviation of $18 \%$ for both supply and return. The standard deviation gives a precision error of $18 \%$ of the total $25 \mathrm{~Pa}$ leakage flow for supply and return leakage by assuming this leakage split. If we use the $100 \mathrm{cfm} @ 25$ Pa leakage flow for both supply and return used previously in example calculations, the precision error due to assuming the supply/return leakage split is then $18 \mathrm{cfm}$. This is a significant reduction in the precision of the method because we have had to make assumptions about the leakage split rather than measuring it directly.

\section{Repeatability of the Pressurization tests}

One of the key issues when using any field test is the repeatability uncertainty so that decisions regarding code compliance or screening for retrofitting can be made. The duct pressurization test was found to have good repeatability both between different testers (CEC and LBNL) and for repeated tests by the same test crew. The average RMS differences between tests for the Irvine houses were $15 \mathrm{cfm}$ at $25 \mathrm{~Pa}$. This result indicates that precision of the flow and pressure measurements meet the repeatability requirements for screening or compliance (e.g., the IQ+ program). Converting to operating conditions using the measured duct pressures will create additional sources of repeatability uncertainty if different testers measure the return pressure in different locations. If the proposed ASHRAE 152P test method is followed (using 
pressure pans) this duct pressure variability will be small (based on our field experience) and will not introduce significant repeatability errors.

\section{Theoretical analysis of precision errors}

Andrews (1997) has performed a theoretical analysis of both the house pressure and duct pressurization tests. This analysis does not use any measured data, but instead uses a standard approach (combining partial derivatives) to obtain relationships between the uncertainties in the duct leakage and the uncertainties in the input parameters used in the calculations. This method examines the precision (or random) uncertainties and does not include biases. Andrews set a criteria of maximum acceptable uncertainty of the greater of $25 \%$ of the leakage flow or $40 \mathrm{cfm}$, and then determined the precision of the input parameters required to meet this criteria.

In general, the results of this theoretical analysis agree with the other analyses presented elsewhere in this report that indicate that it is much easier to obtain precise pressurization measurements than house pressure test measurements. The major sources of precision uncertainty for the house pressure test are the envelope pressures and the return pressure. Specifically, Andrews found that the envelope pressures must be measured to within about $0.1 \mathrm{~Pa}$ and must be even more precise for leaky houses, or if the envelope pressure change with the return blocked is less than $0.5 \mathrm{~Pa}$. In addition, although the precision requirement for return pressure ratio is about the same as for supply pressure ratio, field experience shows that this requirement is difficult to meet. 


\section{Appendix 6. Field Test Results}

\section{Bay Area House Results}

The house characteristics are summarized in Table A6.1. All of the houses had gas furnaces, and house $\mathrm{H}$ had air conditioning. This house had two duct systems tested separately - so these were labeled $\mathrm{H} 1$ and $\mathrm{H} 2$. The floor area for $\mathrm{H} 1$ and $\mathrm{H} 2$ is the floor area associated with each system. Houses $\mathrm{E}, \mathrm{G}$ and $\mathrm{I}$ had new duct systems (less than one year old) and the other houses had ducts at least 15 years old. The ducts were typically uninsulated sheet metal or R4 flex duct. Some of the older sheet metal ducts (houses B, C and F) had a thin exterior layer of asbestos insulation. The duct systems were typical of California, with single returns, except for houses $\mathrm{C}$ and $\mathrm{F}$ that had two return grilles.

The average fan flow for these systems was about $880 \mathrm{~cm}$. Combined with an average floor area of about $1400 \mathrm{ft}^{2}$, this resulted in about $0.70 \mathrm{cfm} / \mathrm{ft}^{2}$. After the ducts were sealed the average fan flow dropped slightly to $870 \mathrm{cfm}$.

\section{Supply Leak Comparison}

Table A6.2 summarizes the results of the diagnostic tests. The measured supply leakage shows a wide variation between methods, with typical differences on the order of $100 \mathrm{cfm}$. The general trend is that duct pressurization (in all cases but one) predicts the greatest leakage ( $208 \mathrm{cfm}$ average), probably due to including cabinet leakage in the supplies and overestimation of system operating pressures due to using pressure pans. Another reason for the larger duct pressurization leakage is the false zero readings for the other tests, particularly the NPT. These false zeros are due to the sensitivity of the HPT and NPT to small envelope pressure changes and the uncertainty in measuring the appropriate return duct pressure. These differences between the tests are important if we are going to use these measurement techniques as screening tools for duct leakage because we need the test to tell us if the ducts are leaky or not and the results indicate that in some cases that passing or failing a leakage specification would depend on which diagnostic test was used. The NPT and HPT averaged $33 \mathrm{cfm}$ and $54 \mathrm{cfm}$ respectively for these systems, and the NPT and HPT show large differences between them for individual houses.

Another way of evaluating these tests is to see if they measure a lower leakage post sealing. For supplies, the duct pressurization test indicated a higher post sealing leakage in one case, the HPT had none and the NPT had four cases of increased post sealing leakage (more than the number of cases indicating decreased post sealing leakage). For returns, duct pressurization always showed lower leakage, the HPT and NPT both had four cases of increased post sealing leakage. These results imply either that sealing was ineffective and the duct pressurization gave post sealing values that were too low, or that the HPT and NPT are not sensitive enough to detect the leakage reduction due to sealing, particularly for returns. The detection of reduced post sealing leakage was also applied to 18 other HPT tests performed by LBNL. There were three cases of increased supply leakage and 11 cases of increased return leakage for these tests. For these 18 houses, pressurization tests showed that the duct leakage area was reduced by more than $50 \%$ (on average) so a reduction in leakage flow would be expected. These additional tests confirm that the HPT is not sensitive enough to differentiate between good and poor ducts due to the precision errors in return leakage being greater than the change in duct leakage due to sealing.

The tracer gas measurements of supply leakage cannot be used as a reference for these supplies because of problems with the measurements. The problems with the tracer measurements is due to a couple of factors: the two tracer gasses were not at equilibrium (this was due to time restrictions) and the concentration of tracer at the leaks was unknown and assumed to be uniform. In these cases the uniform concentration assumption was probably poor. Overall, it was not possible to use the tracer gas results for supplies to determine which of the other tests was the most accurate.

\section{Return Leak Comparison}

The results for return leakage (shown in Table A6.2) are more uniform than the supply duct leakage tests, with a typical range of about a factor of two between test methods. For the tracer gas tests, the return measurements have much less uncertainty than supplies because only a single tracer was used and the assumptions about equilibrium concentration and uniform concentration at all locations are not as critical. 
Therefore it was possible to use the tracer gas results as a reference for the return leakage. The average absolute differences between the tracer tests and the other diagnostics were $40 \mathrm{cfm}$ for duct pressurization, $50 \mathrm{cfm}$ for NPT and $51 \mathrm{cfm}$ for the HPT. These differences are close to the following estimate for the uncertainty in the tracer gas test method. The tracer uncertainty is dominated for return leakage measurement by the approximately $5 \%$ uncertainty in fan flow. Using the average of $880 \mathrm{cfm}$ for the houses in this study, the tracer gas uncertainty is then about $44 \mathrm{cfm}$. In addition, given the house to house variations for these diagnostic tests, this result is inconclusive. However, it should be noted that all the diagnostic tests tended to underestimate the leakage when compared to the tracer gas results.

\section{Retrofit/Compliance Decisions}

Another way of characterizing the comparisons between test methods is to use the measured leakage to make a decision about whether or not a duct system requires retrofitting, or it passes a code requirement. The test results were used to predict the number of decisions that would be different if a different test were used, and the results are shown in Tables A6.8, A6.9 and A6.10. In these tables, the decision to retrofit the ducts was made for three different leakage criteria: maximum allowable leakage $6 \%$ of fan flow, $10 \%$ of fan flow and $22 \%$ of fan flow. The $6 \%$ of fan flow is the requirement of the proposed changes to California Title 24 in order to obtain credit for sealing duct systems. The $22 \%$ of fan flow represents the typical leakage of ducts in new California construction (based on this project and previous data taken by LBNL). Note that for all these cases the leakage is the total of supply and return. Table A2.8 shows the expected result that as the requirements are restricted (lower allowable leakage) more houses require fixing or would fail the criteria required to obtain a credit in a home energy rating or meet a code requirement.

At the level proposed for Title 24 duct leakage credit almost all the duct systems in the bay area homes (only one of which is new construction - House I) will not pass even after leak sealing. For duct pressurization, House G passes at this leakage level, but for the NPT and HPT it is house F that passes. Table A6.9 looks at differences between the tests at each leakage level and adds up all the occurrences where the tests predict different results. Differences between duct pressurization and the other two tests tended to increase as the level of allowable leakage increased. So the tighter the duct leakage specification that the system must pass, the better the agreement between the tests. Basically - all tests showed that at the $6 \%$ leakage level all the systems required retrofitting, except for house $D$ and house $H$ for the NPT. This is due to the NPT generating false zero readings for these two houses. Concentrating on the two tests most likely to be adopted; the HPT and duct pressurization, at the lowest leakage level the tests would disagree two out of nineteen times. Little discrimination is required at these low leakage rates because almost all the houses have poor duct systems whose leakage is much greater than these low leakage levels, even after leak sealing. When a leakage criteria is chosen that is close to the typical duct leakage (the $22 \%$ level) the tests only agree for about half the houses. In addition, the test methods disagree about which houses had duct retrofits that passed the $6 \%$ leakage criterion. The HPT and NPT showed that only house F passed, but the Duct Pressurization test showed that only house $G$ passed. This is a critical result because retrofit/compliance decisions need to be independent of the test method used.

Looking at the pass/fail criteria applied to the duct systems as a group, Table A6.10 gives the number of systems to be retrofitted based on the results of each test. The most significant differences are at the highest leakage level where the HPT and NPT show that three fewer systems require retrofitting compared to duct pressurization both pre and post retrofit.

\section{Irvine House Results}

All of the new Irvine houses were very similar in construction, floor plan, detail, architecture and duct system installation. Details of these houses are given in Table A6.3. Each house had two systems, one for upstairs and one for downstairs, with the air handler, furnace and cooling coils for both systems located in the attic. All the houses had both gas furnaces and split system air conditioning. The houses had minimal return systems with either one or two returns per system. The ducts were all constructed from R4 flex duct with diameters ranging from $15 \mathrm{~cm}(6 \mathrm{in})$ to $45 \mathrm{~cm}$ (18 in). There were no return plenums and the return ducts were connected directly to the fan box. The supply plenums were fabricated from duct board and contained the cooling coils. All the houses used an interior wall cavity for one or more of the returns which 
was a major source of return leakage. All the systems in Irvine had the filters at the returns, and should avoid the return pressure problems with the HPT and NPT results found in the Bay Area tests. Table A6.3 summarizes the house and duct system characteristics for the Irvine houses.

In all the Irvine tests, the duct pressurization was for the sum of supply and return leakage because it was not possible to split the supply from the return. The houses had the IQ+ duct pressurization test performed twice by CEC staff and once by LBNL staff. The HPT was performed by both CEC and LBNL staff in each house also. These multiple tests were used as repeatability checks on the two types of test.

\section{Comparison of total duct leakage measured using HPT and duct pressurization}

The tests in houses $\mathrm{J}$ through $\mathrm{O}$ included both HPT and duct pressurization tests. Table A6.4 summarizes the comparison of the two tests (for combined supply and return leakage). The duct pressurization test used for comparison here is the $25 \mathrm{~Pa}$ total leakage test (IQ+ protocol). Because the duct pressurization test is not corrected for leakage to inside or to operating condition pressures the differences between the two tests averaged over all the systems were acceptable, with the HPT giving $14 \mathrm{cfm}$ greater leakage. The average absolute differences for individual houses, however were significantly larger at $174 \mathrm{cfm}$. Houses $\mathrm{N}$ and $O$ had the largest differences, with the HPT predicting very large duct leakage (greater than $700 \mathrm{cfm}$ ) and the pressurization tests predicting less than half of this amount.

\section{Multiple test comparisons in houses $\mathrm{M}$ and $\mathrm{N}$}

Houses $\mathrm{M}$ and $\mathrm{N}$ were tested in detail, using the same test procedures as in the Bay Area houses. The tests are summarized in Table A6.5. Looking at combined system leakage (i.e., total for the whole house) the NPT gives the lowest leakage and HPT the highest, with the duct pressurization leakage to outside at operating conditions in the middle. There is a large range between the NPT and HPT of more than a factor of two in house $\mathrm{M}$ to almost a factor of three in house $\mathrm{N}$.

\section{Repeatability of IQ+ protocol tests (Duct Pressurization total leakage at 25}

$\mathrm{Pa}$ )

The results of the repeatability tests for duct pressurization are given in Table A6.6. The RMS difference between the tests was used as an estimate of repeatability. The mean RMS difference was $16 \mathrm{cfm}$ (3\% of the measured leakage flow). Looking at the differences between the two tests in each house performed by CEC, this gives an indication of the repeatability of the test if the same testers test the same house at different times. This resulted in an average RMS difference of only $11 \mathrm{cfm}$ or $2 \%$ of the measured values. These results show that repeatability errors are low for pressurization tests because the precision of the physical measurements is high.

\section{Retrofit/Compliance Decisions}

As with the bay area houses, the measured leakage can be to make a decision about whether or not a duct system requires retrofitting, or it passes a code requirement. The test results were used to predict the number of decisions that would be different if a different test were used, and the results are shown in Table A6.11. The same acceptable leakage criteria of $6 \%, 10 \%$ and $22 \%$ of fan flow as used in the bay area houses were applied to the new houses in Irvine. In addition, the IQ+ limit for leakage was also used. The IQ+ program uses a formula based on floor area for acceptable leakage because systems are tested without measuring system fan flow. The formula used is $50 \mathrm{cfm}$ of leakage at $25 \mathrm{~Pa}$ for every $1000 \mathrm{ft}^{2}$ of house floor area. The results in Table A6.11 show that this is roughly equivalent to the proposed 6\% limit for Title 24 duct leakage credit, however there is some variation because the measured fan flows did not scale very well with floor area. Both duct pressurization and the HPT showed that the ducts required leakage fixing for $6 \%, 10 \%$ and IQ+ leakage levels. At the $22 \%$ leakage level, the tests agreed for houses $\mathrm{M}, \mathrm{K}$ and $\mathrm{L}$, 
disagreed for houses $\mathrm{J}, \mathrm{N}$ and $\mathrm{O}$. Note that for houses $\mathrm{K}$ and $\mathrm{L}$ the HPT results were very close to the $22 \%$ fan flow results and a change of less than $1 \%$ of the measured flows (less than $5 \mathrm{cfm}$ ) would have changed the HPT results sufficiently that they would not have agreed with the pressurization results.

This apparent good result at the low limits must be tempered by the fact that all of the duct systems had excessive leakage and so the comparison of the ability of the tests to discriminate between houses was not strongly verified. The results in Table A6.11 show that if a HERS rater is screening for poor duct systems (at the 22\% leakage level) then the differences between the different test methods is probably unacceptable. The bay area tests confirm this with agreement only half of the time between duct pressurization and the HPT at $22 \%$ leakage.

With current duct construction practice the decision about passing or failing the Title 24 or IQ+ minimum leakage criteria does not depend on the test method used. However, as system installations improve the different results from different tests will become critical. To obtain a more definitive answer regarding disagreement between test methods houses with good duct systems need to be found and tested.

Eliminating the HPT tests that do not meet the three applicability criteria, Tables $6.8 \mathrm{~b}$ and $6.11 \mathrm{~b}$ show that using "good" HPT tests only does not significantly change the above results. At the $22 \%$ leakage level the results between the pressurization and HPT test disagree about one third of the time (4 out of 13 combining the results in the two tables). 
Table A6.1 House and System Characteristics for Bay Area Houses.

\begin{tabular}{|c|c|c|c|c|c|c|c|c|c|c|c|c|}
\hline House code & Clty & $\begin{array}{l}\text { Supply Duct } \\
\text { Locatton }\end{array}$ & $\begin{array}{l}\text { Retum Duct } \\
\text { Location }\end{array}$ & $\begin{array}{l}\text { Supply Duct } \\
\text { Materlal }\end{array}$ & $\begin{array}{c}\text { Retum Duct } \\
\text { Material }\end{array}$ & $\begin{array}{l}\text { Supply Duct } \\
\text { Insulation }\end{array}$ & $\begin{array}{l}\text { Retum Duct } \\
\text { Insulation }\end{array}$ & $\begin{array}{c}\text { Fan Fiow } \\
\text { cfm }\end{array}$ & $\begin{array}{c}\text { Floor Area } \\
\text { tthe }\end{array}$ & $\begin{array}{c}\text { Fan } \\
\text { now/Floor } \\
\text { area }\end{array}$ & $\begin{array}{c}\text { Envelope } \\
\text { leakage } \\
\text { cfin } 925 \mathrm{~Pa}\end{array}$ & $\begin{array}{l}\text { Sealing } \\
\text { Method }\end{array}$ \\
\hline $\bar{A}$ & Berkeley & Alttc & Crawlspace & Sheot Metal & Crawispace & R4 & none & 508 & 1500 & 0.34 & 3000 & Mastlc \\
\hline B & Alameda & Attic & Attlc & Sheet Metal & Sheet Metal & none & none & 322 & 690 & 0.47 & 4260 & Mastic \\
\hline C & $\begin{array}{l}\text { Wainut } \\
\text { Creok }\end{array}$ & Basement & Basement & Sheet Metal & $\begin{array}{l}\text { Panned } \\
\text { Jolst }\end{array}$ & none & none & 1077 & 1000 & 1.08 & 3100 & $\begin{array}{c}\text { Mastic and } \\
\text { Tape }\end{array}$ \\
\hline D & Fremont & Attic & Attic & Sheet Metal & Sheet Metal & $\mathbf{R 4}$ & R4 & 936 & 1035 & 0.90 & 1150 & Aeroseal \\
\hline $\mathbf{E}$ & El Corrito & Crawlspace & Craw/space & Sheet Metal & Sheet Metal & none & none & 688 & 725 & 0.85 & 1000 & $\begin{array}{c}\text { Mastic and } \\
\text { Tape }\end{array}$ \\
\hline $\boldsymbol{F}$ & Berkeley & $\begin{array}{c}\text { Attlc } \\
\text { Crawspace }\end{array}$ & Crawlspace & Sheet Metal & $\begin{array}{l}\text { Panned } \\
\text { Jolst }\end{array}$ & none & none & 1017 & 2881 & 0.35 & 4150 & Aeroseal \\
\hline $\mathbf{Q}$ & Oakland & Crawispace & Crawlspace & Flex Duct & Sheet Metal & R4 & none & 987 & 1252 & 0.79 & 2300 & Aeroseal \\
\hline H1 & Lafeyette & Crawtspace & Crawspace & Flox Duct & Flex Duct & R4 & R4 & 1280 & 1550 & 0.83 & 4200 & $\begin{array}{l}\text { Aeroseal, } \\
\text { Mastlo and } \\
\text { Tape }\end{array}$ \\
\hline H2 & Lafoyotto & Crambapace & Crawlopace & Flex Duot & Flex Duot & P4 & A4 & 1170 & 1680 & 0.78 & 4200 & $\begin{array}{l}\text { Aoroseal, } \\
\text { Mastlo and } \\
\text { Taps }\end{array}$ \\
\hline 1 & Rlohmond & $\begin{array}{l}\text { Baoement } \\
\text { Walls }\end{array}$ & Basement & $\begin{array}{l}\text { Flox } \\
\text { Duotsheot } \\
\text { metal }\end{array}$ & Flex Duot & R4/none & R4 & 842 & 1660 & 0.84 & 1700 & $\begin{array}{l}\text { Maetlo and } \\
\text { Tape }\end{array}$ \\
\hline
\end{tabular}


Table A6.2 Results of Duct leakage tests for Bay Area houses (cfm to outside)

\begin{tabular}{|c|c|c|c|c|c|c|c|c|c|c|c|c|c|c|}
\hline \multicolumn{2}{|l|}{ Test Method } & \multicolumn{3}{|c|}{ Duct Pressurization } & \multicolumn{3}{|c|}{ NPT } & \multicolumn{4}{|c|}{ HPT } & \multicolumn{3}{|c|}{ Tracer } \\
\hline House code & $\begin{array}{l}\text { PRE/POST } \\
\text { sealing }\end{array}$ & Supply & Return & Total & Supply & Return & Total & Supply & Retum & Total & Moets all 3 & Supply & Retum & Total \\
\hline A & PRE & 51 & 116 & 167 & 17 & 151 & 168 & 0 & 78 & 78 & $Y$ & - & 160 & - \\
\hline B & PRE & 22 & 7 & 29 & 0 & 77 & & 38 & 100 & 138 & $\mathbf{N}$ & - & $\cdot$ & - \\
\hline C & PRE & 651 & 224 & 875 & 0 & 213 & 213 & 104 & 322 & 526 & $Y$ & - & 318 & - \\
\hline D & PRE & 150 & 89 & 239 & 0 & 33 & 33 & 55 & 96 & 151 & $Y$ & - & - & . \\
\hline$E$ & PRE & 139 & - & - & 170 & 212 & 382 & 13 & 42 & 55 & $Y$ & - & - & - \\
\hline $\mathbf{F}$ & PRE & 229 & 88 & 317 & 0 & 73 & 73 & 50 & 70 & 120 & $Y$ & 347 & 129 & 476 \\
\hline $\mathbf{G}$ & PRE & 57 & 91 & 148 & 0 & 101 & 101 & 0 & 132 & 132 & $Y$ & 598 & 109 & 707 \\
\hline H1 & PRE & 640 & 208 & 848 & 40 & 40 & 80 & 143 & 55 & 198 & $\mathbf{N}$ & - & - & - \\
\hline $\mathrm{H} 2$ & PRE & 322 & 118 & 440 & 0 & 0 & 0 & 147 & 46 & 193 & $\mathbf{N}$ & - & - & - \\
\hline 1 & PRE & 254 & 0 & 254 & 93 & 0 & 93 & 103 & 0 & 103 & $\mathbf{N}$ & 256 & 43 & 299 \\
\hline A & POST & - & - & - & 0 & 150 & 150 & 0 & 75 & 75 & $Y$ & - & 155 & - \\
\hline B & POST & 71 & 0 & 71 & 0 & 32 & 32 & 0 & 26 & 26 & $\mathbf{N}$ & - & - & - \\
\hline C & POST & 446 & 213 & 659 & 0 & 108 & 108 & 0 & 165 & 165 & $Y$ & - & 208 & - \\
\hline D & POST & 63 & 89 & 152 & 0 & 100 & 100 & 0 & 111 & 111 & $Y$ & - & - & - \\
\hline E & POST & 95 & - & - & 61 & 61 & 122 & 26 & 43 & 69 & $\mathbf{Y}$ & - & - & - \\
\hline $\mathbf{F}$ & POST & 128 & 13 & 141 & 48 & 10 & 58 & 0 & 23 & 23 & $\mathbf{N}$ & - & - & - \\
\hline G & POST & 10 & 42 & 52 & 0 & 38 & 38 & 0 & 116 & 116 & $Y$ & 4 & 64 & 68 \\
\hline H1 & POST & 180 & - & - & 109 & 79 & 188 & 83 & 137 & 220 & $\mathbf{N}$ & - & - & - \\
\hline $\mathrm{H} 2$ & POST & 107 & 27 & 134 & 32 & 160 & 192 & 139 & 57 & 196 & $\mathbf{N}$ & - & - & - \\
\hline 1 & POST & 189 & 0 & 189 & 57 & 10 & 67 & 133 & 25 & 158 & $\mathbf{N}$ & 99 & 56 & 155 \\
\hline
\end{tabular}


Table A6.3 House and System Characteristics for New Construction in Irvine.

\begin{tabular}{|c|c|c|c|c|c|c|c|c|c|c|}
\hline $\begin{array}{l}\text { House } \\
\text { code }\end{array}$ & $\begin{array}{l}\text { Supply Duct } \\
\text { Location }\end{array}$ & $\begin{array}{l}\text { Retum Duct } \\
\text { Location }\end{array}$ & $\begin{array}{l}\text { Supply Duct } \\
\text { Material }\end{array}$ & $\begin{array}{c}\text { Retum Duct } \\
\text { Materlal }\end{array}$ & $\begin{array}{l}\text { Supply Duct } \\
\text { Insulation }\end{array}$ & $\begin{array}{l}\text { Rotum Duct } \\
\text { Insulation }\end{array}$ & $\begin{array}{l}\text { Fan Flow } \\
\text { cfim }^{9} \\
\text { Tracer Gas }\end{array}$ & $\begin{array}{l}\text { Floor Area } \\
\text { ft12 }\end{array}$ & $\begin{array}{c}\text { Fan } \\
\text { flow/Floor } \\
\text { area }\end{array}$ & $\begin{array}{c}\text { Envelope } \\
\text { leakage } \\
\text { cfm } \odot 25 \mathrm{~Pa}\end{array}$ \\
\hline $\mathbf{J}$ & Attic/Wall & AtticWall & Flex Duct & $\begin{array}{c}\text { Flex } \\
\text { DuctWall } \\
\text { Cavity }\end{array}$ & R4 & $\overline{\mathrm{R4}}$ & 2048 & 3607 & 0.57 & 2090 \\
\hline $\mathbf{K}$ & Attic/ Wall & Attic/Wall & Flex Duct & $\begin{array}{l}\text { Flex } \\
\text { DuctWall } \\
\text { Cavity }\end{array}$ & A4 & R4 & 2035 & 3144 & 0.65 & 3250 \\
\hline L & Attic/ Wall & Attic/ Wall & Flex Duct & $\begin{array}{c}\text { Flex } \\
\text { DuctWall } \\
\text { Cavity }\end{array}$ & R4 & R4 & 1628 & 3441 & 0.45 & 2500 \\
\hline $\mathbf{M}$ & Attic/ Wall & Attic/Wall & Flex Duct & $\begin{array}{l}\text { Flox } \\
\text { Duct/Wall } \\
\text { Cavity }\end{array}$ & R4 & R4 & 2665 (2310) & 2856 & 0.93 & 1900 \\
\hline $\mathbf{N}$ & Attic/ Wall & Attid Wall & Flex Duct & $\begin{array}{l}\text { Flex } \\
\text { DuctWall } \\
\text { Cavity }\end{array}$ & R4 & R4 & $2528(2090)$ & 2750 & 0.92 & 2850 \\
\hline 0 & Attid Wall & Attic/Wall & Flex Duct & $\begin{array}{l}\text { Flex } \\
\text { Ducthall } \\
\text { Cavity }\end{array}$ & R4 & R4 & 2856 & 2856 & 0.94 & 3000 \\
\hline $\mathbf{P}$ & Attic/ Wall & Attid Wall & Flex Duct & $\begin{array}{l}\text { Flex } \\
\text { DuctWall } \\
\text { Cavity }\end{array}$ & R4 & R4 & - & 3607 & $\cdot$ & - \\
\hline $\mathbf{Q}$ & Attl / Wall & Attld Wall & Flex Duct & $\begin{array}{l}\text { Flex } \\
\text { Ductwall } \\
\text { Cavity }\end{array}$ & R4 & R4 & - & 3144 & - & - \\
\hline
\end{tabular}

\footnotetext{
These are the sum of supply register flows measured with a flowhood by CEC staff.
} 
Table A6.4 Comparison of HPT to total duct leakage at $25 \mathrm{~Pa}, \mathrm{cfm}$

\begin{tabular}{|c|c|c|c|}
\hline House & HPT & $\begin{array}{c}\text { Meots all } 3 \text { applicablitity } \\
\text { criterla }\end{array}$ & Duct Pressurization \\
\hline J1 & 180 & $\bar{Y}$ & 152 \\
\hline J2 & 70 & $\mathbf{N}$ & 245 \\
\hline K1 & 249 & $Y$ & 250 \\
\hline K2 & 200 & $Y$ & 481 \\
\hline L1 & 246 & $\mathbf{N}$ & 182 \\
\hline L2 & 118 & $\mathbf{N}$ & 375 \\
\hline M & 410 & $Y$ & 354 \\
\hline $\mathbf{N}$ & 729 & $\mathbf{N}$ & 435 \\
\hline $\mathbf{0}$ & 747 & $\mathbf{N}$ & 338 \\
\hline moan & & 28 & 312 \\
\hline
\end{tabular}

Table A6.5 Results of multiple duct leakage tests, cfm

\begin{tabular}{|c|c|c|c|c|c|c|c|c|c|c|c|}
\hline \multirow[t]{2}{*}{ House } & \multicolumn{3}{|c|}{ NPT } & \multicolumn{3}{|c|}{ HPT } & \multirow{2}{*}{$\begin{array}{l}\text { Duct } \\
\text { pressurzation } \\
\text { leakage to } \\
\text { outside at } \\
\text { operating } \\
\text { conditions } \\
\end{array}$} & \multirow{2}{*}{$\begin{array}{l}\text { IQ+ prolocol } \\
\text { (duct } \\
\text { pressurtzation } \\
\text { total leakage } \\
\text { at } 25 \mathrm{~Pa} \text { ) }\end{array}$} & \multicolumn{3}{|c|}{ Tracer Gas } \\
\hline & Supply & Retum & Total & Supply & Rotum & Total & & & Supply & Retum & Total \\
\hline $\begin{array}{l}\text { M system } 1 \\
\text { M system } 2\end{array}$ & $:$ & $\vdots$ & $\therefore$ & $\vdots$ & $\vdots$ & $:$ & $\begin{array}{l}193 \\
177\end{array}$ & $\begin{array}{l}188 \\
166 \\
\end{array}$ & $\begin{array}{l}429 \\
358 \\
\end{array}$ & $\begin{array}{c}123 \\
78 \\
\end{array}$ & $\begin{array}{l}552 \\
436 \\
\end{array}$ \\
\hline$M$ total & 128 & 91 & 219 & 235 & 175 & 410 & 370 & 354 & 787 & 201 & 788 \\
\hline $\begin{array}{l}\text { system } 1 \\
\text { N system } 2\end{array}$ & : & $=$ & - & 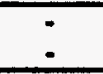 & : &. & $\begin{array}{l}201 \\
203 \\
\end{array}$ & $\begin{array}{l}234 \\
201 \\
\end{array}$ & $\begin{array}{l}541 \\
329 \\
\end{array}$ & $\begin{array}{l}49 \\
78 \\
\end{array}$ & $\begin{array}{l}590 \\
407 \\
\end{array}$ \\
\hline$N$ total & 138 & 94 & 232 & 427 & 302 & 729 & 405 & 435 & 870 & 127 & 997 \\
\hline
\end{tabular}


Table A6.6 Repeatability of IQ+ protocol tests (Duct Pressurization total leakage at 25 Pa)

\begin{tabular}{|c|c|c|c|c|c|c|c|c|c|}
\hline House & System 1 & $\begin{array}{c}\text { CEC1 } \\
\text { System } 2\end{array}$ & Total & System 1 & $\begin{array}{c}\text { CEC2 } \\
\text { System } 2\end{array}$ & Total & System 1 & $\begin{array}{c}\text { LBNL } \\
\text { System } 2\end{array}$ & Total \\
\hline$J$ & 230 & 157 & 387 & 234 & 154 & 388 & 245 & 152 & 397 \\
\hline K & 486 & 385 & 871 & 482 & 334 & 816 & 481 & 250 & 731 \\
\hline L & 370 & 167 & 537 & 330 & 172 & 502 & 375 & 182 & 557 \\
\hline M & 174 & 172 & 347 & 160 & 163 & 323 & 166 & 188 & 354 \\
\hline $\mathbf{N}$ & 200 & 224 & 424 & 217 & 245 & 462 & 301 & 234 & 435 \\
\hline 0 & 134 & 190 & 324 & 133 & 188 & 321 & 138 & 200 & 338 \\
\hline$P_{0}$ &. & $\therefore$ & - & - & - & 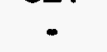 & 340 & 273 & 613 \\
\hline$Q^{2}$ & 185 & 211 & 396 & 185 & 244 & 429 & - & - & - \\
\hline $\mathbf{R}$ & 202 & 240 & 442 & 198 & 246 & 444 & - & - & - \\
\hline $\mathbf{S}$ & 454 & 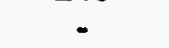 & 454 & 663 & . & 663 & - & - & - \\
\hline
\end{tabular}

Table A6.7 Repeatability of HPT in new Irvine houses

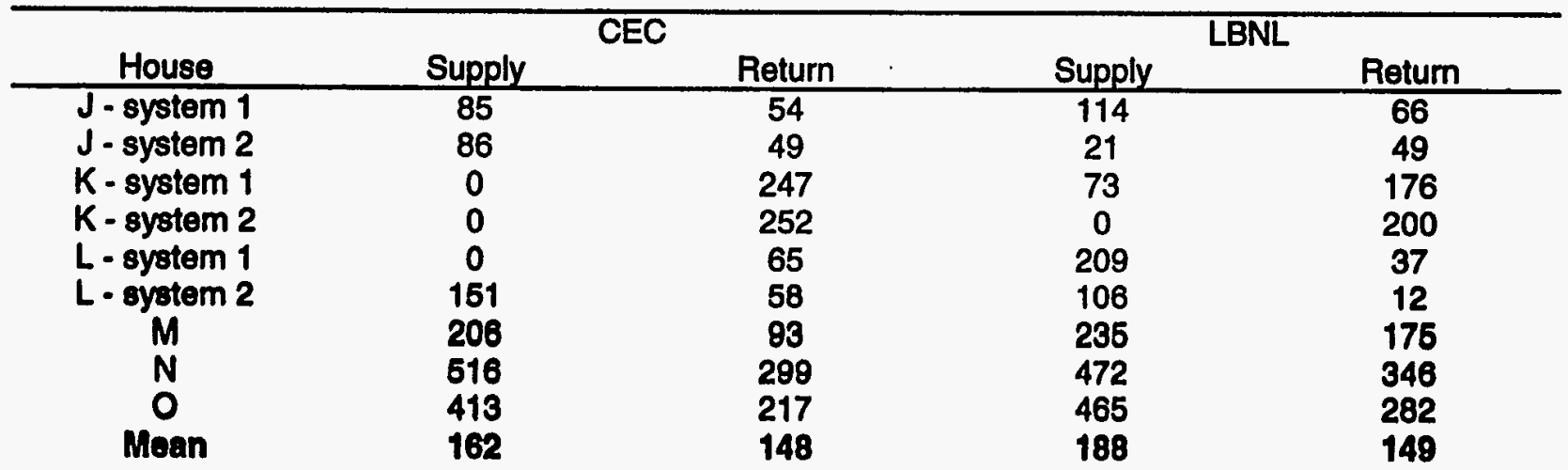

\footnotetext{
${ }^{2} \mathrm{CEC} 1$ is data from training session and $\mathrm{CEC} 2$ is from LBNL demonstration.
} 


\begin{tabular}{|c|c|c|c|c|c|c|c|c|c|c|c|c|c|c|c|c|}
\hline $\begin{array}{l}\mathbf{N} \\
\mathbf{N} \\
\mathbf{N} \\
\mathbf{N} \\
\mathbf{N} \\
\mathbf{N} \\
\mathbf{N} \\
\mathbf{N} \\
\mathbf{N} \\
\mathbf{N} \\
\mathbf{N} \\
\mathbf{N} \\
\mathbf{N} \\
\mathbf{N} \\
\mathbf{N} \\
\mathbf{N} \\
\mathbf{N} \\
\mathbf{\lambda} \\
\mathbf{\lambda} \\
\mathbf{N} \\
\end{array}$ & 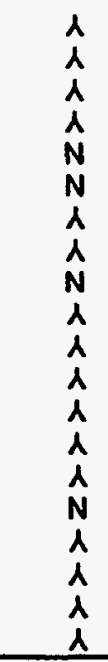 & $\begin{array}{l}\hat{\lambda} \\
\hat{\lambda} \\
\hat{\lambda} \\
\hat{N} \\
\hat{\lambda} \\
\hat{\lambda} \\
\hat{\lambda} \\
\hat{\lambda} \\
\hat{\lambda} \\
\hat{\lambda} \\
\hat{\lambda} \\
\hat{\lambda} \\
\hat{\lambda} \\
\hat{\lambda} \\
\hat{\lambda} \\
\hat{\lambda} \\
\hat{\lambda} \\
\hat{\lambda} \\
\hat{\lambda}\end{array}$ & 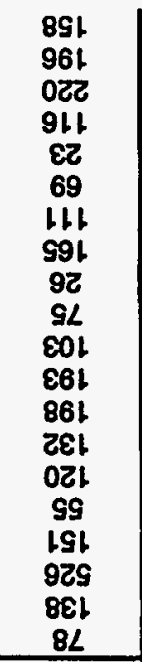 & $\begin{array}{l}\mathbf{N} \\
\mathbf{N} \\
\mathbf{N} \\
\mathbf{N} \\
\mathbf{N} \\
\mathbf{N} \\
\mathbf{N} \\
\mathbf{N} \\
\mathbf{N} \\
\mathbf{N} \\
\mathbf{N} \\
\mathbf{N} \\
\mathbf{N} \\
\mathbf{N} \\
\mathbf{N} \\
\mathbf{\lambda} \\
\mathbf{N} \\
\mathbf{N} \\
\mathbf{\lambda} \\
\mathbf{A}\end{array}$ & 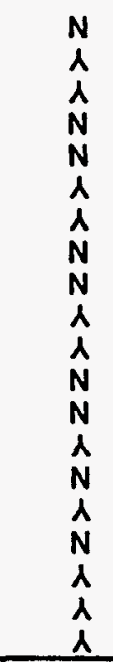 & $\begin{array}{l}\hat{\lambda} \\
\hat{\lambda} \\
\hat{\lambda} \\
\hat{N} \\
\hat{\lambda} \\
\hat{\lambda} \\
\hat{\lambda} \\
\hat{\lambda} \\
\hat{\lambda} \\
\hat{N} \\
\hat{\lambda} \\
\hat{\lambda} \\
\hat{\lambda} \\
\hat{N} \\
\hat{N} \\
\hat{\lambda} \\
\hat{\lambda} \\
\end{array}$ & $\begin{array}{c}\angle 9 \\
Z 61 \\
881 \\
8 \varepsilon \\
89 \\
Z Z 1 \\
001 \\
801 \\
Z \varepsilon \\
091 \\
\varepsilon 6 \\
0 \\
08 \\
101 \\
\varepsilon L \\
Z 8 \varepsilon \\
\varepsilon \varepsilon \\
\varepsilon 1 Z \\
\angle L \\
891 \\
\end{array}$ & $\begin{array}{l}\hat{A} \\
N \\
N \\
N \\
N \\
N \\
N \\
\lambda \\
\lambda \\
\vdots \\
\hat{\lambda} \\
\hat{\lambda} \\
\hat{N} \\
N \\
\hat{N} \\
N \\
N \\
\lambda \\
N \\
\lambda \\
\end{array}$ & $\begin{array}{l}\hat{\lambda} \\
\hat{\lambda} \\
\hat{N} \\
\hat{N} \\
\hat{N} \\
\hat{\lambda} \\
\hat{\lambda} \\
\dot{\lambda} \\
\hat{\lambda} \\
\hat{\lambda} \\
\hat{\lambda} \\
\hat{\lambda} \\
\hat{\lambda} \\
\hat{\lambda} \\
\hat{N} \\
\hat{\lambda}\end{array}$ & 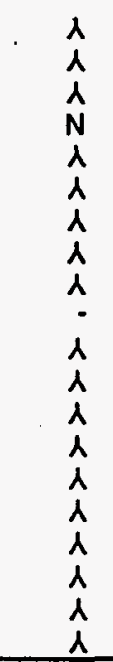 & 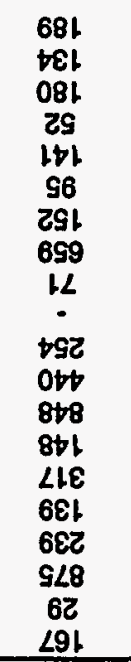 & $\begin{array}{l}981 \\
092 \\
282 \\
812 \\
b Z 2 \\
291 \\
\angle 0 Z \\
882 \\
0 L \\
Z 11 \\
981 \\
092 \\
282 \\
812 \\
t 22 \\
291 \\
\angle 0 Z \\
882 \\
0 L \\
Z 11 \\
\end{array}$ & $\begin{array}{c}68 \\
811 \\
821 \\
66 \\
201 \\
69 \\
66 \\
801 \\
2 E \\
19 \\
68 \\
811 \\
821 \\
66 \\
201 \\
69 \\
66 \\
801 \\
26 \\
19 \\
\end{array}$ & $\begin{array}{l}19 \\
1 L \\
\angle 1 \\
69 \\
19 \\
16 \\
99 \\
99 \\
61 \\
08 \\
19 \\
1 L \\
11 \\
69 \\
19 \\
16 \\
99 \\
99 \\
61 \\
08 \\
\end{array}$ & 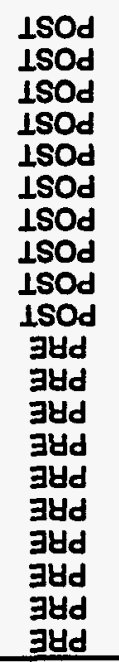 & $\begin{array}{c}1 \\
2 H \\
1 H \\
0 \\
\exists \\
\exists \\
0 \\
0 \\
9 \\
\forall \\
1 \\
2 H \\
1 H \\
0 \\
J \\
\exists \\
0 \\
0 \\
9 \\
\forall \\
\end{array}$ \\
\hline 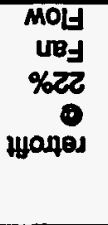 & $\begin{array}{c}\text { MOJ } \\
\text { Ued } \\
\% 01 \\
0 \\
0 \\
\text { Hapes }\end{array}$ & $\begin{array}{l}\text { Mols } \\
\text { urd } \\
\% 90 \\
\text { Hana }\end{array}$ & 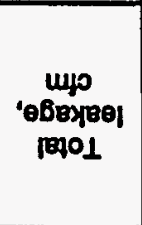 & 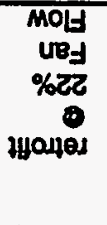 & $\begin{array}{l}\text { MOH } \\
\text { ues } \\
\% 01 \\
\% \\
\text { youres }\end{array}$ & 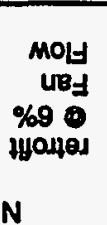 & 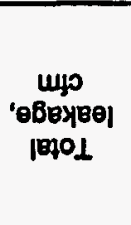 & $\begin{array}{r}\text { Mold } \\
\text { us] } \\
\% \text { \% } \\
\text { Hangd }\end{array}$ & $\begin{array}{r}\text { Moly } \\
\text { ued } \\
\% 010 \\
\text { Holpel }\end{array}$ & $\begin{array}{c}\text { MOIJ } \\
\text { usy } \\
\% 90 \\
\text { H1101\% }\end{array}$ & 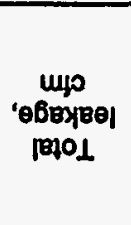 & $\begin{array}{l}\text { wyo } \\
\text { 'moly } \\
\text { ured } \\
\% \text { कट }\end{array}$ & $\begin{array}{l}\text { upo } \\
\text { MOld } \\
\text { ued } \\
\% 01\end{array}$ & $\begin{array}{l}\text { uур } \\
\text { 'мо겅 } \\
\text { ury } \\
\% 9\end{array}$ & $\begin{array}{l}\text { 6uppes } \\
180 d \\
10 \text { Jyd }\end{array}$ & $\begin{array}{c}\text { epos } \\
\text { esnoH }\end{array}$ \\
\hline
\end{tabular}

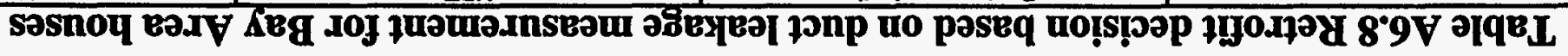


Table A6.8b Retrofit decision based on duct leakage measurement for Bay Area houses, eliminating HPT and NPT tests that do not meet the three applicability criteria

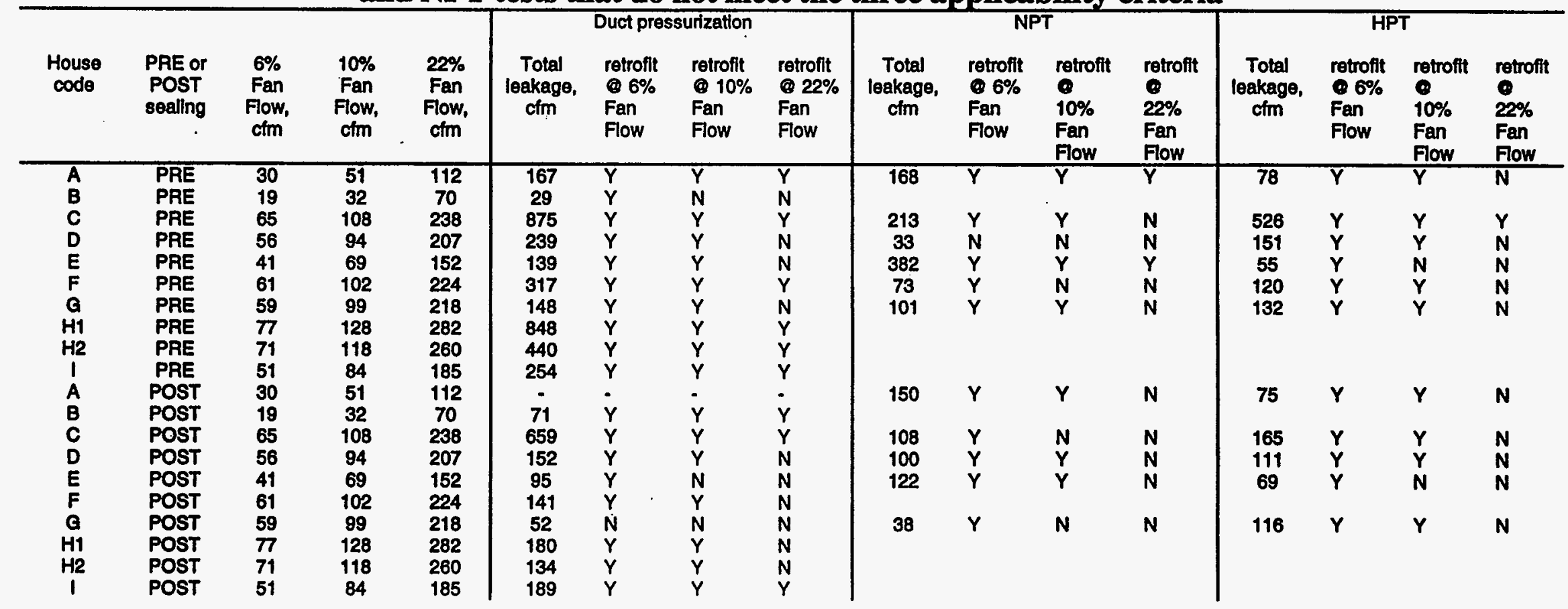

Table A6.9 Number of disagreements for retrofitting between test methods for Bay Area Houses

\begin{tabular}{cccc}
\hline $\begin{array}{c}\text { Acceptable leakage } \\
\text { level }\end{array}$ & $\begin{array}{c}\text { Duct Pressurization } \\
\text { and HPT }\end{array}$ & $\begin{array}{c}\text { Duct Pressurization } \\
\text { and NPT }\end{array}$ & HPT and NPT \\
\hline $6 \%$ & 2 & 3 & 3 \\
$10 \%$ & 5 & 10 & 9 \\
$22 \%$ & 9 & 10 & 3
\end{tabular}


Table A6.10 Number of systems to be fixed according to each test method for Bay Area houses

\begin{tabular}{ccccccc}
\hline $\begin{array}{c}\text { Acceptable leakage } \\
\text { level }\end{array}$ & \multicolumn{2}{l}{ Duct Pressurization } & \multicolumn{3}{c}{ NPT } & HPT \\
\hline & PRE & POST & PRE & POST & PRE & POST \\
$6 \%$ & 10 & 7 & 8 & 8 & 10 & 9 \\
$10 \%$ & 9 & 7 & 6 & 5 & 1 & 4 \\
$22 \%$ & 6 & 3 & 3 & 0 & 2 & 0
\end{tabular}

Table A6.11 Retrofit decision based on duct leakage measurement for Irvine houses

\begin{tabular}{|c|c|c|c|c|c|c|c|c|c|c|c|c|c|c|}
\hline \multirow[b]{2}{*}{$\begin{array}{l}\text { House } \\
\operatorname{cod} \theta\end{array}$} & \multirow[b]{2}{*}{$\begin{array}{c}6 \% \text { Fan } \\
\text { Flow. } \\
\text { ctm }\end{array}$} & \multirow[b]{2}{*}{$\begin{array}{l}10 \% \\
\text { Fan } \\
\text { Flow, } \\
\text { ctm }\end{array}$} & \multirow[b]{2}{*}{$\begin{array}{l}22 \% \\
\text { Fan } \\
\text { Flow, } \\
\text { cfm }\end{array}$} & \multirow[b]{2}{*}{$\begin{array}{l}\text { IQ+ } \\
\text { limit }\end{array}$} & \multicolumn{5}{|c|}{ Duct pressurization } & \multicolumn{5}{|c|}{ HPT } \\
\hline & & & & & $\begin{array}{c}\text { Total } \\
\text { leakage, } \\
\text { cfm }\end{array}$ & $\begin{array}{l}\text { retrofit @ } \\
6 \% \text { Fan } \\
\text { Flow }\end{array}$ & $\begin{array}{l}\text { retrofit } \\
10 \% \text { Fan } \\
\text { Flow }\end{array}$ & $\begin{array}{l}\text { retrofit @ } \\
22 \% \text { Fan } \\
\text { Flow }\end{array}$ & $\begin{array}{l}\text { retrofit } \\
\text { IQ+ } 11 \text { mit }\end{array}$ & $\begin{array}{l}\text { Total } \\
\text { leakage, } \\
\text { cfm }\end{array}$ & $\begin{array}{l}\text { retrofit } 6 \% \\
\text { Fan Flow }\end{array}$ & $\begin{array}{l}\text { retrofit } \\
10 \% \text { Fan } \\
\text { Flow }\end{array}$ & $\begin{array}{l}\text { retrofit } 8 \\
22 \% \text { Fan } \\
\text { Flow }\end{array}$ & $\begin{array}{l}\text { retrofft } 2 \\
1 Q+\| m i t\end{array}$ \\
\hline $\begin{array}{l}J \\
K \\
L \\
M \\
N \\
O\end{array}$ & $\begin{array}{c}123 \\
122 \\
98 \\
160 \\
152 \\
171\end{array}$ & $\begin{array}{l}205 \\
204 \\
163 \\
267 \\
253 \\
287\end{array}$ & $\begin{array}{l}451 \\
449 \\
359 \\
587 \\
557 \\
631\end{array}$ & $\begin{array}{l}180 \\
157 \\
172 \\
143 \\
138 \\
143\end{array}$ & $\begin{array}{l}397 \\
731 \\
557 \\
354 \\
435 \\
338\end{array}$ & $\begin{array}{l}Y \\
Y \\
Y \\
Y \\
Y \\
Y\end{array}$ & $\begin{array}{l}Y \\
Y \\
Y \\
Y \\
Y \\
Y\end{array}$ & $\begin{array}{l}N \\
Y \\
Y \\
N \\
N \\
N\end{array}$ & $\begin{array}{l}Y Y \\
Y \\
Y \\
Y \\
Y \\
Y\end{array}$ & $\begin{array}{l}250 \\
450 \\
364 \\
410 \\
729 \\
747\end{array}$ & $\begin{array}{l}Y Y \\
Y \\
Y \\
Y \\
Y \\
Y\end{array}$ & $\begin{array}{l}Y \\
Y \\
Y \\
Y \\
Y \\
Y\end{array}$ & $\begin{array}{l}\mathbf{Y} \\
Y / N \\
Y / N \\
N \\
Y \\
Y\end{array}$ & $\begin{array}{l}Y \\
Y \\
Y \\
Y \\
Y \\
Y\end{array}$ \\
\hline
\end{tabular}

Table A6.11b Retrofit decision based on duct leakage measurement for Irvine houses, eliminating HPT and NPT tests that do not meet the three applicability criteria

\begin{tabular}{|c|c|c|c|c|c|c|c|c|c|c|c|c|c|c|}
\hline \multirow[b]{2}{*}{$\begin{array}{l}\text { House } \\
\text { code }\end{array}$} & \multirow[b]{2}{*}{$\begin{array}{c}6 \% \text { Fan } \\
\text { Fow, } \\
\text { cfm }\end{array}$} & \multirow[b]{2}{*}{$\begin{array}{c}10 \% \\
\text { Fan } \\
\text { Flow, } \\
\text { cfm }\end{array}$} & \multirow[b]{2}{*}{$\begin{array}{c}22 \% \\
\text { Fan } \\
\text { Flow, } \\
\text { cfm }\end{array}$} & \multirow[b]{2}{*}{$\begin{array}{l}\text { IQ+ } \\
\text { limit }\end{array}$} & \multicolumn{5}{|c|}{ Duct pressurization } & \multicolumn{5}{|c|}{ HPT } \\
\hline & & & & & $\begin{array}{l}\text { Total } \\
\text { leakage, } \\
\text { cfm }\end{array}$ & $\begin{array}{l}\text { retrofit } 1 \\
6 \% \text { Fan } \\
\text { Flow }\end{array}$ & $\begin{array}{l}\text { retrofit @ } \\
10 \% \text { Fan } \\
\text { Flow }\end{array}$ & $\begin{array}{l}\text { retrofit } \\
22 \% \text { Fan } \\
\text { Flow }\end{array}$ & $\begin{array}{l}\text { retrofit } \\
\text { IQ+ limit }\end{array}$ & $\begin{array}{l}\text { Total } \\
\text { leakage, } \\
\text { ctm }\end{array}$ & $\begin{array}{l}\text { retrofit } 6 \% \\
\text { Fan Flow }\end{array}$ & $\begin{array}{l}\text { retrofit } \\
10 \% \text { Fan } \\
\text { Flow }\end{array}$ & $\begin{array}{l}\text { retrofit } \\
22 \% \text { Fan } \\
\text { Flow }\end{array}$ & $\begin{array}{l}\text { retrofit } 9 \\
\text { IQ+ limit }\end{array}$ \\
\hline $\begin{array}{l}J \\
K \\
L \\
M \\
N \\
O\end{array}$ & $\begin{array}{c}123 \\
122 \\
98 \\
160 \\
152 \\
171\end{array}$ & $\begin{array}{l}205 \\
204 \\
163 \\
267 \\
253 \\
287\end{array}$ & $\begin{array}{l}451 \\
449 \\
359 \\
587 \\
557 \\
631\end{array}$ & $\begin{array}{l}180 \\
157 \\
172 \\
143 \\
138 \\
143\end{array}$ & $\begin{array}{l}397 \\
731 \\
557 \\
354 \\
435 \\
338\end{array}$ & $\begin{array}{l}Y \\
Y \\
Y \\
Y \\
Y \\
Y\end{array}$ & $\begin{array}{l}Y \\
Y \\
Y \\
Y \\
Y \\
Y\end{array}$ & $\begin{array}{l}\mathbf{N} \\
\mathbf{Y} \\
\mathbf{Y} \\
\mathbf{N} \\
\mathbf{N} \\
\mathbf{N}\end{array}$ & $\begin{array}{l}Y \\
Y \\
Y \\
Y \\
Y \\
Y\end{array}$ & $\begin{array}{l}250 \\
450 \\
\\
410\end{array}$ & $\begin{array}{l}\mathbf{Y} \\
\mathbf{Y} \\
\mathbf{Y}\end{array}$ & $\begin{array}{l}\mathbf{Y} \\
\mathbf{Y} \\
\mathbf{Y}\end{array}$ & $\begin{array}{l}\mathbf{Y} \\
\mathbf{Y} N \mathbf{N} \\
\mathbf{N}\end{array}$ & $\begin{array}{l}Y \\
Y \\
Y\end{array}$ \\
\hline
\end{tabular}




\section{Appendix 7. Duct Sealants And Longevity Testing}

All current air distribution systems require some sort of sealant between duct sections, at branches and at a terminus. Without these seals, duct systems would be extremely leaky and hence inefficient. While houses are usually designed for a 30 year life expectancy, current duct systems are not. A major contributing factor in the reduced life of duct systems is the failure of duct seals.

While some duct sealant technologies are rated (e.g. by Underwriters Laboratory) on their manufactured properties, none of these ratings addresses the in-service lifetime. A key piece of the sealant selection puzzle would be answered if relative ratings for sealant longevity existed. The results below are focussed on our attempt to answer this question with accelerated aging of sealants.

\section{Aerosol Sealant Test Data}

Three years ago EPA funded construction of a test apparatus to measure the longevity of the aerosol sealant technique under accelerated conditions. This testing involved, heat-only testing with about a 20 minute cycle time. The system has been taking data for over 18 months and its leakage is displayed in Figure A7.1. The apparatus consists of eight test sections in parallel; before applying the sealant, the leaks were approximately $100 \mathrm{cfm}$ (at $25 \mathrm{~Pa}$ ) combined. As shown in the figure, after sealing they were down to approximately $7 \mathrm{cfm}($ at $25 \mathrm{~Pa})$.

The data displays very little change over the measurement period. Not only has there been no failure, but a slight downward drift may be seen in the data compared to the horizontal line. If true, this trend would indicate that the seal was getting tighter with time as might be caused by dust build-up improving the seal. The trend is sufficiently small, however, that it is more likely statistical or experimental bias. These measurements will continue; a more in depth error analysis and recalibration will be carried out after the data collection stops to help determine whether the slight trend is real or not.

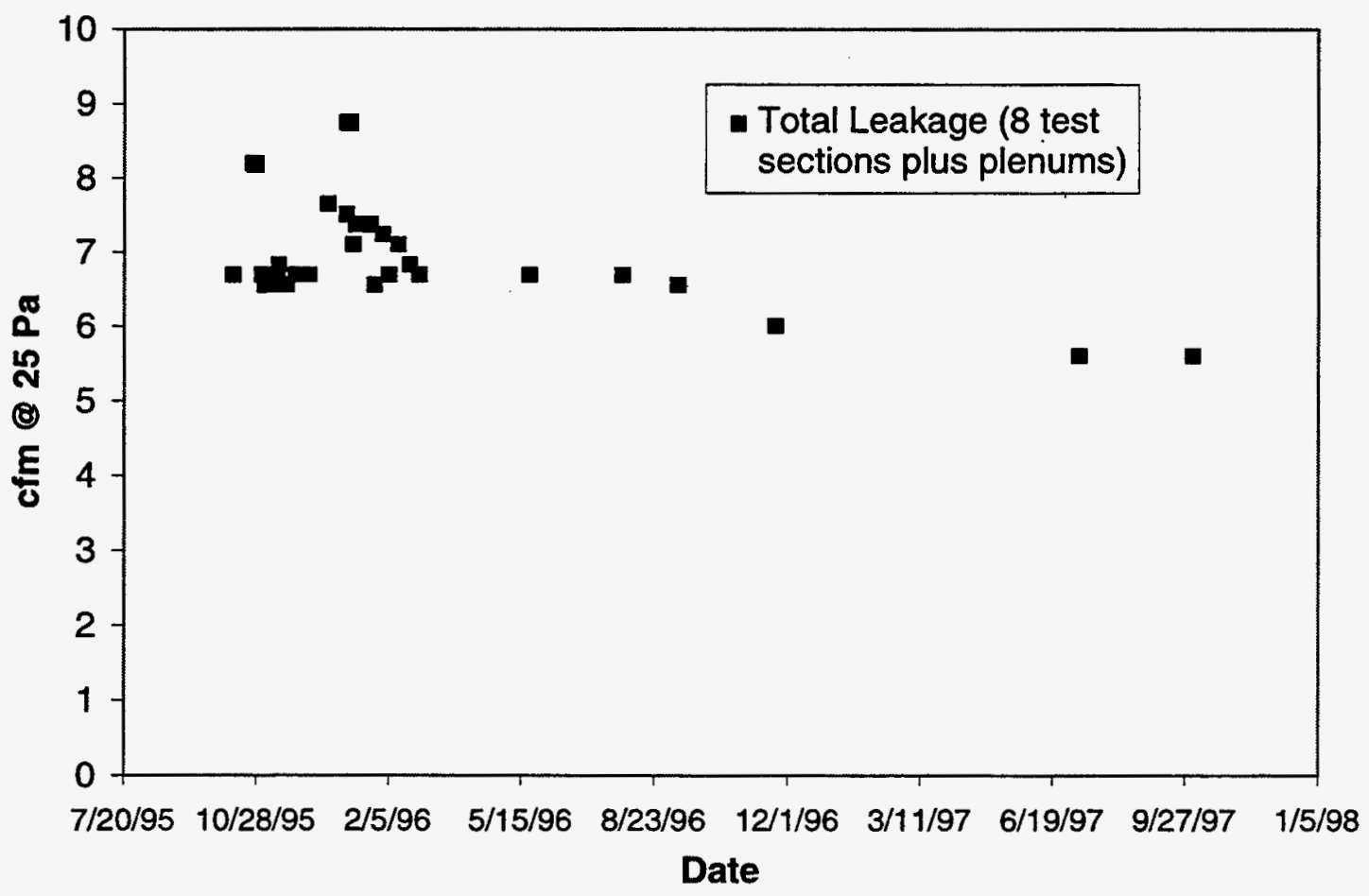

Figure A7.1 Aerosol Longevity test results from EPA test apparatus. 


\section{Longevity Testing Apparatus}

Current efforts focus on the design and construction of an apparatus capable of faster aging and testing a variety of different sealant methods in a comparable manner. The design of the new longevity apparatus is intended to overcome many of the limitations imposed by the simple rig built for EPA and ultimately to perhaps become a standardized way of testing the longevity of duct sealant systems using accelerated methods (UL 181 does not deal with longevity issues). The specific design objectives include the following:

- Combined thermal $\left(0\right.$ to $60^{\circ} \mathrm{C}$ [ 32 to $\left.140^{\circ} \mathrm{F}\right]$ ) and pressure cycling (up to $200 \mathrm{~Pa}$ ).

- Rapid cycle times: 6 minute target.

- Maximum duct surface temperature should be as hot as the hottest attic, but under $200^{\circ} \mathrm{F}$ due to temperature limits set by some duct tape ratings.

- Minimum duct surface temperature should be cold enough to form condensation and perhaps frost.

- A standardized leak and process should be used so that only the sealant is being tested.

- Multiple sealant materials evaluated simultaneously:

- Automated data taking and leak monitoring.

To meet these criteria, a test system has been developed which has a source of hot air (the hot deck) and a source of cold air (the cold deck). (See Figure A7.2). A selector valve, controlled by a linear actuator, directs air from either the hot deck or the cold deck to flow through the test section. Air exiting the test section is recirculated to reduce the heating and cooling load. Half of the test sections have hot air while the other half have cold air flowing through them. In this arrangement the hot and cold decks can have high (thermal) mass to make the load on the system steadier.

An orifice downstream of the fan is used to control the pressure at the leak site and is also used to monitor the flow. The mass in the hot air deck consists of multiple pieces of sheet metal and weighs about $150 \mathrm{lb}$. The flow resistance of this mass has been calibrated so that it can be used as a flow meter. Makeup air enters through leaks in the system that have not been sealed (these are separate from the duct connection leaks under test).

The decks are made of two kinds of insulation. The inner layer is standard one inch thick fiberglass duct board. The outer layer is two inch thick cyano-acrlyic board. Cyano-acrlyic board has a moderate upper temperature limit, thus the two layer approach. Combined they have a high insulation value ( about R-19).

The test section has as low a mass as possible to decrease cycle time. Each test section connects to the hot/cold deck selector. The initial setup will test the sealant applied to a standard 4" sheet metal collar in a plenum. This leak geometry was selected because it represents common practice and is a typical site for large duct leakage flows in field installations.

The test section has three quick connect fittings which are fitted with appropriate orifices when the leakage is to be measured. (See Figure A7.4.) It is expected that initially the leaks will be nearly $100 \%$ sealed and a method of measuring very low leakage is required. Several orifices (from $1 / 4$ to $11 / 4$ inch) have been calibrated to measure leakage from 0.1 to $25 \mathrm{cfm} @ 25 \mathrm{~Pa}$. A two inch orifice is fitted just after the hot/cold selector because it was found that a flow straightener was necessary for repeatable results from the measurement orifice. The test sections that have been built have pre-sealed leakage within a narrow range of $10.2 \pm 0.4 \mathrm{cfm} @ 25 \mathrm{~Pa}$.

The longevity apparatus has been in continuous operation for several months, with 18 samples undergoing testing. Several sealants have been repeated to confirm the repeatability of the tests. These multiple samples were of sealants that failed rapidly. In addition, 12 samples have been placed in a oven to test sealant behavior at constant elevated temperatures. The oven temperature is similar to the peak temperature used in the cycling apparatus.

A failure criterion has been set at $50 \%$ of the initial leakage. Results so far show that the failed samples are those that use cloth tape with a rubber based adhesive, with the metal foil tapes, plastic backed tape, mastic and aerosol sealant showing insignificant leakage changes. 


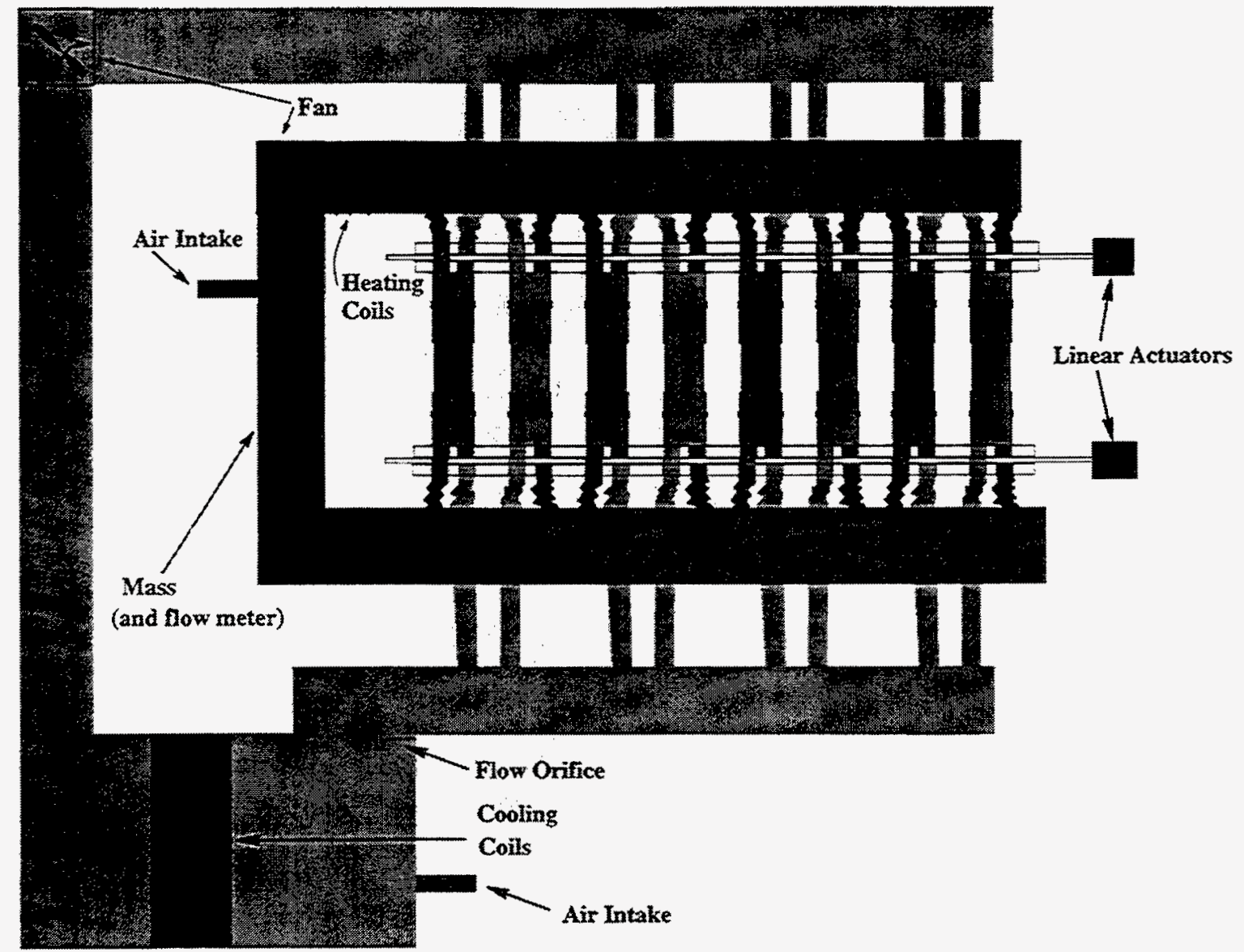

Figure A7.2 Longevity Test Apparatus

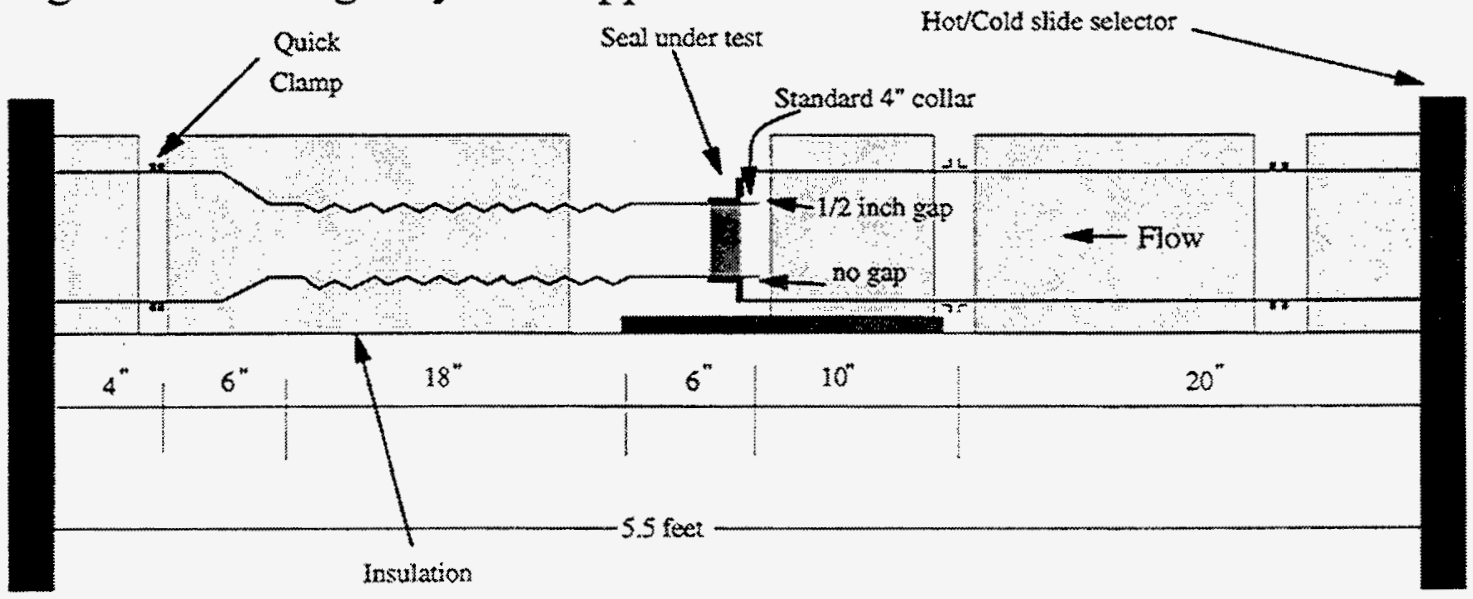

Figure A7.3 Test Connection for Duct Seal Longevity Testing 


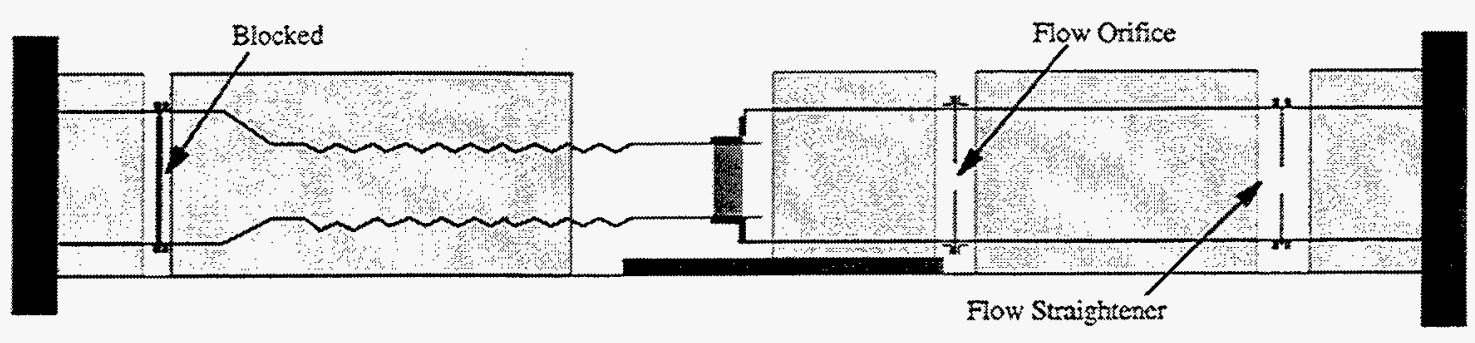

Figure A7.4 Leakage Flow Measurement Setup

\section{Sample Selection}

The samples to be tested in the LBNL Longevity apparatus are those tapes and sealants which are either commonly used or are being considered for use in various programs. One exception to this criterion is that no testing of any tape that has a maximum temperature rating of $120^{\circ} \mathrm{F}\left(49^{\circ} \mathrm{C}\right)$ or below. Not only would it to fail quickly in the accelerated testing because of its higher temperatures, but any duct tape with such a poor temperature rating should never be used on a duct system.

In preparation for testing, several tape and sealant manufacturers have been contacted to make sure we know the range of products available and to see which ones are being certified by UL. Many samples of "Duct Tape" have been obtained from several companies. There is a wide range of products available that claim to suitable for duct sealing, but there is often little in their specs or product literature to differentiate them.

While there is general agreement that there are several grades of "Duct Tape" it is not clear what that means. For example one major manufacturer lists 16 different cloth duct tapes (available in a range of colors) and 8 metalized tapes. Some of these tapes have their product codes printed on the tape, some on the hubs, and some do not have any product number on them. All the cloth tapes meet UL 723 (Test for Surface Burning characteristics of Building Materials) but only some of the metalized ones do. Some are listed as "Code Approved" (BOCA, HUD) and a tape that has nearly the same specs does not indicate that it is "Code Approved".

Catalogues call the different qualities Economy, Utility, General Purpose, Contractors, Industrial, Professional, Premium and even Nuclear. They are all listed as being used on HVAC ducts. Several companies have just come out with a UL 181B-FX tape, generally these are not even listed in the product catalogs yet.

While we have not investigated mastics as much, there seems to be fewer grades. We have only found one mastic that is UL 181B approved although many are UL $181 \mathrm{~A}$. It is expected that this situation will change in the near future.

Taking all of the information from both the sponsors and manufacturers together we have currently prioritized a set of samples in Table 1 in the main report. The first column is the ranking for immediate testing in the apparatus. The first eight samples have already begun testing. The cloth tapes failed rapidly and several have been retested to examine the repeatability of the longevity test procedure. The second column represents the priority for baking in the oven prior to testing. Initial results show that these samples have not shown the same rapid failure as in the longevity test apparatus. This result indicates that the combined pressure and temperature cycling of the longevity test apparatus is required to realistically test the samples because simple elevated temperature testing does not produce the same rapid tape failure.

\section{Sealant Types and UL 181}

UL Standard 181 deals with sealants for duct systems. The main standard deals mostly with factory assembly issues, but UL 181A and UL 181B, both of which are relatively new, deal with field assembled rigid and flexible duct systems respectively. The most recent addition to the UL 181 family of standards is UL 181B- FX. The most common duct system in new construction is field-assembled flexible ductwork, therefore UL 181B and UL $181 \mathrm{~B}-\mathrm{FX}$ are the most relevant to CIEE's interests. 
While the UL standards do not directly address longevity issues they are relevant to the choice of sealants for various uses. Table A7.1 indicates the tests that are included in UL 181A \& B:

\section{Table A7.1 UL 181 tests}

Test Name

Tensile Strength Test

Tensile Joint Strength Test

Peel Adhesion Test at 180 Degree Angle

Shear Adhesion Test

Adhesion Test

Peel Adhesion Test at 20 Degree Angle

Freeze/Thaw Test

Surface Burning Characteristics Test

Mold Growth and Humidity Test

Temperature/Pressure Cycling Test

Temperature Test

Burning Test
UL 181 A UL 181 B Notes

\begin{tabular}{|c|c|c|}
\hline $\mathbf{x}$ & $\mathrm{x}$ & For Tapes \\
\hline $\mathbf{x}$ & & For Mastics only \\
\hline $\mathbf{x}$ & $\mathbf{x}$ & For Tapes \\
\hline $\mathbf{x}$ & $\mathrm{x}$ & \\
\hline $\mathrm{x}$ & & for Mastics only \\
\hline $\mathbf{x}$ & & tapes \\
\hline $\mathrm{x}$ & & $\begin{array}{l}\text { For mastics in their } \\
\text { containers }\end{array}$ \\
\hline $\mathbf{x}$ & $\mathrm{x}$ & \\
\hline $\mathbf{x}$ & $\mathrm{x}$ & \\
\hline $\mathbf{x}$ & & \\
\hline & $\mathbf{x}$ & \\
\hline
\end{tabular}

Some interesting limitations and differences for the UL tests include the following:

- Fabric duct tapes have a clamp on the joint (not common in field).

- Shear Adhesion test (several parts) has one temp at $23^{\circ} \mathrm{C}$ and another at $66^{\circ} \mathrm{C}$, the only attempt at aging has no load for 60 days at $66^{\circ} \mathrm{C}$ and then a test at $23^{\circ} \mathrm{C}$ for 24 hours, in which the tape may come off by $1 / 8$ inch/24 hours (at that rate it can come off in 16 days or even two days and still pass).

- The High Temperature Test $\left(60\right.$ days at $\left.100^{\circ} \mathrm{C}\right)$ is evaluated by visual inspection only, no adhesion test

- The Mastic Freeze/Thaw Test is done (unless the container says to prevent freezing) with the mastic in its container, not applied to a surface.

- The surfaces to which the tape/mastic are applied are all clean (not common in the field), this is a limitation that our current setup will also have .

- That there is no cycling of temperature or pressure to adhesion tests in 181B (181A has pressure cycling at $74,32,-18{ }^{\circ} \mathrm{C}$, but no temperature cycling)

- No cold conditions, and no condensation and/or freeze test at all (the Freeze/Thaw test is for mastic in their containers, not applied to a duct system)

- That the Shear Adhesion test is only for 24 hours of load 


\section{Appendix 8. Duct System Interactions with System Sizing and Capacity}

\section{Background}

For a duct system with no losses all of the equipment capacity will reach the conditioned space. However, with real systems, the duct system losses reduce the amount of energy delivered to the conditioned space. Therefore, to meet the same building load a poor duct system needs to have more energy input, and this means that higher capacity equipment is required to meet the load. Conversely, if a given equipment capacity is adequate with a poor duct system (as are currently installed) then a good duct system should perform better with smaller capacity equipment. When a system is first installed, or renovations are being performed to a system, the use of a good duct system allows the purchase of lower capacity equipment, with resulting capital savings.

The estimation of equipment capacity reduction resulting from air sealed and insulated ducts, requires thermal modeling of the duct system. Proposed ASHRAE standard 152P has developed a model for this purpose, and it's calculation methods can be used to determine the fraction of equipment capacity that is delivered to conditioned space. Conversely, if the space load is known, the distribution system efficiency calculated using ASHRAE 152P allows the estimation of required equipment capacity. Because ASHRAE $152 \mathrm{P}$ is based on many simplifying assumptions to make it easy to use for Home Energy Rating or Energy Codes (e.g., California Title 24), there is scope for more complex models to be used in parametric studies of duct system/equipment sizing performance. More complex models will be particularly useful in looking at non steady state tasks, e.g., pulldown times, that heating and cooling systems are often asked to perform.

In addition to direct losses from the duct system by leakage and conduction, the duct system can also change equipment performance by the design and construction of the duct layout. Ducts that are too small or are designed or installed with too many bends and turns will restrict the flow in the duct system. This flow restriction can change the operation of the equipment and adversely affect the equipment efficiency. In addition, the lower flow over the heating or cooling coils will tend to make the temperature of air in the supply ducts more extreme, which will lead to increased supply duct losses compared to a system with the correct system flows.

\section{Introduction}

The purpose of this section is to summarize existing work on the interacting factors between duct systems and air conditioner size and capacity. The three reports that are summarized here are Rodriguez et al. (1995), Blasnik et al. (1996), and Nerland et al. (1995). These three papers all take a different approach to determining the effects of various parameters on air conditioner capacity and peak energy demand. The Rodriguez report is a parameterization of the effects that refrigerant charge, return duct leakage, and reduced airflow across the air conditioning coil have on air conditioner capacity. All of the testing was carried out in a laboratory under controlled conditions. The Blasnik report is a study of the air conditioning systems in 28 new homes in Arizona. It examines the same parameters as the Rodriguez report, but does so under field conditions. It also looks at issues such as peak demand and cost effectiveness of various duct and air conditioner improvements. The Nerland report uses field data and attempts to asses the impact of various parameters on peak demand and seasonal energy use. Several additional papers discuss the impacts of occupant and HVAC contractor behavior on system sizing, energy consumption, and peak loads are summarized in this appendix.

There are many factors that affect capacity and power consumption of air conditioning units. Refrigerant charge, air flow across the coil, and duct leakage are the major factors identified in these reports, with oversizing of air conditioning systems as an additional factor. Blasnik et al. simulated the energy savings, peak reduction, and cost effectiveness of instituting various duct and system retrofit measures. Nerland et al. estimated the energy savings and peak load reduction obtainable by duct sealing and duct insulation 
retrofits.

\section{Refrigerant Charge Levels}

The clearest results of the impacts of refrigerant charge come from the controlled laboratory tests in Nerland et al., in which the refrigerant charge varied from $70 \%$ to $140 \%$ of the manufacturers recommendations. The tests were repeated for two systems: a 3 ton unit with a scroll compressor and a short tube orifice expansion valve and 3.5 ton unit with a thermal expansion valve (TXV). The air flow across the coil was maintained at the manufacturers recommended value and there was no duct leakage. The results from the 3 ton unit will be focussed on here, because it more closely resembles the average system installed in California homes. At $95^{\circ} \mathrm{F}$ outdoor drybulb temperature, this three ton system had a capacity of about 1.25 tons at $70 \%$ of the manufactures recommended charge and a maximum of 2.63 tons at $110 \%$ of the manufactures recommended charge. The capacity dropped off slightly to 2.33 tons by the time the charge was $140 \%$ of the manufacturers recommended charge. The power consumption at $95^{\circ} \mathrm{F}$ outdoor temperature was $2.85 \mathrm{~kW}$ at $70 \%$ of recommended charge and $3.1 \mathrm{~kW}$ at the recommended charge. The power consumption remained roughly constant to $140 \%$ of the recommended charge. The effective $\operatorname{COP}$ (at $95^{\circ} \mathrm{F}$ outdoor dry bulb) thus goes from 1.54 at $70 \%$ of the charge to 2.98 at the recommended charge and drops to 2.64 at $140 \%$ of the recommended charge. It is clear that efficiency of this system is decreased when undercharged.

The TXV system showed a similar but considerably less pronounced result (a drop from approximately 3.5 tons at the recommended charge to 3.16 tons at $70 \%$ of the recommended charge). The TXV system was not significantly affected by overcharge. Also, power consumption remained roughly constant over the range of $70 \%$ charge to $130 \%$ overcharge.

The Blasnik report measured the charge on 27 newly installed units in Arizona homes and found that 5 of them were within $5 \%$ of the correct charge, 21 of them were undercharged and 1 was overcharged. The average system had a charge of $84 \%$ of the manufacturers recommended value. The most significantly undercharged unit had a charge that was $55 \%$ of the manufacturers recommendation and the one overcharged unit was at $107 \%$ of the manufacturers charge. These results contradict the assertion of the Rodriguez report which suggest that approximately half the units on the market are undercharged and half are overcharged.

\section{Air Handler Flow}

Manufacturers typically recommend that a fan flow rate of $400 \mathrm{cfm}$ per ton of air conditioning. Lower air flows result in reduced efficiency and, if low enough, can cause damage to the system. Manufacturers typically suggest that flow below $350 \mathrm{cfm} /$ ton is the point at which the system needs corrective action to prevent damage to the condenser and evaporator.

The Rodriguez report tested the effect of reduced airflow on two 3.5 ton heat pumps. The first of these systems had a reciprocating compressor and a short-tube orifice expansion device, the second had a scroll compressor and a TXV. The capacity of the first system was 3.46 tons at the rated airflow of $1400 \mathrm{cfm}$. It consumed $4.5 \mathrm{~kW}$ of power at the rated airflow. Table A8.1 shows how reduced air flow reduces system performance in terms of system capacity, power consumption, and COP.

The Blasnik et al. study found that of 28 systems tested, over half of the units had flows low enough (below $350 \mathrm{cfm}$ per ton) to require corrective action. The average system had $86 \%$ of the manufacturers recommended air flow (standard deviation of $16 \%$ ). The worst system had $57 \%$ of the manufacturers recommended air flow. In addition, seven systems had flows that were at or above the manufacturers recommended rated flow, however no information was given regarding equipment efficiency changes with flow rates that are too high. 


\section{Table A8.1 Effects of reduced airflow on Heat Pump Performance (from Rodriguez et al. (1995))}

\begin{tabular}{cccccc}
\hline $\begin{array}{c}\text { Reduction in } \\
\text { Airflow } \\
{[\%]}\end{array}$ & $\begin{array}{c}\text { Reduction in } \\
\text { Capacity } \\
{[\%]}\end{array}$ & $\begin{array}{c}\text { Measured } \\
\text { Capacity } \\
\text { [Tons] }\end{array}$ & $\begin{array}{c}\text { Reduction in } \\
\text { Power } \\
\text { Consumption } \\
{[\%]}\end{array}$ & $\begin{array}{c}\text { Power } \\
\text { Consumption } \\
{[\mathrm{kW}]}\end{array}$ & COP \\
\hline & & & & & \\
$0 \%$ & $0.0 \%$ & 3.5 & $0.0 \%$ & 4.5 & 2.70 \\
$10 \%$ & $7.1 \%$ & 3.2 & $0.6 \%$ & 4.5 & 2.53 \\
$20 \%$ & $9.5 \%$ & 3.1 & $1.2 \%$ & 4.4 & 2.48 \\
$35 \%$ & $15.3 \%$ & 2.9 & $2.3 \%$ & 4.4 & 2.34 \\
$50 \%$ & $24.8 \%$ & 2.6 & $3.7 \%$ & 4.3 & 2.11 \\
\hline
\end{tabular}

\section{Duct Leakage}

Duct leakage was found to have a significant effect on air conditioning efficiency. The Rodriguez report examined the particular effect that return duct leakage from a hot attic has on effective capacity and power consumption. The effective capacity is based on the amount of energy exchanged at the registers so that the increase in the heat transfer at the equipment due to return leakage is balanced by the increased delivery temperature, with a net reduction in capacity. The test conditions included a variety of runs with different amounts of leakage and different attic conditions. The test with most relevance to California homes has an outdoor drybulb temperature of $100^{\circ} \mathrm{F}\left(37^{\circ} \mathrm{C}\right)$, and an attic drybulb temperature of $130^{\circ} \mathrm{F}\left(55^{\circ} \mathrm{C}\right), 20 \%$ RH. The capacity dropped from 3.08 tons with no return leakage, to 2.67 tons with $5 \%$ (of fan flow) return leakage, to 2.25 tons at $10 \%$ leakage and to 1.92 tons with $15 \%$ leakage. The power consumption increased slightly from $3.78 \mathrm{~kW}$ to $3.82 \mathrm{~kW}$ over this range. Thus, the COP dropped from 2.86 with no leakage to 1.21 with $15 \%$ return leakage at these conditions.

The homes tested by Blasnik et al. had relatively tight duct systems. The duct leakage averaged about $9 \%$ of fan flow (110 cfm at operating conditions) on the supply side and $5 \%$ (68 cfm at operating conditions) of fan flow on the return side.

\section{Impacts of Duct Leakage on Capacity at the Registers}

The importance of duct leakage in diminishing air conditioning capacity cannot be overstated. In particular, the effect of return duct leakage in cooling systems dramatically reduces effective capacity "at the register". The effective capacity at the register is calculated by determining the cooling energy of air delivered to the home through the registers. From the point of view of thermal comfort and energy calculations, this delivered capacity at the registers (delivered to the conditioned space) is a key parameter. The following example calculations illustrate the consequences of return leakage. The additional effects of conduction losses, supply leak losses and change in equipment capacity due to return air temperature changes are neglected.

For a 2 ton $(7 \mathrm{~kW})$ AC system, with its rated fan flow of $800 \mathrm{cfm}(0.45 \mathrm{~kg} / \mathrm{s})$.

The temperature drop across the heat exchanger is $7 \mathrm{~kW} / 0.45 \mathrm{~kg} / \mathrm{s} / 1000 \mathrm{~kJ} / \mathrm{kgK}=15^{\circ} \mathrm{C}\left(27^{\circ} \mathrm{F}\right)$

Assuming an indoor temperature (at the return grille) of $25^{\circ} \mathrm{C}\left(77^{\circ} \mathrm{F}\right)$, this gives a temperature out of the supply ducts of $10^{\circ} \mathrm{C}\left(50^{\circ} \mathrm{F}\right)$. The cooling capacity at the registers is then $0.45 \mathrm{~kg} / \mathrm{s} * 1000$ $\mathrm{kJ} / \mathrm{kgK} *\left(25^{\circ} \mathrm{C}-10^{\circ} \mathrm{C}\right)=7 \mathrm{~kW}(2$ Tons).

Introducing $20 \%$ return leakage at an attic temperature of $59^{\circ} \mathrm{C}\left(138^{\circ} \mathrm{F}\right)$ [this is not an extreme 
attic temperature, it is based on the outdoor air design (0.4\%) temperature from ASHRAE fundamentals for Sacramento of $39^{\circ} \mathrm{C}$, with an additional $20^{\circ} \mathrm{C}$ added for an unvented attics from proposed ASHRAE $152 \mathrm{P}$ ] we get a mixed air temperature entering the coil of $\left(0.2 * 59^{\circ} \mathrm{C}\right.$ $\left.+0.8^{*} 25^{\circ} \mathrm{C}\right)=32^{\circ} \mathrm{C}\left(90^{\circ} \mathrm{F}\right)$. The temperature on the other side of the coil (and therefore out of the supply ducts) is $17^{\circ} \mathrm{C}\left(63^{\circ} \mathrm{F}\right)$. The cooling capacity at the registers is therefore $0.45 \mathrm{~kg} / \mathrm{s} * 1000$ $\mathrm{kJ} / \mathrm{kgK}^{*}\left(25^{\circ} \mathrm{C}-17^{\circ} \mathrm{C}\right)=3.6 \mathrm{~kW}$ ( 1 Tons).

In other words, this $20 \%$ return leak in an attic that is not extremely hot attic reduces the capacity at the registers by half. A $40 \%$ return leak would remove ALL cooling capacity and room temperature air would come out of the registers. A greater than $40 \%$ leak would cause the system to run at a negative efficiency and the air-conditioner would heat the home. These calculations assume a perfectly charged system with no conduction losses on the supply or return side and no supply side leaks and the correct system fan flow. Losses associated with these factors could decrease the effective capacity of the system.

\section{Cost Effectiveness of Retrofit Measures and Peak Energy Savings}

The Blasnik et al. report used the measured data on 28 systems and created a simulation to model the effects of various programs aimed at reducing energy use in Arizona Public Services territory. The simulation modeled energy reduction resulting from a computer simulation and uses an empirical model to account for occupant behavior when simulating peak electrical demand. All scenarios in the study assume new construction. Table A8.2 summarizes the results.

\section{Table A8.2 Estimated Retrofit Program Impacts \& Costs (without resizing), Severe undercharge excluded (from Blasnik et al. (1996))}

\begin{tabular}{lccccc}
\hline & $\begin{array}{c}\text { Direct } \\
\text { Cost, \$ }\end{array}$ & \multicolumn{3}{c}{ Savings } \\
& & $\mathrm{kWh}$ & $\%$ & $\mathrm{~kW}$ & $\%$ \\
\hline Baseline - Systems as found & 0 & 3729 & & 3.67 & \\
\hline $\begin{array}{l}\text { A. Restrict Duct Leakage to 3\% of system } \\
\text { air flow }\end{array}$ & 75 & 417 & 11 & 0.50 & 14 \\
$\begin{array}{l}\text { B. Duct Leakage at 3\% \& R8 duct } \\
\text { insulation }\end{array}$ & 140 & 581 & 16 & 0.64 & 17 \\
\hline $\begin{array}{l}\text { C. Correct AC charge and air flow rate } \\
\text { D. Duct Leakage at 3\%, charge \& air flow }\end{array}$ & 145 & 1458 & 39 & 1.12 & 31 \\
$\begin{array}{l}\text { E. Duct Leakage at 3\%, R8, charge \& air } \\
\text { flow }\end{array}$ & 210 & 1571 & 42 & 1.22 & 33 \\
\hline F. EER 2 Higher, Charge, air flow & 420 & 1795 & 48 & 1.32 & 36 \\
G. All of the above & 560 & 2152 & 58 & 1.69 & 46
\end{tabular}

Slightly higher energy and peak demand reductions occur if the air conditioning units are resized to reflect a more accurate calculation of the system load.

The Nerland et al. report uses an extensive model of occupant behavior to model the impacts of duct sealing and insulating on 4 different types of systems. The simulation results are calibrated with measurements taken as part of the Pacific Gas and Electric (PG\&E) Appliance Metering Project. This report identified no peak savings from increasing duct insulation from R-4 to R-8, or from decreasing duct leakage to $20 \%$ of the base case leakage. This lack of peak savings was attributed to the fact that even though cooling systems 
become more efficient as a result of increased duct efficiency, this does not necessarily cause a reduction in peak energy usage. Homeowners effectively trade off increased system efficiency with increased occupant comfort. For example, many homeowners turn off the air-conditioning during the day, and turn it on when they return from work. The system then stays on for a long period of time as it attempts to bring a hot house to the thermostat set point (often called the pull down time). A more efficient system will cause this cooling to occur more rapidly, but the system will likely contribute the same power consumption to the peak demand. The report identifies a seasonal energy saving of $6 \%$ for improving the insulation and $8 \%$ for sealing the duct work. It presents little data on the costs and cost effectiveness of such programs.

The Nerland et al. report, like the Blasnik et al. report, identifies greater peak savings and energy savings if the duct system is improved and the air conditioning system is downsized accordingly to reflect the lower effective load. Including the downsizing, the simulation predicts a $17 \%$ reduction in peak energy demand as a result of sealing the duct work, insulating the duct work, or instituting both measures. The seasonal energy savings are $8 \%$ for either insulating or sealing the duct work and $15 \%$ for doing both. Blasnik's report showed reductions in peak energy use of about $5 \%$ were attributable to the resizing of the system.

\section{Contractor and Occupant Behavior}

The Blasnik report found that a large percentage of air-conditioning units are dramatically oversized. This agrees with the research done by many others. The typical reference for correct system sizing is ACCA Manual J for load determination and ACCA Manual S for system selection. The following table indicates some of the research that has been done on the incidence of oversizing:

\begin{tabular}{ccccl}
\hline \multicolumn{5}{c}{ Table 8.3 Contractor and Occupant behavior surveys } \\
\hline $\begin{array}{c}\text { Principal } \\
\text { Author }\end{array}$ & Year & $\begin{array}{c}\text { Region or } \\
\text { State }\end{array}$ & $\begin{array}{c}\text { Sample } \\
\text { Size }\end{array}$ & \multicolumn{1}{c}{ Oversizing relative to Manual J } \\
\hline & & & & \\
Blasnik & 1996 & Arizona & 28 & Average home has a unit that is 48\% oversized \\
Lucas $^{1}$ & 1993 & Northwest & 75 & Two thirds of homes have oversized AC units \\
James & 1997 & Florida & $400+$ & $50 \%+$ of units are 120\%+ oversized \\
PG\&E $^{2}$ & 1995 & California & $?$ & $53 \%$ of units are a ton or more oversized \\
PNL $^{2}$ & $?$ & National & $?$ & One third of units are a ton or more oversized \\
Reddy & 1992 & Texas & $?$ & 63\% of units are oversized \\
\hline
\end{tabular}

Tas cited in Vierra et al (1996)

${ }^{2}$ as cited in Proctor et al (1996)

The causes of systemic oversizing are many and varied. Vierra et al. administered a survey to about 500 air conditioning contractors in Florida and asked them how they sized air-conditioners. The survey respondents were largely Florida ACCA members and thus their responses might be skewed towards ACCA promoted methods (Manual J). A third of the contractors sized using Manual J techniques and another third used software (this is confusing as there is at least one widely used software package, Right-J, which is merely a computerized form of Manual $\mathrm{J}$ ). The remaining third mostly used a square footage technique(350-700 $\mathrm{ft}^{2} /$ ton with an average of $500 \mathrm{ft}^{2} /$ ton) or some other rule of thumb that required very simple or no calculation procedures.

All of these techniques might lead to oversizing. Contractors who size units with Manual J or a piece of software that uses similar calculations often include a large safety factor to avoid callbacks or to appease a customer who demands extra cooling power. Many contractors ignore the fact that a system designed with Manual J already has an oversize factor as part of its calculation routines. Additionally, model inputs such as design temperature, are often rounded up or changed to account for the contractors experience and perceptions about the model inputs. In general, contractors are extremely risk-averse and would much rather install extra capacity and not risk a callback. Many contractors have been in the business for a number of years and have used rule of thumb sizing techniques successfully (i.e. no callbacks and satisfied customers). Finally, many contractors know that there are many factors which can contribute to a loss of 
effective capacity (such as refrigerant charge levels, insufficient airflow, and duct leakage), oversizing is one way of not having to worry about these factors.

The effects of oversizing are numerous. In terms of comfort, the fractional on time of an air conditioner decreases as the system gets larger. This means that the air-conditioner will more quickly satisfy the sensible load of the home and will be able to do little or no latent cooling (Latent capacity requires that the air conditioning coil stay cold long enough for water to condense on the coil and exit the system through the condensate drain). Additionally, several authors have pointed out that short system on-times can lead to inadequate air mixing and consequent hot and cold spots throughout a home.

Oversizing also directly impacts energy usage and peak energy consumption. Henderson (1992) constructed a model of an air-conditioner, thermostat, and a home and predicted that a 50\% oversizing would lead to a 9\% increase in energy consumption. Henderson does not describe a duct system and attributed the energy loss to cycling losses. Reddy \& Claridge (1993) suggest that oversizing and occupant behavior combine to contribute to higher peak summer energy demands. Occupants leave their airconditioners off during the day and return and turn on their air conditioner. The air conditioners creates additional demand because it is oversized. The combination of coincident air conditioner use and large air conditioner demand can dramatically increase peak demand.

\section{Conclusions}

The results of the studies summarized above show that much work remains to be done before useful information regarding sizing issues can be given to HVAC installers and builders. For example, one question that remains is how might these various effects combine to effect capacity and peak energy demand? All of the reports cited in this study assume that these are multiplicative, which may not be true. For instance, will a unit with insufficient charge and reduced airflow across the coil be have a different efficiency than the product of each of these effects? Another question that remains is how peak energy demand and capacity will be affected by a system that was already oversized and then has a duct retrofit so it becomes even more oversized (because the effective building load gets smaller). This may affect the cost-effectiveness of many air-conditioning energy efficiency measures. Henderson (1992) argues that this effect is important and can be very large, Proctor (1996) argues that it is small.

To answer many of these questions, there is a need to develop and use modeling tools that account for the interactions discussed in this report. Proposed ASHRAE 152P allows for steady state interactions between duct losses and the equipment, but does not account for detailed interactions between the ducts and their surroundings. Previous modeling efforts at LBNL have produced complex and unwieldy calculation methods that attempted to model the duct system on an hour by hour basis, with assumptions made for equipment fraction ontime estimates. Future work for the current project will concentrate on developing equipment and duct models that are interactive and will allow transient analyses (for pulldown experiments) to be performed, as well as improving thermal loss calculations for duct systems.

\section{References}

ACCA. 1986. Manual J-Load Calculations for Residential Winter and Summer Air Conditioning. Washington D.C.; Air Conditioning Contractors of America (H. Rutkowski, Technical Director).

ASTM. 1992. ASTM E779. Standard test Method for Determining Air Leakage Rate by Fan Pressurization. American Society for Testing and Materials. Philadelphia, P.A.

Andrews, J. 1997. Personal comunication.

Blasnik, M., Downey, T., Proctor, J. and Peterson, G. 1996. Assessment of HVAC installations in New Homes in APS Service Territory. Proctor Engineering Group Report for Arizona Public Service Company. 
Henderson, H. 1992. Simulating Combined Thermostat, Air Conditioning and Building Performance in a House. Transactions of the American Society of Heating, Refrigeration, and Air-Conditioning Engineers, 98(1):370-386.

Neal, L. and O'Neal. D. 1994. The Impact of Air Conditioner Charging and Sizing on Peak Demand. Proceedings of the 1994 ACEEE Summer Study on Energy Efficiency in Buildings, 2:189-200. Washington D.C.; American Council for an Energy Efficient Economy.

Nerland, E.,Treidler, B., and Modera, M. 1995. Peak Impacts of Residential Air Conditioning. LBNL Report

Proctor, J., Katsnetlson, Z. and B. Wilson. 1995. Bigger is Not Better: Sizing Air-Conditioners Properly. Home Energy, 12(3):19-26.

Reddy, T.A. and Claridge, D.E. 1993. Effect of Air Conditioner Oversizing and Control on Electric Peak Loads in Residences. Energy, 11:1139-1152.

Rodriguez, A.G., O'Neal, D.L., Bain, J.A., and Davis, M.A.1995. The Effect of Refrigerant Charge, Duct Leakage, and Evaporator Air Flow on the High Temperature Performance of Air Conditioners and Heat Pumps. Energy Systems Laboratory report for EPRI, Texas A\&M University.

Vierra, R.K., Parker, D.S., Klongerbo, J.F., Stone, J.K., Cummings, J. 1996. How Contractors Really Size Air Conditioning Systems. Proceedings of the 1996 ACEEE Summer Study on Energy Efficiency in Buildings, 8:207-213. Washington D.C.; American Council for an Energy Efficient Economy. 


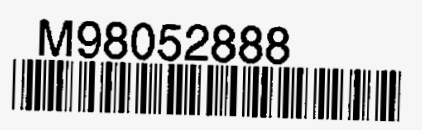

Report Number (14)CBNC--41118

Publ. Date (11)

Sponsor Code (18)

UC Category (19) UC $-160 \mathrm{Q}$, DOE/ER 